\title{
Understanding membrane fouling in produced water treatment
}

Janneke M. Dickhout

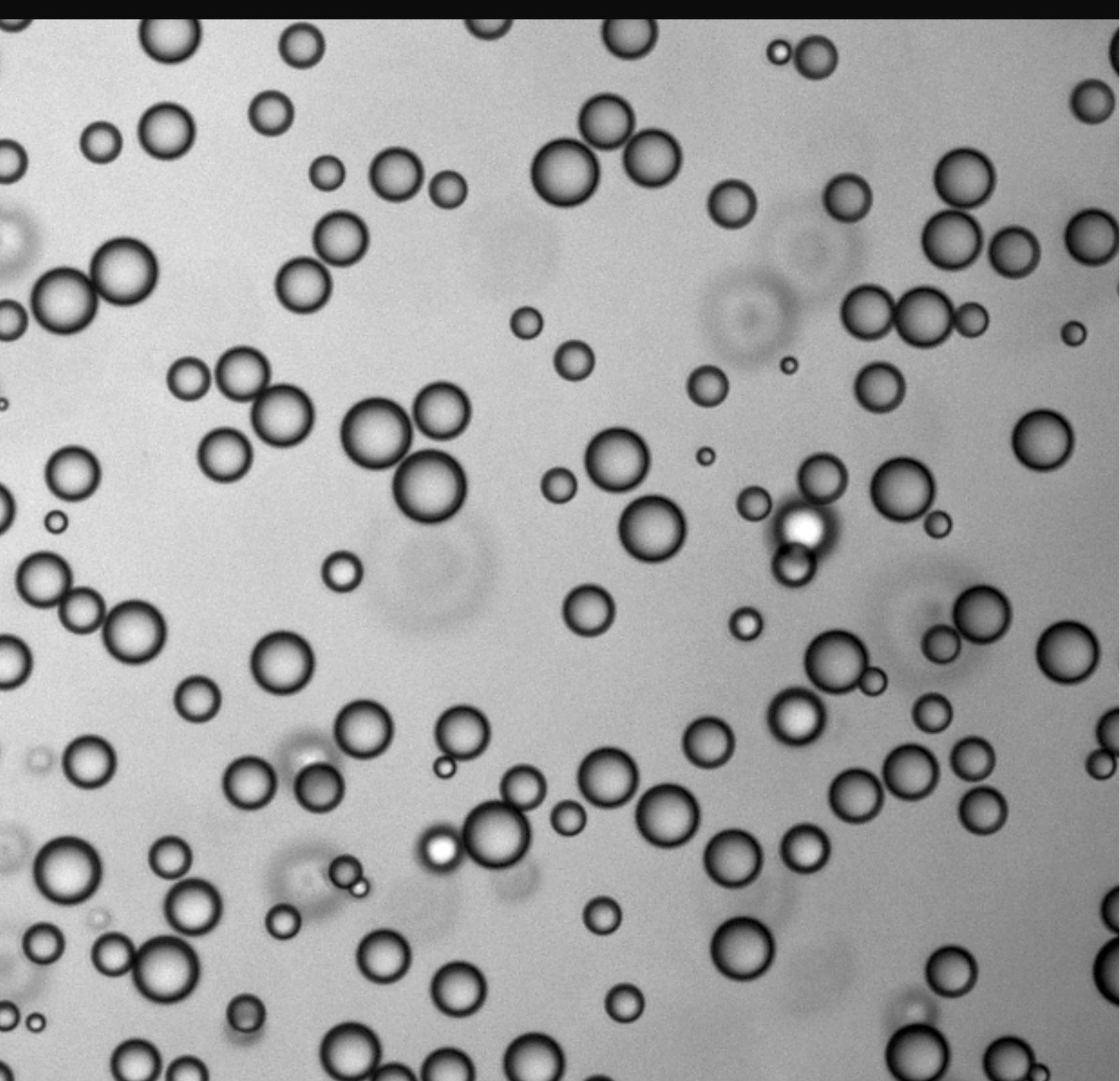




\section{Understanding membrane fouling in produced water treatment}




\section{Promotiecommissie}

Voorzitter Prof. dr. ir. J.W.M. Hilgenkamp Universiteit Twente

Promotor Prof. dr. ir. R. G. H. Lammertink Universiteit Twente

Copromotor Assoc. Prof. dr. ir. W. M. de Vos Universiteit Twente

Overige leden Prof. dr. P. Bacchin

Université Paul Sabatier

Prof. dr. F.G. Mugele

Universiteit Twente

Prof. dr. ir. A. Nijmeijer

Universiteit Twente

Prof. dr. ir. C.G.P.H. Schroen

Wageningen University \& Research

Dr. ir. J.M. Kleijn

Wageningen University \& Research

The work described in this thesis was performed in the Membrane Science and Technology cluster at the Mesa+ Institute for Nanotechnology at the University of Twente and in the cooperation framework of Wetsus, European Centre of Excellence for Sustainable Water Technology (www.wetsus.eu). Wetsus is co-funded by the Dutch Ministry of Economic Affairs and Ministry of Infrastructure and Environment, the Province of Fryslân and the Northern Netherlands Provinces. The author would like to thank the participants of the research theme "Concentrates" for the fruitful discussions and their financial support.

\section{Understanding membrane fouling in produced water treatment}

ISBN: 978-90-365-4637-9

DOI: $10.3990 / 1.9789036546379$

URL: https://doi.org/10.3990/1.9789036546379

Typeset: IATEX

Printed by: Gildeprint

Copyright (C)2018 by Janneke Dickhout 


\section{UNDERSTANDING MEMBRANE FOULING IN PRODUCED WATER TREATMENT}

\section{PROEFSCHRIFT}

ter verkrijging van

de graad van doctor aan de Universiteit Twente, op gezag van de rector magnificus,

prof. dr. T. T. M. Palstra,

volgens besluit van het College voor Promoties

in het openbaar te verdedigen

op donderdag 1 November 2018 om 12:45 uur

door

Janneke Marrit Dickhout

geboren op 9 april 1988

te Arnhem, Nederland 
Dit proefschrift is goedgekeurd door:

Prof. Dr. R. G. H. Lammertink en Dr. W. M. de Vos 




\section{Contents}

1 Introduction 11

1.1 Produced water . . . . . . . . . . . . . . 11

1.2 Produced water as a global challenge . . . . . . . . . . . . 13

1.2.1 North America: The second oil revolution . . . . . . . . . . 13

1.2.2 Europe: Offshore management . . . . . . . . . . 16

1.2.3 Middle East: An opportunity for water shortage . . . . . . 17

1.2.4 Africa: Challenges and opportunities . . . . . . . . . 18

1.3 Membrane treatment of PW . . . . . . . . . . . . . . . . . . 19

1.4 Conclusion . . . . . . . . . . . . . . . 20

1.5 Scope of this thesis . . . . . . . . . . . . . . 21

2 Produced water treatment by membranes: A review from a colloidal $\begin{array}{ll}\text { perspective } & 27\end{array}$

2.1 Introduction . . . . . . . . . . . . . . . . . . . . . 28

2.2 Produced water as an emulsion . . . . . . . . . . . . . . 28

2.2.1 Influence of different factors on emulsion stability . . . . . . 31

2.2 .2 Surfactants . . . . . . . . . . . . . . . 32

2.2 .3 Ionic strength . . . . . . . . . . . . . . . 33

2.2.4 Dissolved hydrocarbons/solvents . . . . . . . . . . 34

2.2.5 Solid particles................. 34

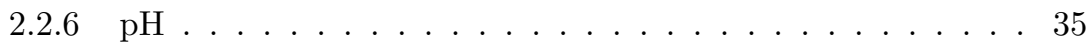

2.2.7 Temperature . . . . . . . . . . . . . . 35

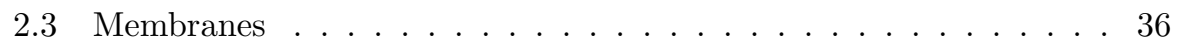

2.3.1 Membrane materials . . . . . . . . . . . . . 37

2.3.2 Membrane properties. . . . . . . . . . . . 38

2.3.3 Fouling mechanisms . . . . . . . . . . . . . . . . . 41

2.3.4 Recent developments in anti-fouling membranes . . . . . . . 42

2.4 Oily wastewater treatment with membranes . . . . . . . . . . . . 43

2.4.1 Oil/water separation with membranes . . . . . . . . . 43

2.4.2 Oil/Water separation in industrial wastewater . . . . . . . 45

2.5 Produced water treatment using membranes . . . . . . . . . . . 46

2.5.1 Produced water treatment using membranes: lab scale . . . 46

2.5.2 Produced water treatment using membranes: pilot scale . . 47

2.6 Conclusion . . . . . . . . . . . . . . . . . . . 48 
3 Adhesion of emulsified oil droplets to hydrophilic and hydrophobic surfaces - effect of surfactant charge, surfactant concentration and ionic strength $\quad 55$

3.1 Introduction . . . . . . . . . . . . . . . . . . 56

3.2 Materials and methods . . . . . . . . . . . . . . . . . 57

3.2.1 Materials . . . . . . . . . . . . . . . . 57

3.2.2 Emulsion preparation and characterization . . . . . . . 58

3.2.3 Glass modification and characterization . . . . . . . . . 58

3.2.4 Contact angle and interfacial tension measurements . . . . 59

3.2.5 Reflectometry measurements ............. 59

3.2.6 Flow cell setup . . . . . . . . . . . . . . . . 60

3.2 .7 Flow cell operation . . . . . . . . . . . . . . 60

3.2 .8 Image analysis . . . . . . . . . . . . . . . . 61

3.3 Results and discussion . . . . . . . . . . . . . . . . . . . . . 62

3.3.1 Surfactant adsorption . . . . . . . . . . . . 62

3.3.2 Interfacial tension surfactant solution/oil . . . . . . . . 63

3.3.3 Contact angle measurements . . . . . . . . . . 65

3.3 .4 Flow cell ................... 66

3.4 Conclusion . . . . . . . . . . . . . . . . . 73

3.A The vapor despostion setup . . . . . . . . . . . . . . . 74

3.B Exact settings of flow cell and pump . . . . . . . . . . . . . . 74

3.C Contact angles after 30 minutes . . . . . . . . . . . . . . . 75

3.D Images of TX in flow cell . . . . . . . . . . . . . . 76

4 Membrane filtration of anionic surfactant stabilized emulsions: Ef$\begin{array}{ll}\text { fect of ionic strength on fouling and droplet adhesion } & 81\end{array}$

4.1 Introduction . . . . . . . . . . . . . . . . . . . . . . 82

4.2 Materials and methods . . . . . . . . . . . . . . . . . . . 84

4.2.1 Emulsion preparation . . . . . . . . . . . . 84

4.2.2 Glass preparation for flow cell . . . . . . . . . . 85

4.2.3 Contact angle and interfacial tension measurements . . . . 85

4.2.4 Flow cell setup . . . . . . . . . . . . . . 85

4.2.5 Flow cell operation . . . . . . . . . . . . . 86

4.2.6 Membrane filtration . . . . . . . . . . . . . . 87

4.3 Results and discussion . . . . . . . . . . . . . . . . . . . 88

4.3.1 Contact angle measurements . . . . . . . . . . . 88

4.3.2 Interfacial tension measurements . . . . . . . . . . . . 88

4.3 .3 Flow cell . . . . . . . . . . . . . . . 89

4.3.4 Membrane filtration . . . . . . . . . . . . . . 91

4.4 Conclusion . . . . . . . . . . . . . . . . . . 97

4.A Clean water fluxes membrane sheets . . . . . . . . . . . . . 99

4.B Extraction protocol permeate analysis . . . . . . . . . . . . 99 
5 Comparing the effects of ionic strength for various surfactant types on membrane fouling during produced water treatment

5.1 Introduction . . . . . . . . . . . . . . . . . . . . 108

5.1 Theory ......................... 110

5.2 Materials and methods . . . . . . . . . . . . . . . . . 113

5.2 .1 Materials .................... 113

5.2.2 Emulsion preparation and characterization . . . . . . . 113

5.2 .3 Membrane filtration . . . . . . . . . . . . . . . 114

5.2 .4 Permeate analysis . . . . . . . . . . . . . . . . . 114

5.2.5 Contact angle and interfacial tension measurements . . . 115

5.3 Results . . . . . . . . . . . . . . . . . . 115

5.3 .1 Interfacial tension . . . . . . . . . . . . . 115

5.3 .2 Contact angle . . . . . . . . . . . . . . . 116

5.3 .3 SDS stabilized emulsions . . . . . . . . . . . . . 118

5.3.4 CTAB stabilized emulsions . . . . . . . . . . . . 120

5.3.5 TX stabilized emulsions . . . . . . . . . . . . . . . . . . . . . . . . . . . . . . . . . .

5.3.6 DDAPS stabilized emulsions . . . . . . . . . . . . 122

5.4 Discussion . . . . . . . . . . . . . . . . . . 125

5.5 Conclusion . . . . . . . . . . . . . . 126

6 Summary and outlook 133

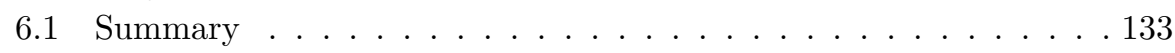

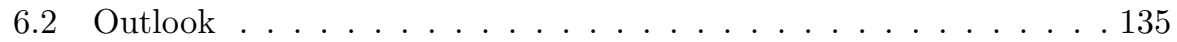

6.2.1 Towards further understanding . . . . . . . . . . . 136

6.2.2 Application in the field . . . . . . . . . . . . 139

6.3 General conclusion . . . . . . . . . . . . . . . . 140

$\begin{array}{ll}\text { Algemene Nederlandse samenvatting } & 147\end{array}$

$\begin{array}{ll}\text { Acknowledgements } & 151\end{array}$ 



\section{CHAPTER 1}

\section{Introduction}

As most people know, water and oil do not mix. Only when we start looking into more complex mixtures, such as mayonnaise, it is possible to mix a watery (vinegar) and an oily phase into a relatively stable result upon the addition of a stabilizer (egg yolk) [1]. On the other end of the spectrum, oil and grease stains can be washed from clothing with water containing soaps [2]. Although those two examples seem very different, there is one thing that connects them: the mixing of watery and oily phases that takes place with so-called surfaceactive substances or surfactants. In the case of mayonnaise, the added egg yolks contain long protein molecules that stabilize the vinegar droplets in the oil. In the washing detergent, the soap molecules dissolve the oil and grease in the water, so your clothes become clean again. In both cases, the surfactants stabilize oil in water (or the other way around) by sitting at the interface between the two phases, resulting in a relatively stable mixture or so-called emulsion of the two immiscible phases. These emulsions can be found everywhere in daily life: in our food (ice cream, salad dressings), cosmetics, medicine, but also industrial applications. Many cutting oils, lubricants and paints are emulsions, all tailored to meet the needs of the process they are used in. In many cases, however, oil-inwater emulsions are a byproduct of industrial processes, and form a waste stream that has to be treated before the water can be disposed of. Oil droplets from a factory or plant get emulsified in water, sometimes stabilized by other chemical compounds present, such as soaps, solid particles or acids. Produced water, the main focus of this thesis, is an excellent example of such a waste stream.

\subsection{Produced water}

All oil-based product we use nowadays, such as fossil fuels, plastics, mineral waxes and asphalt, are produced from crude oil recovered from reservoirs deep in the earth. The first commercial oil well was drilled in 1859 by Edwin L. Drake, which marks the beginning of the modern age of the petroleum industry [3]. Drilling techniques improved since then, and with the introduction of the automobile in 1892, gasoline became a necessary product in society. By 1920, 9 million cars were in use in the US already. The exploitation of oil started to boom in the beginning 


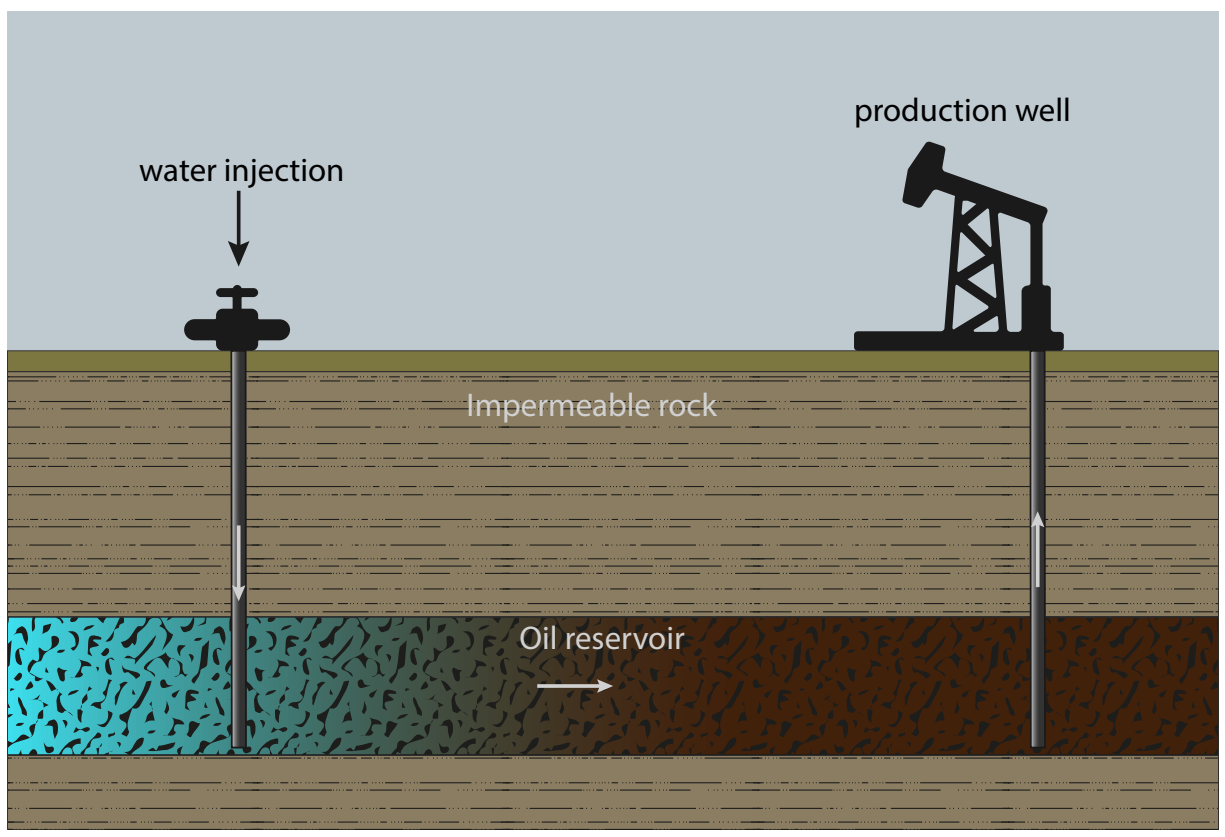

Figure 1.1: Schematic of an oil pumping operation. Water is pumped in at the left and pushes the oil from the reservoir towards the production well at the right.

of the 20th century, and nowadays an estimated 80.8 million barrels of oil per day are produced globally [4]. When imagining pumping up oil, most people will think of a flow of oil coming from a big bubble of oil underground, but in reality, the oil is captured in porous layers of stone captured under non-porous layers, like a sponge. The oil reservoir does not contain just oil, but also water, which can be present in both in the porous reservoir rock and the surrounding rock layers. In addition to this naturally occurring water, water is often injected for Enhanced Oil Recovery (Figure 1.1). The pumping down of water in the reservoir can have many purposes: in conventional oil recovery, flooding the reservoir with water containing chemicals or polymers helps to extract the oil from the bedrock. In the recovery of shale oil however, the oil is captured in formations which are far less porous, and water is pumped down to break the rock in the reservoir in a process called fracking. Water from these sources comes up with the oil in the production well and is then called produced water (PW). The amount of PW that comes up varies between oil wells, and also changes over the lifetime of a well. In new wells the amount of PW can be as low as 3 barrels of water per barrel of oil, but for older wells, this can increase to as much as 50 barrels of water per barrel of oil.

PW is a very complex mixture. The crude oil, which is a mixture of thousands 
of different hydrocarbon compounds in itself, is emulsified and is present in the water as droplets. In addition to this, produced water also contains dissolved hydrocarbons (solvents that are miscible with water), clay particles, heavy metals, production chemicals added to the water that was pumped down, and salts. Some of those compounds, such as production chemicals but also compounds present in the crude oil, can act as surfactants and help to stabilize the oil droplets in the water [5]. In addition, solid particles can also stabilize the oil droplets. Salt interacts with the surfactants, making them either more or less effective, depending on the kind of surfactant and the salt concentration.

Because PW contains so many contaminants, it has to be treated before the water can be disposed or re-used for injection or other purposes. The challenge in PW treatment however is that the mixture is very complex, and each compound influences treatment in a favorable or less favorable way. Moreover, the composition also changes over the lifetime of a well, or even from day to day. Therefore, there is no universal applicable technique that works for every single well. The most techniques that are applied at this moment include various kinds of filters, hydrocyclones, evaporation and chemical treatments. The larger oil droplets, down to a size of $10 \mu \mathrm{m}$, can be removed from the PW with these conventional techniques, but the smaller oil droplets can not be removed and still add up to a relatively high fraction of oil in the PW, so also these stable droplets have to be removed. The current approach to PW differs from region to region, just as the restrictions set on what can be disposed, or what the proposed re-use of PW can be.

\subsection{Produced water as a global challenge}

Oil is pumped up in places all over the world, and the culture and practices concerning oil drilling and PW treatment differ from region to region. Depending on the environment where the oil is found, PW can be either a nuisance or an opportunity. In all cases however, it is a waste stream that has to be dealt with, or, preferably, reused to beneficial ends.

\subsubsection{North America: The second oil revolution}

After the initial wave of conventional oil exploitation in the last century, with a record of 9.6 million barrels of oil per day in 1970, the oil production declined due to the decreasing conventional oil reserves. But since the uprise of unconventional oil production techniques, such as fracking of tight formations and horizontal drilling, the production of oil has been increasing again, to an estimated amount of 9.3 million barrels of oil per day in 2017. For 2018, the U.S. Energy Information Administration (eia) expects oil production to reach 10.3 million barrels of oil per day, beating the previous 1970's record [6]. The largest contributor to the 
increased oil production is the Permian Basin, a large oil field under Texas and New Mexico. Starting out as a region where conventional oil drilling was common practice, it is now developing into a region with more and more unconventional shale oil recovery. The potential of shale oil is so large, that the growth in onshore oil and gas winning is almost completely caused by the productiveness of the Permian Basin [7]. The estimated amount of oil left in the Permian Basin is 60 billion to 70 billion barrels of oil, but the numbers keep rising as new oilcontaining formations are found, as well as new techniques developed [8]. The number of oil wells in the region keeps growing explosively (Figure 1.2). Treating PW makes up a considerable portion of the costs associated with oil production, an if the treatment and disposal of this water is not considered and planned in advance, the oil industry might be left with more water than they can treat on-site. [9]

For conventional oil production in the Permian Basin region, the average amount is 13 barrels of PW per barrel of oil. Most of this PW however is injected back into pressure-depleted oil reservoirs [10].

For oil shale formations, less PW is produced, about 3 barrels of water per barrel of oil [10]. Most of the PW is produced in the first 6 months of operating a well, about $30-40 \%$ of what the well will produce in a decade of operation [9]. The big difference with conventional oil production is the consumption of water, which can increase with a factor of 10-16 per well [11]. The fracking fluid injected in the reservoir consists of water, chemicals and propants such as sand. Most of the salt and organic materials that are found in PW that comes up from these well is of natural origin, but recently researchers found that the chemicals used for fracking combined with the bacteria present in the reservoir may be the origin of dangerous compounds found in PW that do not occur in nature. This emphasizes the need not only for better treatment of PW, but also of a different approach to the fracking process [12]. The PW produced can not be injected back into the reservoir for fracking because of the lesser permeability of the rock, and is often disposed in nonproducing formations, inducing seismic activity [13, 14]. The potential of using shale formation PW for hydraulic fracking after sufficient treatment is therefore considerable. New developments in hydraulic fracturing allow for a higher concentration in dissolved solids in the fracking water, making the reuse of PW more likely in the near future [10]. Treatment of PW to make it suitable for re-use in fracking would solve a small part of the PW that has to be handled. More importantly, it would decrease the amount of fresh water that is now used for fracking in an area under water pressure [15]. In the whole US the amount of water used for fracking is only $1 \%$ of the total used amount of water, but in small rural counties of Texas, the water use can be as high as $29 \%$ of the total used water [15]. In addition, it would also solve future questions about water ownership in the dry region [16]. The amount of PW generated in the US is on the same level as water use [11]. The infrastructure to make the 


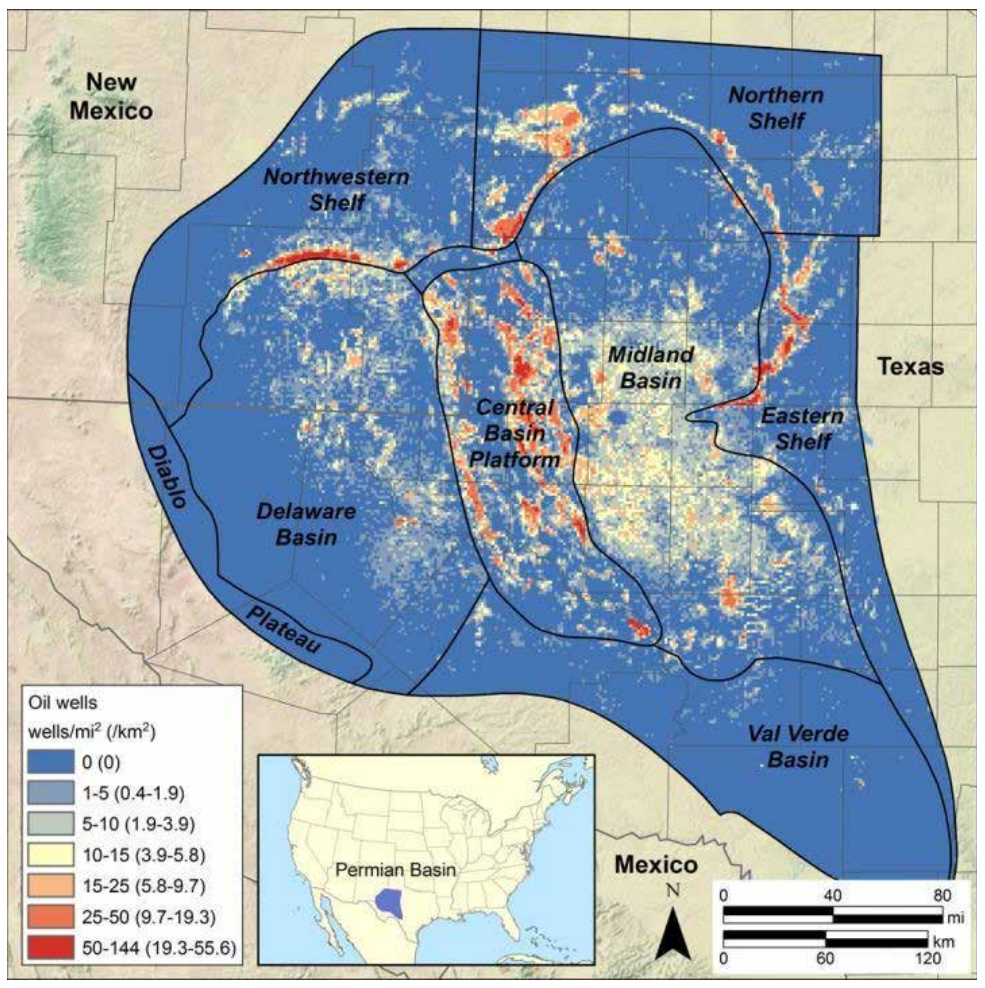

Figure 1.2: The Permian Basin extends over $168,000 \mathrm{~km}^{2}$ in West Texas and New Mexico. Unconventional oil wells are found mostly in the Midland Basin and the Delaware Basin. Oil well density in the Permian Basin is based on $\sim 162,000$ producing wells during the 2005-2015 period. High well densities around the margins of the Midland and Delaware basins and in the Central Basin Platform between the basins reflect primarily conventional reservoirs. Low densities in the Midland and Delaware basin floors represent mostly unconventional wells. Picture and data from [10]. 
PW suitable for reuse however is often the more expensive and difficult option, and therefore using fresh water is the preferred option for the oil exploitants in the Permian Basin.

Despite the forecasts that shale oil will keep flowing for many years to come, the US and Canada are already looking at a new source of oil: so-called oil sands. The heavy oil and bitumen in this sand is recovered by either digging up the sand and washing it with hot water, or injecting steam into formations that are deeper under the surface [17]. The water from this process is often stored in tailings ponds. These ponds, however, which are supposed to retain the heavily contaminated water have shown to leak harmful components into the groundwater and rivers [18]. In addition, the volatile and possible carcinogenic substances are released into the air [19]. In Alberta, Canada, the amount of water that can be used for oil sand recovery is limited to $1 \%$ of the annual flow of the Athabasca river, pushing the oil drilling operators to recycle their process water. Between 80 to $95 \%$ of the process water is therefore recycled, but with the increasing amount of oil recovery sites and thus the volume of water required, the industry is pushed to innovate their water management. Nevertheless, the impact on the environment caused by oil sand exploitation is considerable.

\subsubsection{Europe: Offshore management}

Europe has many offshore oil and gas fields in the North Sea region. Offshore oil recovery brings its own challenges, both in oil recovery itself and in PW management [20]. Water injection to maintain reservoir pressure is common practice, but the water has to be pretreated due to high salinity and scaling potential which causes damage to equipment and the reservoir [21]. Similar to onshore oil drilling, chemicals are often added to enhance the oil recovery. The PW that comes out with the oil has to be treated and either re-used for oil recovery or discharged into the environment. More PW is produced than can be re-used, so discharge is a common practice. PW treatment in offshore operations is often challenging, as the space and weight limitations of platforms also limit the equipment that can be used. Because the water is discharged into the environment, strict regulations apply to the contaminants in PW. The North Sea region is protected by the Oslo Paris convention (OSPAR), which is a mechanism in which 15 European countries and the EU work together. The OSPAR convention is implemented to control and monitor the release of pollutants in the maritime environment, including PW, and assure that the Best Available Techniques (BAT) and Best Environmental Practice (BEP) are implemented. Currently, the amount of oil and grease in PW is limited at $30 \mathrm{mg} / \mathrm{L}$ on a monthly average [22]. In addition, OSPAR also strove to phase out so-called 'substitution chemicals', which could be replaced by less harmful chemicals, by 2017 [23]. The strict rules and regulations active in the North Sea region pay off, as can be seen in the numbers over the past 
years (Figure 1.3). In 2015, the UK oil and gas industry reported that in 2015, the amount of chemicals discharged had increased by $3 \%$, more than half of this due to accidental spills. The volume of PW discharged however had decreased with $37 \%$ since 2000, despite increasing production of oil [24]. OSPAR researches the effects of PW discharge on the marine environment, and has stated that the oil discharged has caused no damage so far, as many of the compounds break down in a relatively short period in the environment. The long term effects on the environment however are still under monitoring. Therefore, OSPAR strives to evaluate the harm to the environment from each offshore installation by 2020 and take measurements where necessary.

The oil discharged via PW accounts for $10 \%$ of the oil that ends up yearly in the North Sea [25]. Therefore, it is also necessary to compare the influence on the environment of zero discharge against the increased $\mathrm{CO}_{2}$ emissions that can come with improved treatment [25].

The OSPAR discharge limits however only apply to the oil and grease in PW, and not to the other pollutants. Several studies have shown that for instance the aromatic BTEX and PAH compounds present in PW can have an adverse effect on the environment, as long-term exposure to low concentrations of those compounds can cause chronic toxicity. Although no causal connection has been found yet between the release of those compounds in PW discharges and the observed effects on marine wildlife, more research is needed to determine the full effect of PW discharge on the environment [26-29]. In addition, unidentified compounds are found in PW still, which can have adverse effects [30]. Alkylphenols for instance have been shown to disrupt the endocrine system of cod in controlled studies, but it has not been shown yet to have the same effect in wild populations of cod. In addition, if such effects are observed, it has yet to be established PW is the cause $[25,31]$.

\subsubsection{Middle East: An opportunity for water shortage}

The Middle East has been known for a long time as the world's largest oilproducing region, only matched in recent years by the US [6]. The largest conventional oil field in the world, the Ghawar field, is situated under Saudi Arabia, and accounts for more than half of the oil produced in the country [33]. On the other hand, the Middle East is also one of the regions with the highest water scarcity in the world [34]. To illustrate, in Saudi Arabia, the price for a litre of water was the same as a litre of gasoline in 2015 [35]. To provide its inhabitants with drinking water, expensive desalination techniques such as reverse osmosis and flash distillation are used to turn sea water into fresh water [36, 37]. Therefore, PW presents an opportunity to provide the region with an additional source of water [38]. If, however, PW is to be re-used, all contaminants will have to be removed from the water, and multiple countries in the region are investing in 


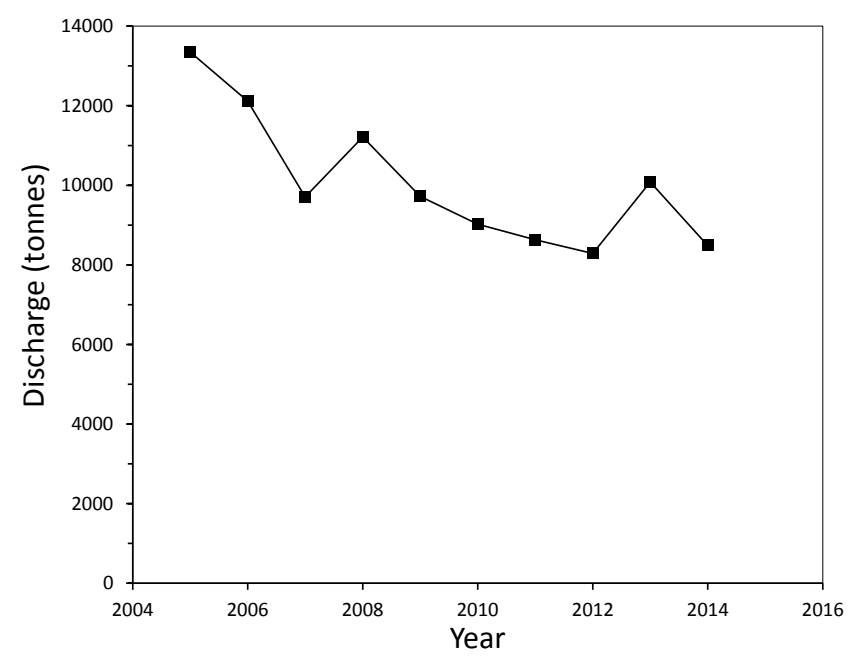

Figure 1.3: Oil and dissolved hydrocarbons discharged to the maritime area in displacement and produced water (in tonnes), 2004-2015. Data retrieved from [32]

reaching this goal. Oman and Kuwait are investing in the treatment and re-use of PW for multiple purposes, including agriculture [39]. In Oman, the volume of PW produced each year is $20-40 \%$ of the nation's water usage, and the potential of this water source is therefore substantial. Right now most PW is reinjected or injected in deep aquifers, but concerns over possible pollution in the ground water are spurring research into how PW can be used beneficially. Water ownership is tightly regulated in Oman, putting restrictions on moving water away from the well and trading water. Since 2004, a new framework is in place to regulate the investments in water infrastructure from the private sector, as these sources are becoming more and more important [40]. In Qatar, the Pearl GTL project has a treatment system in which all PW is treated and re-used [41]. Instead of only looking at the costs of treating PW, the Middle East rather focuses on the value this water source can bring to their region.

\subsubsection{Africa: Challenges and opportunities}

The African continent has had a few big oilfield and particularly gasfield discoveries over the past years, both onshore and offshore. Angola has been known for several deep sea operations for quite some years, but now also Nigeria and Tunisia are taking their oil drilling operations offshore [42]. Despite the uprise of oil and gas operations, Africa suffers from various drawbacks. Firstly, oil drilling started fairly recently, and the oil prices are quite low nowadays. Therefore, investments can take long to earn back. Corruption and the call from society for greener 
alternatives to fossil fuel can make production companies reluctant to invest in the region, together with political instability. The existing operations however are also not without problems. Due to poor maintenance, oil theft and militant actions in some regions, oil spills occur regularly. In 2009, approximately 14000 tonnes of oil flooded the Niger delta, with severe damage to the environment and the population in the region [43]. The long-term effects of these spills are severe, and pointing out the guilty party is often hard. Nevertheless, many African countries see the fossil fuel industry as a means to prosperity. The produced water that comes with oil and gas drilling has been treated with several of the established techniques, but new techniques especially developed in this region are also on the rise. Africa, just like the Middle East, has a limited supply of fresh water, and re-using PW is a big opportunity to alleviate the pressure on fresh water supply. With sufficient treatment, such as the construction of wetlands, the PW can be re-used for irrigation and livestock[44, 45]. The application of basins where aerobic digestion reduces the pollutants also seems successful on a pilot scale [46]. Nevertheless, poverty and a lack of regulations will be the main problem for oil exploitation on the African continent.

\subsection{Membrane treatment of PW}

As illustrated in the previous paragraph, treating PW is of paramount importance as long as oil drilling is common practice around the world. The techniques used nowadays often are not sufficient at removing oil content to an acceptable level for disposal, let alone dealing with all the other compounds found in PW. Therefore, new techniques have to be explored. The application of membrane filtration is a viable option, if we deal with some of the problems they experience.

A membrane is a semi-permeable barrier, which means that it lets through certain compounds while retaining others, depending on the properties of the membrane and the materials involved, see Figure 1.4. A membrane is comparable to a very fine sieve, and is capable of retaining small droplets of oil, while letting water and the compounds therein pass through. Where a sieve has holes of a certain size, membranes are made in different pore sizes, determining the field of application. Whereas in some processes we want to retain clay particles and big pores will suffice, some membranes have very small pores that can even select on the molecular level, separating dissolved salt from water. In addition to pore size and shape, membranes can also have properties such as a surface charge, surface chemistry (for instance hydrophilic or hydrophobic) and surface roughness that influence the behavior of the membrane.

Unfortunately, membrane filtration also has a drawback: fouling. If we think of a kitchen sieve, we can imagine that some materials we put in there block the holes in the sieve, allowing less water to pass through. The more we put in 


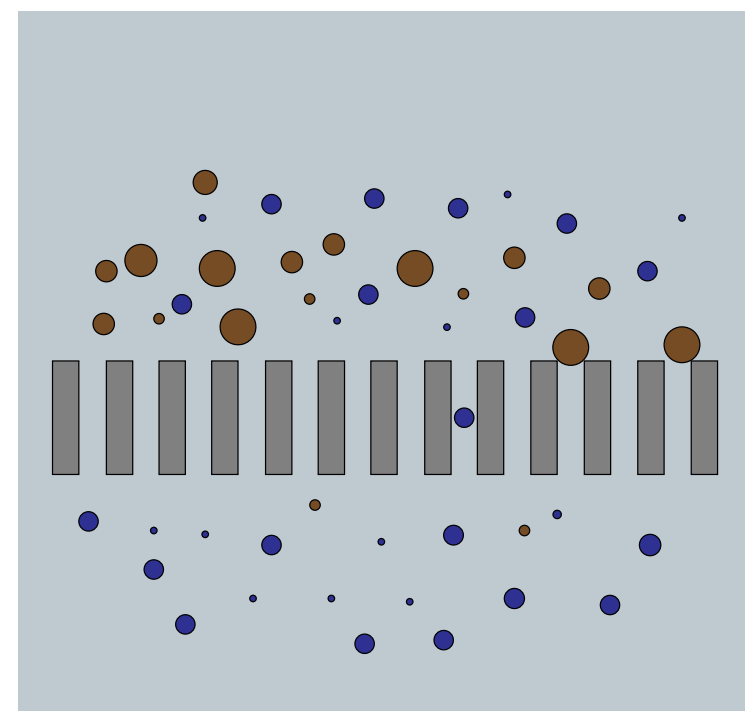

Figure 1.4: Schematic representation of a membrane. In this image, the membrane (grey) lets through the blue particles, whereas the brown particles stay behind.

the sieve, the less water can go through, and we need to empty and clean the sieve to start over after a while. The same happens to membranes. The retained material forms a layer on the surface of the membrane and even goes into the pores, decreasing the flux. Only if an effective cleaning procedure is applied can the membrane be used again.

Produced water treatment with membranes is a technology that is applied in various operations already. Fouling, however, is a serious drawback, as cleaning brings additional costs and downtime to the treatment process. The results of membrane treatment on water quality however are promising, and it has been the only technique shown to be capable of dealing with the most stable and most difficult to remove oil droplets of $<10 \mu \mathrm{m}[47]$.

\subsection{Conclusion}

Produced water is a waste stream that can be found all over the world, and different regions deal with it in different ways. All PW's have in common, however, that they contain oil, grease and other substances that can be harmful to the environment if the PW is disposed of without treatment. In addition, treated PW can be re-used in oil and gas operations, if it is treated to meet standards for re-injection, thereby alleviating pressure on fresh water supplies in dry regions. Conventional techniques can remove the oil droplets larger than $10 \mu \mathrm{m}$, but smaller droplets pose a challenge. Membrane technology is capable of re- 
moving those small droplets, but suffers from fouling, leading to performance decline of the used membrane. Although membranes are applied in PW treatment already, not much is understood about the mechanisms behind fouling by oil droplets, especially as research has been focused on improving the performance rather than understanding the fouling mechanism. The potential of membrane treatment is clear, as it is a relatively cost-effective method, but much needs to be improved to make it a method that is preferred over conventional methods. For this to happen, membrane treatment should be affordable and efficient and for this, fouling needs to be first understood and then alleviated. With that, a new step towards zero discharge of harmful substances into the environments is taken.

\subsection{Scope of this thesis}

In the previous sections, we have explained what PW is, how it is formed and why it needs to be treated before disposal. We point out the large potential of using membranes for this application, but also point out that membranes suffer from fouling. Understanding the mechanisms that take place during membrane fouling can be a difficult task, especially for complex feed waters. Still, understanding is a first critical step towards controlling and alleviating membrane fouling. The work presented in this thesis is focused on understanding the influence of the various components present in $\mathrm{PW}$ on the occurrence and extend of membrane fouling.

In Chapter 2 we present a literature review on the chemical and physical background of PW, and it's treatment by membranes. We identify the most important components in PW influencing emulsion stability and discuss the mechanisms by which they influence each other. We illustrate the challenge of treating PW with membranes with many examples from literature, and discuss why PW causes more membrane fouling than less complex oil-in-water emulsions. Based on this review we propose the ionic strength and the surfactant type as the two critical parameters with regard to membrane fouling. These parameters become the focus of the experimental work carried out in the subsequent chapters.

First, in Chapter 3, we study how droplet adhesion to hydrophilic and hydrophobic surfaces is influenced by surfactant type, surfactant concentration and ionic strength, using a new flow cell based approach. By using a flow cell under a microscope with a glass surface, we can visually observe droplets adhering to a surface. The amount of droplets that remain stuck to the surface with increasing shear force, gives us a measure of the adhesion force between droplets and surface. Indeed, the droplet adhesion is found to depend strongly on the discussed parameters.

In Chapter 4, we make the connection between flow cell adhesion tests and mem- 
brane filtration experiments, with a focus on the effects of ionic strength. Here the flow cell is used to study the droplet adhesion from a surfactant-stabilized emulsion to a cellulose surface as a function of ionic strength. Again, the adhesion force between the oil droplets and the surface is determined by increasing the shear flow and counting the number of droplets attached to the surface. We compare those results to the flux decline, oil retention and flux recovery of a membrane filtration experiment on a cellulose membrane, which is chemically identical to the surface studied in the flow cell. This work builds a bridge between the quite fundamental studies on droplet adhesion in the flow cell, with much more applied membrane studies regarding membrane performance parameters such as flux decline and oil retention.

In Chapter 5 we perform membrane separation of oil-in-water emulsions stabilized with different types of surfactant as a function of ionic strength. We use an anionic, cationic, nonionic and zwitterionic surfactant to stabilize the emulsions. For each surfactant we vary the ionic strength and measure the flux decline, oil permeation and flux recovery. We discuss the influence of the ionic strength on membrane fouling for the different surfactants and the fouling mechanisms involved.

Finally, in Chapter 6 we summarize our work and results. In the Outlook, we propose various directions in which the research on oil-water separation with membranes can continue. We present some ideas to continue the fundamental side of this work in the laboratory to expand on understanding membrane fouling, so we can bridge the knowledge gap to controlling membrane fouling. In addition, we present a few recent developments in the field of PW treatment, and especially how the insights from our research connect to this. 


\section{Bibliography}

[1] A. Viard, Le cuisinier royal (J.-N. Barba, Paris, 1820), p. 62. - p.11.

[2] L. Ho Tan Tai and V. Nardello-Rataj, Detergents, Oléagineux, Corps gras, Lipides 8, 141 (2001). - p.11.

[3] First American Oil Well, https://aoghs.org/petroleum-pioneers/ american-oil-history/ [Accessed: 2018-03-30]. - p.11.

[4] Energy Information Administration, International Energy Statistics, https://www.eia.gov/beta/international/data/ browser/\#/?pa=000gfs0000000000000000000000000000vg\&c= $4100000002000060000000000000 \mathrm{~g} 000200000000000000001 \& \mathrm{tl}$ _id=5-A\& vs $=$ INTL . 53-1-AFRC-TBPD . A\&vo=0\&v=H\&end=2017 [Accessed: 2018-03-30]. - p.12.

[5] S. Henderson, S. Grigson, P. Johnson, and B. Roddie, Potential Impact of Production Chemicals on the Toxicity of Produced Water Discharges from North Sea Oil Platforms, Marine Pollution Bulletin 38, 1141 (1999). p.13.

[6] Energy Information Administration, U.S. Field Production of Crude Oil and Petroleum Products, https://www.eia.gov/dnav/pet/hist/ LeafHandler $. \operatorname{ashx} ? \mathrm{n}=$ PET\&s=MTTFPUS2\&f=M [Accessed: 2018-03-31]. _ p.13, 17.

[7] Energy Information Administration, Drilling Productivity Report March 2018, https://www.eia.gov/petroleum/drilling/pdf/dpr-full.pdf [Accessed: 2018-03-31]. - p.14.

[8] Bloomberg Markets, Permian 'Super Basin' Holds Up to $\$ 3.3$ Trillion in Untapped Oil, https://www.bloomberg.com/news/articles/2017-09-25/ permian-super-basin-holds-up-to-3-3-trillion-in-untapped-oil. - p.14.

[9] T. Jacobs, More Oil, More Water: How Produced Water Will Create Big Cost Problems for Shale Operators, Journal of Petroleum Technology 68, (2016). - p.14.

[10] B. R. Scanlon, R. C. Reedy, F. Male, and M. Walsh, Water Issues Related to Transitioning from Conventional to Unconventional Oil Production in the Permian Basin, Environmental Science \& Technology 51, 10903 (2017). - p.14, 15.

[11] A. Kondash and A. Vengosh, Water Footprint of Hydraulic Fracturing, En- 
vironmental Science \& Technology Letters 2, 276 (2015). - p.14.

[12] S. J. Maguire-Boyle and A. R. Barron, Organic compounds in produced waters from shale gas wells, Environ. Sci.: Processes Impacts 16, 2237 (2014). - p.14.

[13] F. R. Walsh and M. D. Zoback, Oklahoma's recent earthquakes and saltwater disposal, Science Advances 1, e1500195 (2015). — p.14.

[14] R. M. Pollyea, N. Mohammadi, J. E. Taylor, and M. C. Chapman, Geospatial analysis of Oklahoma (USA) earthquakes (20112016): Quantifying the limits of regional-scale earthquake mitigation measures, Geology 46, 215 (2018). - p.14.

[15] J.-P. Nicot and B. R. Scanlon, Water Use for Shale-Gas Production in Texas, U.S., Environmental Science \& Technology 46, 3580 (2012). — p.14.

[16] G. Collins, Technical report, James A. Baker III Institute for Public Policy of Rice University (unpublished). - p.14.

[17] Natural Resources Canada, Oil Sands Extraction and Processing, https: //www.nrcan.gc.ca/energy/oil-sands/18094 [Accessed: 2018-4-26]. p.16.

[18] R. A. Frank, J. W. Roy, G. Bickerton, S. J. Rowland, J. V. Headley, A. G. Scarlett, C. E. West, K. M. Peru, J. L. Parrott, F. M. Conly, and L. M. Hewitt, Profiling Oil Sands Mixtures from Industrial Developments and Natural Groundwaters for Source Identification, Environmental Science \& Technology 48, 2660 (2014). - p.16.

[19] A. Parajulee and F. Wania, Evaluating officially reported polycyclic aromatic hydrocarbon emissions in the Athabasca oil sands region with a multimedia fate model., Proceedings of the National Academy of Sciences of the United States of America 111, 3344 (2014). - p.16.

[20] J. M. Walsh, Produced-Water-Treatment Systems: Comparison of North Sea and Deepwater Gulf of Mexico, Oil and Gas facilities 8 (2015). — p.16.

[21] E. Blanchard, Oil in water monitoring is a key to production separation, Offshore (2013). - p.16.

[22] OSPAR, OSPAR Recommendation 2001/1 for the Management of Produced Water from Offshore Installations (Consolidated text), (2005). — p.16.

[23] OSPAR, OSPAR Recommendation 2006/3 on Environmental Goals for the Discharge by the Offshore Industry of Chemicals that Are, or Which Contain Substances Identified as Candidates for Substitution, (2006). — p.16.

[24] Oil \& Gas UK, Environment report 2016, https://oilandgasuk.co.uk/ wp-content/uploads/2016/11/Environment-Report-2016-0il-Gas-UK. pdf [Accessed: 2018-04-24]. — p.17.

[25] P. Ekins, R. Vanner, and J. Firebrace, Technical report, Policy Studies Institute (unpublished). - p.17.

[26] G. Durell, T. R. Utvik, S. Johnsen, T. Frost, and J. Neff, Oil well produced water discharges to the North Sea. Part I: Comparison of deployed mussels 
(Mytilus edulis), semi-permeable membrane devices, and the DREAM model predictions to estimate the dispersion of polycyclic aromatic hydrocarbons, Marine Environmental Research 62, 194 (2006). - p.17.

[27] J. M. Neff, S. Johnsen, T. K. Frost, T. I. R. Utvik, and G. S. Durell, Oil well produced water discharges to the North Sea. Part II: Comparison of deployed mussels (Mytilus edulis) and the DREAM model to predict ecological risk, Marine Environmental Research 62, 224 (2006). — p.17.

[28] J. Neff, K. Lee, and E. Deblois, Produced Water: Overview of Composition, Fates, and Effects, 2011. - p.17.

[29] T. Bakke, J. Klungsøyr, and S. Sanni, Environmental impacts of produced water and drilling waste discharges from the Norwegian offshore petroleum industry, Marine Environmental Research 92, 154 (2013). — p.17.

[30] J. L. Balaam, Y. Chan-Man, P. H. Roberts, and K. V. Thomas, Identification of nonregulated pollutants in north sea-produced water discharges, Environmental Toxicology and Chemistry 28, 1159 (2009). — p.17.

[31] K. V. Thomas, K. Langford, K. Petersen, A. J. Smith, and K. E. Tollefsen, Effect-Directed Identification of Naphthenic Acids As Important in Vitro Xeno-Estrogens and Anti-Androgens in North Sea Offshore Produced Water Discharges, Environmental Science \& Technology 43, 8066 (2009). — p.17.

[32] A. Taylor, M. Malinovsky, H. Nielsen, E. Garland, K. Machetanz, M. Cronin, I. Abdoellakhan, T. Sørgård, and I. Rønning, Technical report, OSPAR (unpublished). - p.18.

[33] B. D. Al-Anazi, What you know about The Ghawar Oil Field, Saudi Arabia?, CSEG Recorder 32, 40 (2007). - p.17.

[34] M. Kummu, P. J. Ward, H. de Moel, and O. Varis, Is physical water scarcity a new phenomenon? Global assessment of water shortage over the last two millennia, Environmental Research Letters 5, 034006 (2010). — p.17.

[35] G. Lahn, Technical report, Chatham House, The Royal Institute of international affairs (unpublished). - p.17.

[36] A. D. Khawaji, I. K. Kutubkhanah, and J.-M. Wie, Advances in seawater desalination technologies, Desalination 221, 47 (2008). — p.17.

[37] Middle East Monitor, Saudi Arabia expands water desalination production capacity, https://www.middleeastmonitor.com/ 20170321-saudi-arabia-expands-water-desalination-production-capacity/ [Accessed: 2018-04-06]. - p.17.

[38] M. Qadir, A. Bahri, T. Sato, and E. Al-Karadsheh, Wastewater production, treatment, and irrigation in Middle East and North Africa, Irrigation and Drainage Systems 24, 37 (2010). - p.17.

[39] Times of Oman, Oman seeks to utilise $10 \mathrm{mbd}$ of oilfield produced water efficiently, http://timesofoman.com/article/50948 [Accessed: 2018-0424]. - p.18.

[40] R. McDonnell, Technical report, International Water Management Institute 
(unpublished). - p.18.

[41] Veolia Water wins Qatar design \& build contract, Pump Industry Analyst 2007, 3 (2007). - p.18.

[42] S. Oputa, Meeting Deepwater Oil \& Gas Challenges in Africa with Africa-centric Rigs and Alternate Technology, https://www. energycorporateafrica.com/ meeting-deep-water-oil-and-gas-challenge [Accessed: 2018-4-28]. - p.18.

[43] The Guardian, Shell reports record oil spillages in Nigeria, https://www.theguardian.com/environment/2010/may/05/ shell-oil-spill-niger-delta [Accessed: 2018-4-28]. — p.19.

[44] J. E. Horner, J. W. Castle, and J. H. Rodgers, A risk assessment approach to identifying constituents in oilfield produced water for treatment prior to beneficial use, Ecotoxicology and Environmental Safety 74, 989 (2011). p.19.

[45] J. E. Horner, J. W. Castle, J. H. Rodgers, C. M. Gulde, and J. E. Myers, Design and Performance of Pilot-Scale Constructed Wetland Treatment Systems for Treating Oilfield Produced Water from Sub-Saharan Africa, Water, Air, \& Soil Pollution 223, 1945 (2012). — p.19.

[46] M. Pardue, Treatment of oilfield produced water using a pilot-scale constructed wetland treatment system, Ph.D. thesis, Clemson University, 2012. - p.19.

[47] R. Duraisamy, A. Beni, and A. Henni, Water treatment (InTech, 2013). p.20. 


\section{CHAPTER 2}

\section{Produced water treatment by membranes: A review from a colloidal perspective}

While the world faces an increased scarcity in fresh water supply, it is of great importance that water from industry and waste streams can be treated for re-use. One of the largest waste streams in the oil and gas industry is produced water. After the phase separation of oil and gas, the produced water is left. This mixture contains dissolved and dispersed hydrocarbons, surfactants, clay particles and salts. Before this water can be used for re-injection, irrigation or as industrial water, it has to be treated. Conventional filtration techniques such as multi media filters and cartridge filters, are able to remove the majority of the contaminants, but the smallest, stabilized oil droplets $(<10 \mu \mathrm{m})$ remain present in the treated water. In recent years, research has focused on membranes to remove these small oil droplets, because this technology requires no frequent replacement of filters and the water quality after treatment is better. Membranes however suffer from fouling by the contaminants in produced water, leading to a lower clean water flux and increased energy costs. Current research on produced water treatment by membranes is mainly focused on improving existing processes and developing fouling-resistant membranes. Multiple investigations have determined the importance of different factors (such as emulsion properties and operating conditions) on the fouling process, but understanding the background of fouling is largely absent. In this review, we describe the interaction between the membrane and a produced water emulsion from a colloidal perspective, with the aim to create a clear framework that can lead to much more detailed understanding of membrane fouling in produced water treatment. Better understanding of the complex interactions at the produced water/membrane interface is essential to achieve more efficient applications.

This chapter has been published as: Produced water treatment by membranes: A review from a colloidal perspective, J.M. Dickhout, J. Moreno, P.M. Biesheuvel, L. Boels, R.G.H. Lammertink, W.M. de Vos, Journal of Colloid and Interface Science (2016) 


\subsection{Introduction}

Produced water $(\mathrm{PW})$ is the largest waste stream in the oil and gas industry, with a global estimated 3:1 volume-to-product ratio [1], adding up to an estimated volume of 21 billion barrels per year in the US and 50 billion barrels per year in the rest of the world over 2009 [2]. Therefore, regulations concerning produced water are necessary to avoid discharge of this waste water into the environment. In the North Sea Region, OSPAR regulations set the upper limit for oil content in discharged water at $30 \mathrm{mg} / \mathrm{L}$ [3]. Treating the vast amounts of PW in a costeffective way on sometimes remote locations (such as offshore platforms) demands smart solutions, often a combination of several separation processes, so the water can be safely discharged or re-used for other purposes. Conventional treatment methods, such as hydrocyclones, gas flotation, adsorption, media filtration and macro-porous polymer extraction (MPPE) are able to remove most of the oil and other harmful components from the PW [4].

Membrane technology is an emerging technology in the field of PW treatment. Membranes can remove the smallest $(<10 \mu \mathrm{m})$ and most stable oil droplets from PW and can be tailored to the specific properties of the oil well involved. All membranes, however, suffer from fouling, in which a layer of oil, solids and other PW components forms on the membrane surface. This leads to decreased flux and thus increasing operating costs. Most membranes can be cleaned, but this often requires extra chemicals or energy, as well as downtime of the treatment installation. Reducing membrane fouling and improving membrane operation can thus lead to a decrease in operating costs and an increase in the application of membrane technology for PW treatment. In literature numerous examples can be found of optimized treatment processes, but surprisingly little articles attempt to understand the background and mechanics of membrane fouling [5-7]. In this review, we attempt to give a base of knowledge to work towards understanding membrane fouling in PW treatment with membranes. In the following sections, we will first discuss the properties of PW from a colloidal view, and the expected influence of the compounds found in PW on the emulsion stability. After that, we will discuss membranes and the surface chemistry taking place at the membrane surface, and finally we will summarize multiple examples from literature on the separation of both simple and complex oil-in-water emulsions, including PW.

\subsection{Produced water as an emulsion}

PW is an oil-in-water emulsion, where the oily phase is dispersed in the aqueous phase, stabilized by surfactants. The composition of PW varies between oil fields and usually changes as the oil field ages. The main components of PW are dispersed oil, dissolved organics, suspended solids and dissolved inorganics. Additionally, process chemicals such as corrosion inhibitors, biocides and extrac- 


\begin{tabular}{lll}
\hline Compound & range $(\mathrm{mg} / \mathrm{L})$ & mean $(\mathrm{mg} / \mathrm{L})$ \\
\hline BTEX & $1.39-20$ & 4.87 \\
PAH & $0.44-0.61$ & 0.53 \\
TOC & $86-971$ & 307 \\
TPH & $86-971$ & 10 \\
TSS & $1.9-106$ & 10.6 \\
Salinity & $38,182-179,766$ & 75434 \\
\hline
\end{tabular}

Table 2.1: Ranges and mean values of the main components of produced water as found in 23 samples from offshore oil platforms in Brazil. Benzene, toluene, ethylbenzene, xylene (BTEX), polycyclic aromatic hydrocarbons (PAH), total organic carbon (TOC), total petroleum hydrocarbon (TPH), total suspended solids (TSS) and salinity. Data reproduced from [9]

tion enhancers can be added [8]. These molecules act as surfactants and play an important role in the emulsion stability of produced water. Typical values for produced water contents are presented in table 2.1.

In order to understand PW, we will first focus on some basic principles of emulsions. Most emulsions are thermodynamically unstable. Because the interfacial area between water and oil increases when making an emulsion, the free energy in the system increases, which can be described as

$$
\Delta F=\gamma \Delta A(\mathrm{~J})
$$

where $\Delta F$ is the change in free energy, $\gamma$ is the interfacial tension and $\Delta A$ is the change in interfacial area. As can be seen from equation 2.1, making an emulsion costs energy. This necessary energy can be provided by stirring or mixing at high speeds $[10,11]$, shaking [12] or ultrasonification [13]. In the case of PW, the pressure drop over the choke valves in the pipe lines of the pump installation [14]. Most interesting processes in an emulsion take place at the oil-water interface of the droplets. The importance of the interface can be understood by calculating its surface area $A$, given by

$$
A=N_{t o t} \pi d^{2}=\frac{6 V \phi}{a}\left(\mathrm{~m}^{2}\right),
$$

where $N_{\text {tot }}$ is the total number of droplets, $\mathrm{V}$ is the dispersion volume, $\phi$ is the volume fraction of the dispersed phase and $a$ is the droplet diameter. This means that, for example, for an emulsion with $V=1 \mathrm{~L}, \phi=1 \times 10^{-3}$ and $a=$ $1 \mu \mathrm{m}$, the interfacial area $A$ is $6000 \mathrm{~m}^{2}$. As can be seen from this example, the interfacial area of a small volume of emulsion can be quite large, especially for very small droplets. This shows that interfacial science plays an important role in understanding emulsions.

An emulsion, however, always tends towards lowering the free energy, causing 
the oil to coarsen. Separation can be either inhibited or enhanced by various additives, which will be discussed later in this section. The two largest factors in emulsion instability, coalescence and Ostwald ripening, are both influenced by the interfacial tension. In both processes the free energy of the system reduces because the surface area reduces, as can be seen from equation 2.1. This equation shows that lowering the surface tension plays an essential role in stabilizing the emulsion.

Coalescence is the fastest destabilization mechanism, of which the kinetics can be described as

$$
\begin{gathered}
-\frac{d N}{d t}=p N^{2}, \\
p=p_{0} e^{\left(-E / k_{B} T\right)}
\end{gathered}
$$

where $N$ is the number of droplets, $p$ is the coalescence rate, $E$ is the activation energy, $k_{B}$ is the Boltzmann constant and $\mathrm{T}$ is the temperature. The forces involved in coalescence are short-ranged, so coalescence takes place when droplets are close together $(h<<a)$. Due to the disjoining pressure exerted by the two interfaces, the liquid film between the two droplets drains, causing film rupture eventually. The interfacial tension $\gamma$ at the oil-water interface is counteracted by the Laplace pressure,

$$
\Delta p=\frac{2 \gamma}{a}\left(\mathrm{~N} / \mathrm{m}^{2}\right)
$$

For small droplets, the Laplace pressure $(\Delta P)$ inside the droplets increases. If two droplets of unequal size coalesce, the higher pressure in the smaller droplet will cause the oil to flow to the bigger droplet.

In the second factor of instability, Ostwald ripening, larger droplets grow at the cost of smaller droplets. Because the Laplace pressure in smaller droplets is the largest, these have an enhanced solubility in the bulk phase, which can be described by the Kelvin equation,

$$
\ln \frac{P}{P_{0}}=\frac{2 \gamma V_{m}}{a R T}
$$

where $P$ is the vapor pressure of the droplet phase, $P_{0}$ is the vapor pressure of the bulk phase, $V_{m}$ is the molar volume of the droplet phase and $R$ is the universal gas constant. This release of oil molecules from the small droplets in the bulk fase causes larger droplets to experience a supersaturation. They pick up oil molecules from the aqueous phase to reduce the concentration of oil molecules again. Ostwald ripening is a much slower progress than coalescence, but certainly contributes to the emulsion destabilization. 


\subsubsection{Influence of different factors on emulsion stability}

The stability of an emulsion is influenced by both attractive van der Waals forces and repulsive electrostatic forces between the droplets. This can be described by the DLVO (Derjaguin-Landau-Verwey-Overbeek) theory, which is based on the addition of the attractive forces $V_{A}$ and repulsive forces $V_{R}$ in the total potential

$$
V_{T}=V_{A}+V_{R}
$$

The attractive van der Waals attraction is caused by the alignment of dipoles in adjacent molecules. The electrons in atoms cause rapidly fluctuating dipoles, and since it is energetically more favourable to be oscillating in unison, the dipoles get coupled (London dispersion interaction). In emulsions, large assemblies of atoms are considered, leading to the van der Waals attractive forces. The attractive potential energy can be found by calculating the interaction of one atom in a droplet with all the atoms in a second droplet, leading to a long-range interaction. When the particle separation distance $h$ is small $(h<<2 a)$, the potential is given by the equation

$$
V_{A}=-\frac{A a}{12 h}(\mathrm{~J})
$$

where $A$ is the Hamaker constant, which depends on the polarizability of the material of the droplet. Thus, the attractive potential between two oil droplets is inversely dependent of the separation distance between the droplets.

The electrostatic repulsion is an important stabilizing factor in emulsions with an aqueous continuous phase. When the oil droplets carry a surface charge, the repulsion will prevent collision between the droplets. The diffuse part of the electrostatic double layer extends into the solution by a length characterized by the Debye length $(1 / \kappa)$, often referred to as the double layer thickness. When two particles approach, their diffuse layers of ions start to overlap. The higher concentration of ions in this area results in an osmotic pressure, forcing the particles apart again. For short distances $(h<<2 a)$ and small surface charge densities $\left(<k_{B} T\right)$, this interaction can be written as:

$$
V_{R}=2 \pi \epsilon_{0} \epsilon_{r} a \psi_{\delta}^{2} e^{(-\kappa h)}(\mathrm{J}),
$$

where $\epsilon_{0}$ is the dielectric constant of vacuum and $\epsilon_{r}$ the dielectric constant of the medium, $\psi_{\delta}$ the surface potential and $\kappa$ is the inverse of the Debye length.

The total potential can now be found by linear addition of the attractive and repulsive potentials, as stated in equation 2.7. This leads to interaction potential curves as shown in figure 2.1. This potential curve shows a primary maximum, which is the energy barrier the droplets have to overcome to coalesce. It is very important to note, that this means an emulsion is kinetically stable. The thermodynamic drive of the system is always towards two separated phases. To 


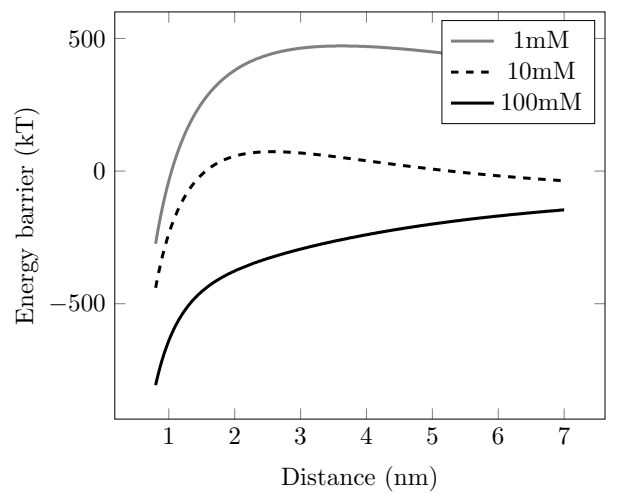

Figure 2.1: Pair-droplet interaction energy between two hexadecane droplets (Hamaker constant: $0.5 \times 10^{-20} \mathrm{~J}$, particle diameter: $10 \mu \mathrm{m}$, surface potential: -10 $\mathrm{mV}$ ) calculated according to the DLVO theory as a function of the droplet separation distance for 1,10 and $100 \mathrm{mM} \mathrm{NaCl}$

keep the two phases separated for an extended period of time, this primary maximum has to be made as high as possible, typically $>15 k_{B} T$.

Furthermore, it is important to note that the DLVO theory in this simple form has its limitations when used for oil-in-water emulsions. This theory is based on particle-pair interactions, but in a concentrated emulsion the interaction between droplets becomes a many-body problem. Concentration is very relevant in the scope of this PW treatment with membranes, as a concentration gradient will build up at the surface of the membrane due to its selective permeability, leading to concentration polarization. Furthermore, DLVO treats the droplets in the emulsion as hard, non-deformable spheres, whereas oil droplets can easily deform. Also the steric hindrance caused by the surfactants at the oil-water interface is not taken into account in this version of the DLVO theory. Extensions can be made in several ways, depending on the extra forces that have to be taken into account. Examples can be found of extra terms including the hydration forces on solid particles in an emulsion [15, 16], which has already been used for Pickering emulsions [17].

\subsubsection{Surfactants}

Surfactants are mostly organic molecules with a polar head group and a nonpolar tail. In PW, a great amount of different surfactants are present. These compounds are added during the oil recovery process, but also compounds from the oil reservoir itself can act as surfactants [8]. The head group of a surfac- 
tant molecule is usually anionic, cationic, non-ionic or zwitterionic. Surfactant molecules adsorb at the oil-water interface, hydrophobic tail in the oil phase and hydrophilic head group towards the aqueous phase. This process lowers the interfacial surface tension, because the interaction between the hydrophilic head groups and the surrounding water is much more favourable than the interaction of oil molecules and water. For all surfactants the Gibbs-Marangoni effect plays an important role in emulsion stabilisation. When the surface of a droplet is not saturated with surfactant molecules, the resulting surface tension gradient causes surfactant molecules along with liquid to flow to the region with high surface tension. In the case of charged surfactant head groups, the resulting surface charge keeps the droplets from coalescing by electrostatic repulsion. Nonionic surfactants cause steric hindrance to coalescence. Zwitterionic surfactants induce the formation of a hydration layer around the oil droplets, which is energetically favourable for the interaction with the aqueous phase. Proteins and polymers can also act as surfactants, spreading their hydrophobic and hydrophilic domains in a favourable configuration over the droplet surface. These molecules cause steric hindrance towards coalescence because of their size, as well as electrostatic repulsion. In the case of proteins, the properties of the aqueous phase play a large role in the morphology of the protein molecule. The influence of $\mathrm{pH}$, ionic strength and temperature might change the configuration of the proteins, including their charge and size.

\subsection{3 lonic strength}

Ionic strength of PW varies from a few parts per million to $300 \mathrm{~g} / \mathrm{L}$ [18]. Especially in situations with high ionic strength, the emulsion stability of PW can be heavily influenced. At high concentrations of ions, the emulsion is destabilized. When the oil droplets carry a surface charge, the ion distribution in the continuous phase is influenced. Ions, with an opposite charge to the droplet surface are drawn to the surface, whereas ions with the same charge are repelled from the surface. This causes the surface charge to be screened and the chance for coalescence increases. When looking again at equation 2.9, the repulsive force between two droplets is dependent of $\kappa$, which is the inverse of the Debye length

$$
\kappa^{-1}=\sqrt{\frac{\epsilon_{r} \epsilon_{0} k_{B} T}{2 N_{A} e^{2} I}}(\mathrm{~m}),
$$

where $k_{B}$ is the Boltzmann constant, $T$ is the temperature in Kelvin, $N_{A}$ Avogadro's number, $e$ the elementary charge and $I$ the ionic strength of the emulsion. At this distance, the electrostatic potential of the droplet has fallen with a factor $1 / e$ of its value at the surface. For $z: z$ aqueous solutions at $25{ }^{\circ} \mathrm{C}$, $\kappa=\left(3.29 \times 10^{9}\right) z\left(c_{b}\right)^{1 / 2}$ with $c_{b}$ in $\mathrm{mol} / \mathrm{m}^{3}$. The Debye length can vary from below $1 \mathrm{~nm}$ to $100 \mathrm{~nm}$, depending on the ion concentration and the valency of the 
ions. In practice this means that at increasing ion valency and ion concentration, the Debye length is shorter and the chance for coalescence increases, which has been experimentally observed $[10,19]$. The presence of ions can have an influence on both coalescence and Ostwald ripening, although the effect on the latter is less pronounced [20]. For very low salt concentrations the stability of an emulsion can be enhanced when using charged surfactants. The charge on the head groups is screened, allowing more surfactant molecules to adsorb on the interface [19]. Although theoretically ions should not interact with nonionic surfactants, the specific adsorption of hydroxyl groups can make the surface negatively charged. [21]. Adding salts can thus have an influence on emulsions stabilized by nonionic surfactants.

\subsubsection{Dissolved hydrocarbons/solvents}

In PW, hydrocarbons such as BTEX (benzene, toluene, ethyl benzene and xylene), PAHs (polyaromatic hydrocarbons), alcohols and organic acids are present in small concentrations. These compounds are dissolved in both the water and the oil phase and a negligible influence might be expected on the interfacial tension. No effect on the emulsion stability is reported in literature.

\subsubsection{Solid particles}

Solid particles present in PW, originating from the surrounding bedrock, can play a role in emulsion stability. It is important to notice that the adsorption of solid particles at the oil-water interface does not lower the interfacial tension. The stabilization of an emulsion by particle adsorption is based on steric hindrance and often also charge [22]. Particles with a rough surface are less capable of stabilizing an emulsion than particles with a smooth surface [23]. The stabilization of an emulsion by solid particles can already be achieved at particle surface coverages as low as 5\%. Solid particles are able to move over the oil-water interface, and when two droplets are close to each other, the particles move to the contact region due to attractive forces between the particles, pushing the two droplets apart (Figure 2.2).

Solid particles in synergy with charged surfactants are excellent emulsion stabilizers $[11,22]$. The mixture of particles and surfactant molecules enhances the stability of emulsions over a wide range of $\mathrm{pH}$ values. In the case of viscous droplets, however, the presence of solid particles can destabilize the emulsion. Bitumen-in-water emulsions undergo gellation and coalescence in the presence of solid particles, whereas this was not observed for less viscous oily phases[24]. They reason that their cationic surfactant is adsorbed on both the bitumen and the silica. 

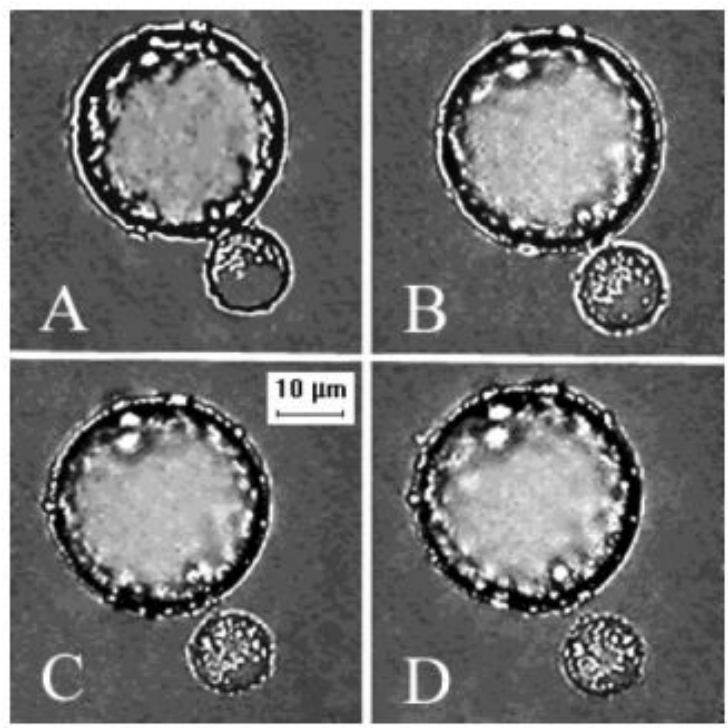

Figure 2.2: Time sequence (from A to D, in order) of detachment and drifting apart of two octanol droplets stabilized by silica particles. Brighter regions on the smaller drop indicate trapped-particle locations. Reproduced with permission from [23].

\subsection{6 $\mathrm{pH}$}

The $\mathrm{pH}$ of an emulsion influences the charge of particles and surfactants present. For silica particles, at high pH the hydroxyl groups on the silica surface become dehydrogenated and are thus negatively charged. Acidic or basic groups can change from positive to negative under the influence of $\mathrm{pH}$. An example of the droplet size (as a measure for emulsion stability) of an emulsion stabilized by protein molecules as a function of the $\mathrm{pH}$ is shown in figure 2.3. Around the isoelectric point, when the proteins on the droplet surface carry no charge, the droplet size increases due to instability. The reason is that at low $\mathrm{pH}$ the molecule or particle is positively charged. At the point of zero charge or isoelectric point the molecule or particle has no net charge, and at higher $\mathrm{pH}$ it is negatively charged. Therefore, to create a stable emulsion, it is important to adjust the $\mathrm{pH}$ of the aqueous phase well above or below the isoelectric point [25]. In PW, multiple compounds that can act as surfactants are present, so no clear isoelectric point can be determined.

\subsubsection{Temperature}

Temperature is an important factor in the emulsion stability of PW, since the water that is pumped up from the oil reservoir can be heated to over $80{ }^{\circ} \mathrm{C}[26]$. As can be seen from equation 2.3, at higher temperatures the coalescence kinetics 
A

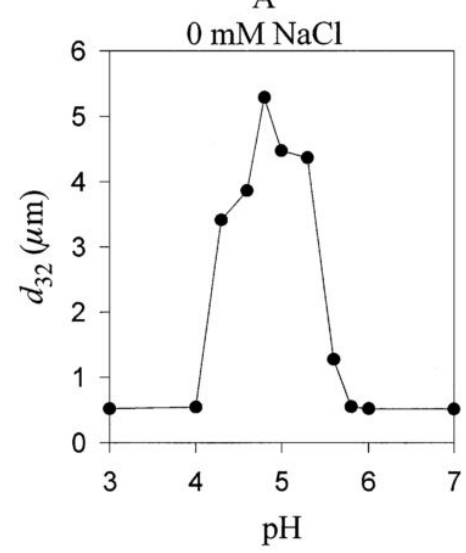

$\mathrm{B}$

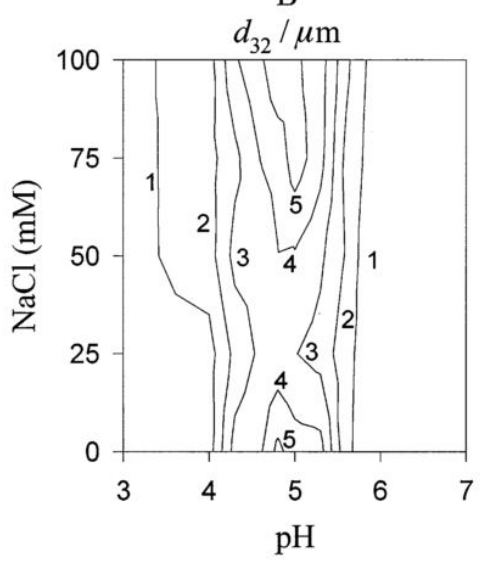

Figure 2.3: Dependence of the mean droplet diameter $\left(d_{32}\right)$ on the $\mathrm{pH}$ and ionic strength of the emulsion. A) Extensive droplet aggregation is observed around the isoelectric point of the whey proteins, i.e., $\mathrm{pH} \approx 4.8$. B) Increasing the ionic strength broadens the range of $\mathrm{pH}$ values over which flocculation occurs. Reproduced with permission from [25].

of the emulsion increase. With increasing temperature, the hydrogen bonds and van der Waals interactions in the aqueous phase become weaker, which causes the interfacial tension to decrease [10]. This can cause phase inversion in concentrated emulsions. Temperature changes can also induce reversible flocculation [27], and the droplets' behavior changing from non-adhesive to adhesive [28]. Temperature quenching can lead to rupture of the liquid films between the oil droplets [27]. The exact mechanism of this behavior change is not clear.

\subsection{Membranes}

Membranes are used in various applications, from desalination of sea water to treatment of wastewater from the food, leather and oil industry [29]. For all these different applications, appropriate membranes need to be selected. A first classification of membranes can be made based on pore size (Figure 2.4). Microfiltration membranes, with pores down to $0.1 \mu \mathrm{m}$, remove suspended particles, bacteria and some virusses, ultrafiltration removes viruses, proteins and colloidal particles and nanofiltration is selective for multivalent ions and dissolved compounds. Reverse osmosis membranes usually allow only water to pass through.

Membranes can be operated in either dead-end filtration or cross-flow filtration. In dead-end filtration, the retentate concentrates on the membrane, whereas in cross-flow filtration, the permeate leaves through the pores of the membrane, and the concentrated retentate flows away over the membrane. Depending on 


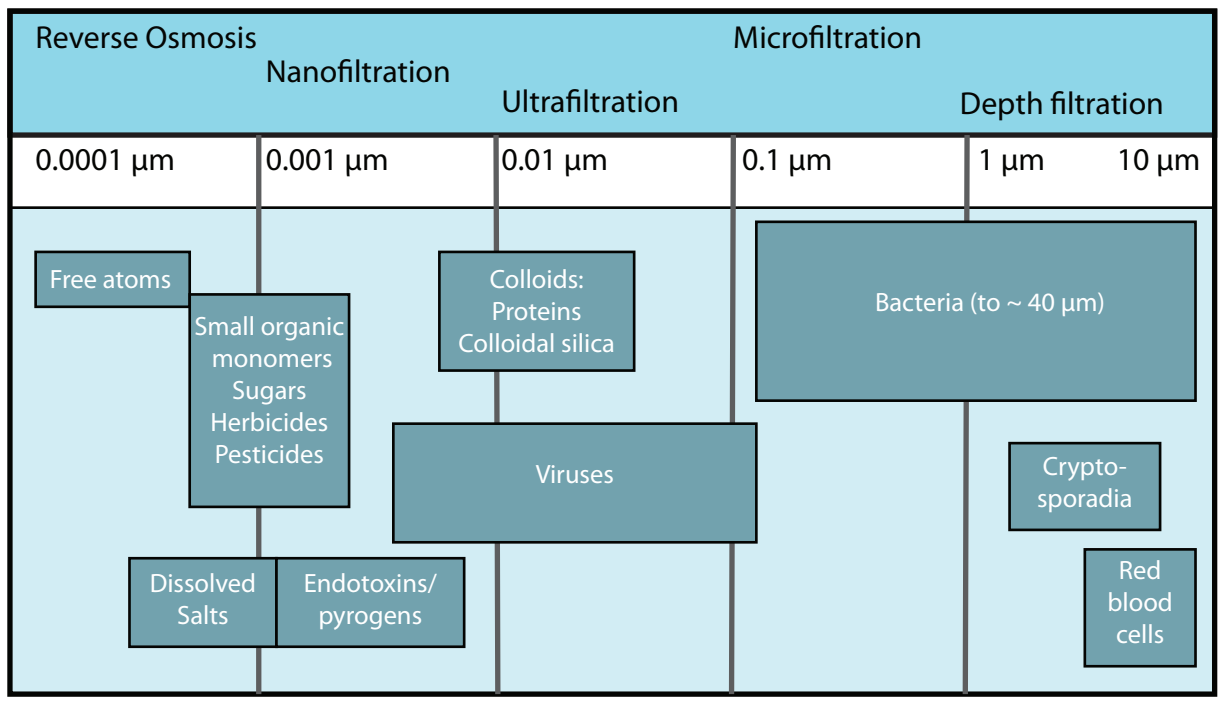

Figure 2.4: Classification of membranes based on pore size. In PW treatment, the focus is on microfiltration and ultrafiltration. Reverse osmosis membranes are sometimes used in combination with one of the former. Redrawn from [30]

the operating conditions of the membrane, flat-sheet or hollow fiber membranes can be used. Flat sheet membranes can be rolled into spiral-wound modules or used in a plate-and-frame setup, which is often used in MBR [30]. Hollow fiber modules contain several hundred to thousands of fibers.

\subsubsection{Membrane materials}

Membranes can be divided in two groups based on the materials they are made of, namely polymeric or ceramic. Ceramic or inorganic membranes, made from materials such as silica, metal oxides or carbon, have superior thermal and chemical stability, and their use in industrial application of oil recovery is an emerging technology [31-33]. Most ceramic membranes, in contrast to polymeric membranes, are inert to treatment with steam, solvents, strong acids, and have a very long expected lifespan. Although these membranes do suffer from fouling, the flux can be restored by harsh cleaning methods. Unlike polymeric membranes, ceramic membranes do not suffer from swelling in the presence of solvents. Ceramic membranes are used for MF [34], UF [35] and NF [36]. The drawback of ceramic membranes is their high production costs and their weight, although the latter is compensated by a relatively high flux in return. Furthermore, ceramic membranes work mainly on size exclusion, and modifying ceramic membranes for molecular affinity separation is much more difficult than for polymeric mem- 
branes.

Polymeric membranes are used in many separation processes in industry. A wide range of polymers can be used, such as cellulose derivatives, polyvinylidenedifluoride (PVDF), polysulfone (PS), polyether sulfone(PES), polyacrilonitrile (PAN), polytetrafluoroethylene (PTFE) and polyvinylchloride (PVC). These membranes can be tailored to the specific needs of the process they are used in, thus giving the opportunity of selective separation. Selecting a polymeric membrane for a certain task is not a trivial exercise, because the polymer has to have the right affinity and has to withstand the environment of the separation. Polymeric membranes can be either made from pure polymers or from polymers blended with compounds to improve the membrane performance [37]. Polymeric membranes can be made both dense and porous, depending on the application. Modifications to the membrane surface can be made to improve the functionality of the membrane [38].

\subsubsection{Membrane properties}

The performance of a membrane is largely dependent on its structural properties, such as pore size and morphology, and surface properties such as charge and roughness. The pore morphology of the membrane can be described in porosity, pore size distribution and the pore tortuosity of the membrane. The surface properties of the membrane, and especially the hydrophilicity, are important for the functioning of the membrane. Although adsorption is energetically favorable on a high $\gamma$ surface, highly hydrophilic surfaces are less prone to fouling by organic compounds and microorganisms, because the hydrophilic surface is covered by a thin layer of water molecules loosely bound by hydrogen bonding [39]. Breaking this ordered structure would increase the energy of the system, thus preventing the hydrophobic compounds from reaching the surface. A good measure for the hydrophilicity of a surface is the contact angle $\theta$ of a water droplet on the surface, as illustrated in Figure 2.5.

If $\theta<5^{\circ}$, the droplet spreads almost completely and the surface is considered superhydrophilic. Surfaces with $\theta<90^{\circ}$ are considered hydrophilic, and surface with $\theta>90^{\circ}$ are hydrophobic. As soon as $\theta>150^{\circ}$ however, the surface is considered superhydrophobic, as almost no contact is made between the droplet and the surface. The spreading of the droplet over a homogeneous, smooth and rigid surface is an equilibrium situation between the different surface tensions and can be written as Young's equation:

$$
\gamma_{s v}=\gamma_{s l}+\gamma_{l v} \cos \theta
$$

where $\gamma_{s v}$ is the solid-vapor surface tension, $\gamma_{s l}$ is the solid-liquid surface tension and $\gamma_{l v}$ is the liquid-vapor surface tension. Unfortunately, Young's equation is based on a homogeneous, rigid and (atomically) flat surface, with no chemical 


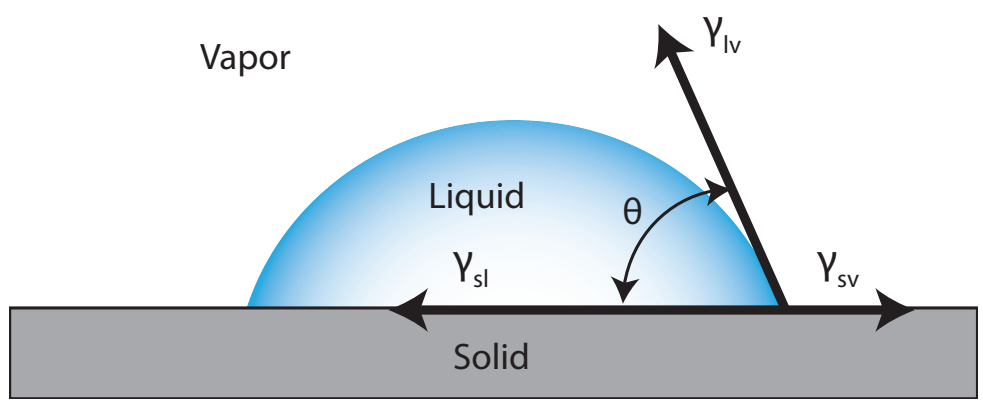

Figure 2.5: Schematic representation of a droplet on a flat surface. Shown are the contact angle $\theta$, and the surface tension of the interfaces $\gamma_{l v}, \gamma_{s l}$ and $\gamma_{s v}$.

interaction between the surface and the liquid. Since real surfaces do not show these properties, the droplet always shows hysteresis to some extent. This means the droplet is either contracting or expanding slightly, influencing the measurement of the contact angle[40]. Furthermore, modifications can be made to the Young equation for systems different from water in air [40, 41].

Agarwal et al. [42] performed a study on the properties a membrane surface should have to prevent adhesion of oil droplets. They coated a fibrous substrate with nanoparticles of different sizes and tested the adhesion of oil droplets in an emulsion. They observed that the coalescence of droplets mainly takes place at the solid surface and not in the bulk phase. According to their measurements, the ideal membrane surface (in terms of oil droplet adhesion) has minimal roughness and is superhydrophilic. Dresselhuis et al. [43] studied the interaction of oil droplets in food emulsions on surfaces, observing the adhesion and spreading of the droplets to a surface under a microscope (Figure 2.6). The emulsion was stabilized by (negatively charged) proteins. By varying the protein (surfactant) concentration and the ionic strength of the emulsion and the hydrophobicity of the surface, adhesion of oil droplets was compared under different circumstances. A higher ionic strength caused more adhesion and spreading of the droplets to the surface, due to charge screening. Furthermore, at low protein concentrations, more adhesion and spreading of the droplets is observed due to less steric and electrostatic hindrance. They concluded that the droplet-surface interaction is crucial in the adsorbing of oil droplets on a surface.

Essafi et al. [44] studied the coating of surfaces with oil droplets from an emulsion. Instead of preventing adhesion to the surface, they wanted to cover their surface in a uniform layer of oil. To prevent coalescence of the oil droplets in solution but to promote the adhesion of oil droplets to the surface, they created an asymmetric situation by adding polar surfactants to the emulsion, while keeping the surface uncharged. By doing so, an electrostatic repulsion between the 


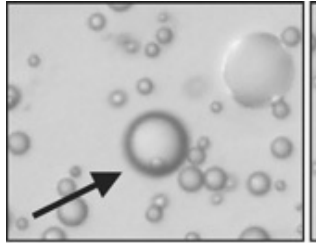

a)

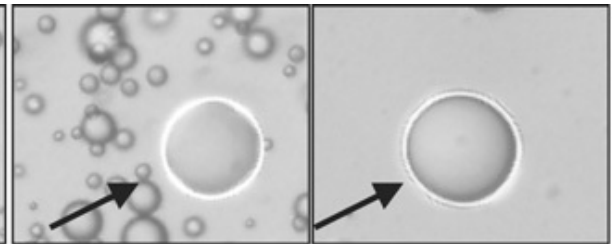

b1) b2)

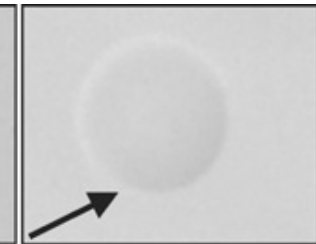

c)

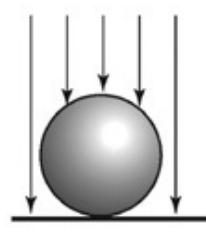

a)

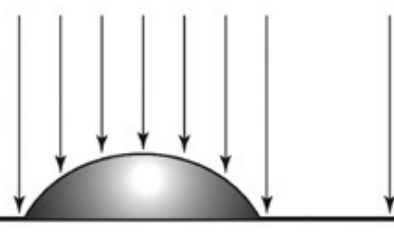

b1 \& b2)

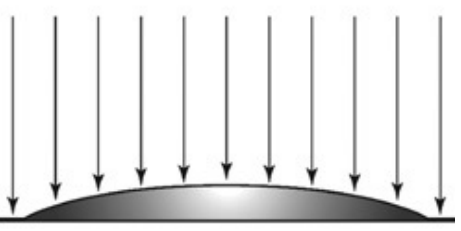

c)

Figure 2.6: Different microscopic appearances of emulsions droplets in contact with a hydrophobic solid surface and the schematic expected side view; a) adhered droplet, b1) spread droplet with relative large contact angle, b2) spread droplet with different contact angle, c) spread emulsions droplet with a relative small contact angle. Reproduced from [43] with permission from The Royal Society of Chemistry.

oil droplets prevented coalescence, whereas adhesion to the surface was not hindered. This kind of asymmetry is important to keep in mind when determining which surfactants to use.

The surface charge of a membrane is an important rejection mechanism. Most membranes are negatively charged, rejecting most organic foulants (like naphthenic acids in PW [45]) and microorganisms, which are also negatively charged. The effect of electrostatic repulsion by a membrane has been shown to be more important than steric hindrance of the pore size for low ionic strength emulsions [46]. The charge of the membrane is however influenced by the $\mathrm{pH}$ of the feed solution, because the charge of the surface is determined by the dissociation of acidic surface groups. The ionic strength of the feed solution also plays a key role, as ions can screen the surface charge.

The roughness of the membrane surface can also play a very important role in the fouling of the membrane. A higher surface roughness increases the surface area of the membrane surface, and thus also the area to which foulants can attach. Vrijenhoek et al. [47] showed that fouling takes place predominantly in the "valleys' of a rough membrane surface due to lower shear forces, causing more severe fouling than on smooth membrane surfaces in cross-flow filtration mode. These valleys are larger structures than pores, but do play a role in fouling. In their research, surface roughness was the main parameter for membrane fouling and was dominant over the other physical and chemical properties of the membrane. 
a

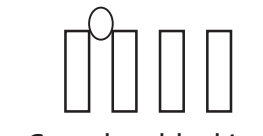

Complete blocking

C

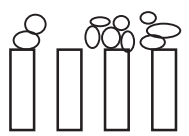

Intermediate blocking b

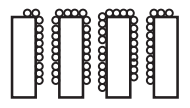

Standard blocking

d

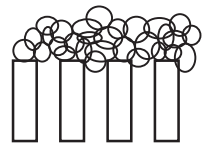

Cake filtration

e

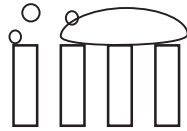

Oil layer blocking

Figure 2.7: Schematic representation of the different fouling mechanisms taking place on the membrane surface.

\subsubsection{Fouling mechanisms}

Fouling of a membrane is the deposition of substances on the membrane surface, like oil droplets or solid particles. This causes a flux decline of the membrane, which is an indirect way of measuring fouling on the membrane. Fouling mechanisms can be categorised in four different processes, shown in Figure 2.7a-d. Those processes can take place at the same time. In complete pore blocking, the pore is blocked by a large particle, no more water can pass through. In standard blocking, small particles coat the inside of the pores, narrowing the channels and thus lowering the flux. In intermediate blocking, a layer of particles or droplets is building up on the surface, narrowing the pore entrances. Cake filtration is the formation of a layer of particles on the surface of the membrane. This layer is not impermeable, but it narrows the pore size, only allowing small particles to pass. In intermediate blocking, particles only partially block the pore entry [48]. In Figure 2.7e we propose an additional fouling mechanism which might play a role in membrane fouling by PW. In this process, oil droplets are coalescing on the membrane surface, forming a continuous oil layer on the surface. This differs from traditional cake layer formation as the fouling layer no longer consists of separate particles. In addition, oil can form a liquid lining inside the pores, reducing the effective pore radius. This difference will affect permeation, but it 
will also affect the cleanability of the membrane.

\subsubsection{Recent developments in anti-fouling membranes}

Developing membranes for oil/water separation is a hot topic in membrane science, as large volumes of oil-contaminated water are produced every day in various industrial applications and the demand for clean water keeps growing. Novel anti-fouling, superhydrophilic and solvent resistant polymeric membranes are designed one after another, but, as stated by Zhu et al. [49], most research focusses on designing new membranes instead of developing knowledge and understanding of the mechanisms behind membrane fouling. In this section, some of those novel membranes will be summarized.

Hadidi and Zydney [39] conducted a comprehensive study on the fouling of zwitterionic membranes by proteins. They modified the surface of cellulose membranes with different functionalities (hydrophilic, hydrophobic, acidic and basic) to compare the fouling behaviour and gain a more fundamental understanding of the electrostatic and hydrophobic interactions between the foulants and the membrane surface. The zwitterionic surface modification proved to be the best, due to the highly ordered layer of water forming at the surface of the membrane. Pagidi et al. [50] compared polysulfone membranes modified by adding different hydrophilic additives in the polymer solution. In their research, out of polyvinyl- pyrrolidone (PVP), polyetherimide (PEI), polyethylene glycol (PEG) and polyethersulfone (PES), PVP proved to be the best additive for removing oil from emulsions while maintaining a high flux, due to its high hydrophilicity and the formation of a porous top layer. Zhao et al. [51] modified the surface of a polymeric membrane with both zwitterionic and low energy brushes, creating a surface with superior anti-fouling and self cleaning properties due to the dense hydration layer formed on the membrane surface. The membrane was operated in dead-end filtration mode with an oil-water emulsion. They reported no irreversible flux decline. Zhu et al. [52] also created a superhydrophilic and superoleophobic membrane by adding a polymer with hydrophilic and oleophobic segments to a PVDF membrane. In their research, they showed that a membrane with both these properties performs better than just a hydrophilic membrane. Liu et al. [53] coated glass fiber mats with a zwitterionic polymer, creating a superhydrophilic and superoleophobic membrane. According to the authors, the improved mechanical stability of the glass filter in combination with the polymeric coating makes this system compatible for harsh operating conditions. Mittal et al. [54] made a low-cost composite membrane consisting of a clay support structure with a hydrophilic membrane on top. In contrast to commercially available membranes, this composite membrane was cheap and showed good rejection for lower oil concentrations.

In all the research papers mentioned here, the membranes are tested in laboratory 
conditions over small time spans, in which the adsorption of oil on the surface is kinetically suppressed. The short-term effectiveness however is not always a measure for long-term efficiency of a membrane. When hydrophilic additives are added to the membrane polymer, it is possible that these additives are released from the hydrophobic membrane material over time, compromising its functionality [49]. Furthermore, in every research membranes are tested in very specific circumstances, making a comparison between different papers very difficult. No thorough testing was performed with a range of ionic strength and surfactant concentrations, and thus the anti-fouling properties cannot be examined appropriately.

\subsection{Oily wastewater treatment with membranes}

PW is an oil-in-water emulsion with a large number of different components. Understanding the behavior of simple emulsions at the membrane surface gives us a starting point to understand and control fouling in the more complex PW.

\subsubsection{Oil/water separation with membranes}

Making direct observations on the behavior of oil droplets during membrane filtration is difficult. Membranes are usually not transparent, making observation through a light microscope impossible. Therefore, experiments concerning membrane fouling usually depend on measuring parameters as permeate flux decline, permeate quality and the transmembrane pressure. Though less insightful, these experiments can give a good indication of the effectiveness of certain membranes. Chakrabarty et al. $[55,56]$ compared dead-end and cross-flow ultrafiltration of oily wastewater with polymeric membranes. They found that in dead-end mode, the flux through the membrane is increased with increasing transmembrane pressure. At higher oil concentrations however, the flux decreased due to the formation of an oil layer on the surface. In cross-flow mode, this fouling layer is removed from the membrane surface due to the flow direction. Unfortunately, at higher cross-flow velocities oil droplets got fragmented on the membrane due to the high shear forces and were able to pass through with the permeate. For a high transmembrane pressure, the applied pressure overcame the capillary pressure (that usually prevents droplets from passing through the membrane), forcing oil droplets through the pores of the membrane. Hesampour et al. [57] performed an experiment to investigate the effect of the operating conditions on the permeate flux of a cellulose ultrafiltration membrane. They used an emulsion from cutting oil (a mixture of mineral oil, emulsifier, biocide and corrosion inhibitor). The experiments were set up as a Taguchi experimental design, varying multiple parameters at the same time. The data obtained were analyzed through ANOVA (analysis of variance). They showed, that, in line with expectations, at low ionic 
strength, the $\mathrm{pH}$ is the most important factor. At higher salt concentrations, the temperature is the most important factor. Although this is a good method to investigate the influence of a great number of parameters at the same time, it gives no insight into the underlying processes of the flux decline. Lobo et al. [58] investigated the influence of the $\mathrm{pH}$ of the emulsion and the cross-flow velocity on the ultrafiltration with ceramic membranes. They used a model emulsion of vegetable oil and a combination of anionic and non-ionic surfactants. At low cross-flow velocity they observed concentration polarization at the membrane surface. Although the $\mathrm{pH}$ did not influence the zeta potential and droplet size distribution of the emulsion, the surface properties of the membrane changed. At low $\mathrm{pH}$, the membrane became positively charged, adsorbing the anionic surfactant from the emulsion. This made the membrane surface more hydrophobic, allowing surfactant momomers to pass through the membrane and also resulted in a flux decline. Li et al. [59] actually observed the particle deposition on the membrane during cross-flow microfiltration. They used an aluminium membrane with straight-through pores, making it transparent when wet. When filtering a suspension of either yeast particles or latex beads, they observed a critical flux at which particles begin to deposit. Adhered particles were not stagnant, but 'rolled' over the surface. Adhered particles, however, did induce the deposition of more particles on the surface by stopping them.

Apart from practical experiments, theoretical and numerical models have also been made to better understand the fouling of membranes during filtration. Mohammadi et al. [60] mathematically modelled the flux decline in ultrafiltration by the formation of a cake layer on the membrane. According to their theory, the initial flux decline observed in membrane fouling is due to pore blocking, but after that the formation of a cake layer on the membrane surface becomes the dominant process. They compared this model with the results of a series of cross-flow ultrafiltration experiments, finding an excellent agreement at lower oil concentrations and transmembrane pressures. This model, however, gives merely predictions on the fouling that can be expected from a given experiment. Ullah et al. [61] developed a 'slotted pore membrane' model to predict the droplet size distribution in the permeate. According to their model, the drag force is responsible for the passage of oil into the permeate. A low interfacial tension of the oil droplets makes them more deformable, and therefore more likely to pass through the membrane pores. This model, like the previous one, is mostly good for predicting the droplet size distribution in the permeate, but does not help us in understanding the underlying processes of membrane fouling in oil/water separation. 


\subsubsection{Oil/Water separation in industrial wastewater}

Membrane filtration is a promising technique for the treatment of oily wastewaters from industry. These are different from the synthetic emulsions usually used in the experiments of the previous section, because they usually consist of a far more complex mixture of compounds. In this section, a few studies on the treatment of oily wastewaters are summarized.

Zhu et al. [49] tested four PVDF membranes with different modifications for three different emulsions: a model emulsion of hexadecane in water, an emulsion made from crude oil and wastewater from a palm oil factory. The membranes were tested for two hours, monitoring the flux decline. The experiment was performed in dead-end filtration mode, to simulate the 'worst case scenario' when it comes to fouling. For all membranes, the crude oil emulsion proved to be the most challenging, showing the largest flux decline. For all emulsions the flux could be almost completely restored after a short backwash. Mohammadi et al. [62] used a polysulfone ultrafiltration membrane for the treatment of vegetable oil factory wastewater. This wastewater is a mixture of organic compounds (fats, oils, fatty acids, glycerine, soaps, gums and detergents) and mineral components (sodium polyphosphate/silicate/sulphonate, calcium, magnesium and sodium carbonates/chlorides) and has a high $\mathrm{pH}$. The membrane was operated in cross-flow mode in runs of 70 minutes. Their results showed that the effectiveness of the membrane was largely independent of the feed properties, making this a promising technique for the treatment of complex wastewaters. In addition, they studied the effect of adding powdered activated carbon (PAC) to the feed solution. The PAC adsorbs organic compounds, and are subsequently retained by the membrane. Adding PAC improved the permeate quality and fouling resistance of the membrane process. Sarfaraz et al. [63] also investigated a combination of a nanoporous polyacrylonitrile membrane and adding PAC to the feed flow. They built a pilot plant to treat the desalter plant wastewater of the Tehran Oil Refinement Company. The wastewater contained oils, greases, detergents and salts in different concentrations. The mixing of PAC in the feed flow increased the oil droplet size and produced a better quality permeate. Fouling with PAC was less compared to using just a membrane. Ochoa et al. [64] studied the effect of hydrophilicity on the fouling of PVDF/PMMA membranes. The effluent of an engine factory was used to perform the tests. They showed that a hydrophilic membrane shows less cake fouling, leading to a higher flux. The sieving effect of a membrane is thus not only dependent on pore size, but also on the hydrophilic porperties of the membrane. The permeate from their tests was clean enough to meet the disposal restrictions. 


\subsection{Produced water treatment using membranes}

The treatment of PW with membranes aims at removing the smallest $(<10 \mu \mathrm{m})$ and most stable oil droplets. As Igunnu and Chen mention [4], membrane technology is a promising technique, where ultrafiltration is most effective in comparison with traditional treatment technologies. Until now, most applications in the field are ceramic membranes because of their superior resistance to high temperatures, harsh chemicals and aggressive cleaning methods. The same conclusion is drawn by Fakru'l-Razi et al. [5]. He states that ceramic membranes are favored over polymeric membranes because of their superior stability. Despite the preference of the field for ceramic membranes, various papers show possibilities for polymeric and ceramic/polymeric hybrid membranes. Alzahrani and Mohammad [6] published a comprehensive review of articles in PW treatment in membranes, mentioning all three kinds of membranes. In this section, we will discuss some results of membrane filtration experiments with PW, from both the lab and the actual field.

\subsubsection{Produced water treatment using membranes: lab scale}

Li et al. [65] compared a tubular PVDF UF membrane with alumina nanoparticles, which improved the hydrophilicity, to the same membrane without nanoparticles. The modified membrane showed a flux twice as high as the unmodified membrane, with an oil rejection of $98 \%$. The flux could be recovered for $90 \%$ by backwashing with pure water, and a $100 \%$ flux recovery was obtained by backwashing with a surfactant solution of $\mathrm{pH} 10$. Chakrabarty et al. [55, 56] published two articles in which they compare four polysulfone membranes, modified with PVP and PEG, in dead-end mode and in cross-flow filtration. The membranes were first tested using synthetic PW, using crude oil with no additives. All four membranes showed high rejection and met the discharge standards in both dead-end and cross-flow filtration. When the two best membranes were tested in cross-flow mode with real PW however, the performance of the membranes deteriorated. The flux decline was much higher for the PW experiments ( $43.1 \%$ vs. $12.5 \%$ with synthetic water for the best performing membrane) and the rejection was far lower $(77.5 \%$ for PW vs. $94.4 \%$ for synthetic water), not meeting the discharge standards for PW. The authors attribute this difference to the differences in the feed, which are mainly the droplet size distribution and the $\mathrm{pH}$ values. Abadi et al. [66] tested a ceramic UF membrane with PW from an American Petroleum Institute (API) unit. The oil content removal was $95 \%$. Backwashing of the membranes restored $95 \%$ of the flux, and chemical cleaning was applied as soon as the flux dropped to $40-50 \%$ of the original value. This system showed better performance than the conventional biological method used 
in the plant. Madaeni et al. [67] used PW from the same API oilfield to test two polysulfone membranes (UF and MF). Both membranes showed a rejection of about $95 \%$, but the UF membrane has a slightly better performance in terms of flux and oil rejection. Again, tests with artificial PW showed a smaller flux decline than experiments with real PW, indicating the complexity of this waste stream. A good pretreatment of the PW before membrane treatment is key in successful application of membranes. Ozgun et al. [68] tested four different pretreatments for a NF-RO system with polyamide membranes, of which three were $\mathrm{MF} / \mathrm{UF}$ membranes and one was a membrane bioreactor (MBR). The MBR system gave the best performance, with $83 \%$ oil removal.

As can be concluded from these articles, various factors play a role in the successful application of membranes for PW treatment. The laboratory-scale experiments cited here show that feed flow composition, pretreatment of the PW before the membranes and operation conditions of the membranes all influence the performance of the system. This shows that for every situation, a different approach might be required.

\subsubsection{Produced water treatment using membranes: pilot scale}

In literature, multiple examples can be found of both ceramic and polymeric membranes used in pilot-scale plants. Bilstad and Espedal [69] did experiments with polymeric MF and UF tubular membranes with a pilot plant on the Snorre oil field in the North Sea. The UF membrane showed the best performance, at $96 \%$ oil removal. No irreversible fouling was observed after cleaning. Visvanathan et al. [70] placed a pilot plant on a natural gas production site in Thailand. They tested various pretreatment steps (two different UF membranes and a NF membrane) for an RO membrane. The NF membrane proved to be the only suitable pretreatment, because no irreversible fouling of the RO membrane was observed. Lee and Frankiewicz [71] ran a pilot plant in West Texas, USA, for 4 months. The membrane they used was a spiral-wound UF hydrophilic UF membrane. After a pretreatment of de-sanding and de-oiling of the PW by hydrocyclones, the membrane was able to remove $54 \%$ of the oil content, to a concentration of $<2$ $\mathrm{mg} / \mathrm{l}$. The cleaning frequency of the membrane was strongly dependent on the oil concentration in the feed flow. The fouling layer on the membrane consisted of an oil layer formed during filtration, and ultra-fine oil-covered solid particles. Webb et al. [26] evaluated the performance of a Veolia OPUS ${ }^{\circledR}$ RO system on the San Ardo Oilfield in Colorado. This system was used for desalination of the PW from the oilfield. The effluent of the pilot plant met the discharge requirements and the system ran for a year without problems. The membranes showed fouling, but the performance was not heavily affected. Downside of this system is the very high consumption of chemicals used in the process. Yong and $\mathrm{Wu}$ [72] tested a polymeric UF membrane as the final step in a PW re-injecting pro- 
cess. To prevent fouling of pipelines and reservoir contamination, PW has to be cleaned before it an be re-injected. This pilot plant met the standards of $<1 \mathrm{mg} / 1$ oil content.

As can be seen from these articles both polymeric and ceramic membranes are successfully tested in pilot plants all over the world. In full-scale operation processes however, there is still a preference for ceramic membranes due to their higher fluxes and superior stability against harsh cleaning.

\subsection{Conclusion}

In this review we have given a summary of factors that can influence membrane fouling in PW treatment. Instead of just studying process parameters, we highlighted the properties of the emulsion itself from a colloidal view. As can be seen in literature, PW is far more complex than an oil-in-water emulsion from either the laboratory or other industries, and has proven to be the most fouling feed in numerous experiments. This is due to the large number of different components that can be found in PW, but also in the variation in composition between wells and age of an oil reservoir. Understanding what makes PW so different from other emulsions is a first step towards understanding membrane fouling and developing tailored membrane processes in the future. Therefore, more research should be done on the role of the different components of PW, membrane properties and process parameters in membrane fouling, in which the fields of colloid and surface science can give us new insights. Only by systematically studying this process we can come to better understanding of membrane fouling by produced water. Parameters such as ionic strength, surfactant properties, the presence of solid particles and membrane properties should be varied in a systematic way to understand the influence of each component and the interaction between them. In addition, visually inspecting the behavior of oil droplets on a model surface could provide insight in the adhesion of oil droplets on the membrane surface and thus fouling. With better understanding, in the future it might be possible to tailor the membrane process to the properties of the specific influent, omitting the need for pilot plants. 


\section{Bibliography}

[1] J. A. Veil, Produced water (Springer New York, New York, NY, 2011), pp. 537-571. - p.28.

[2] H. Duhon, Produced Water Treatment: Yesterday, Today, and Tomorrow A Holistic Approach, Oil and Gas facilities 29 (2012). — p.28.

[3] OSPAR, Establishment of a list of Predicted No Effect Concentrations (PNECs) for naturally occurring substances in produced water (2014). p.28.

[4] E. T. Igunnu and G. Z. Chen, Produced water treatment technologies, International Journal of Low-Carbon Technologies 9, 157 (2012). — p.28, 46.

[5] A. Fakhru'l-Razi, A. Pendashteh, L. C. Abdullah, D. R. A. Biak, S. S. Madaeni, and Z. Z. Abidin, Review of technologies for oil and gas produced water treatment., Journal of hazardous materials 170, 530 (2009). — p.28, 46.

[6] S. Alzahrani and A. W. Mohammad, Challenges and trends in membrane technology implementation for produced water treatment: A review, Journal of Water Process Engineering 4, 107 (2014). — p.28, 46.

[7] K. S. Ashaghi, M. Ebrahimi, and P. Czermak, Ceramic Ultra- and Nanofiltration Membranes for Oilfield Produced Water Treatment: A Mini Review, The Open Environmental Journal 1, 1 (2007). — p.28.

[8] J. J. Sheng, Modern Chemical Enhanced Oil Recovery: Theory and Practice (Gulf Professional Publishing, Burlington, 2011), p. 648. - p.29, 32.

[9] I. T. Gabardo, E. B. Platte, A. S. Araujo, and F. H. Pulgatti, Produced water (Springer New York, New York, NY, 2011), pp. 89-113. — p.29.

[10] P. Kundu, A. Agrawal, H. Mateen, and I. M. Mishra, Stability of oil-inwater macro-emulsion with anionic surfactant: Effect of electrolytes and temperature, Chemical Engineering Science 102, 176 (2013). — p.29, 34, 36.

[11] A. J. Worthen, L. M. Foster, J. Dong, J. A. Bollinger, A. H. Peterman, L. E. Pastora, S. L. Bryant, T. M. Truskett, C. W. Bielawski, and K. P. Johnston, Synergistic formation and stabilization of oil-in-water emulsions by a weakly interacting mixture of zwitterionic surfactant and silica nanoparticles., Langmuir : the ACS journal of surfaces and colloids 30, 984 (2014). - p.29, 34 . 
[12] V. J. Verruto, R. K. Le, and P. K. Kilpatrick, Adsorption and molecular rearrangement of amphoteric species at oil-water interfaces., The journal of physical chemistry. B 113, 13788 (2009). - p.29.

[13] S. Kiani and S. M. Mousavi, Ultrasound assisted preparation of water in oil emulsions and their application in arsenic $(V)$ removal from water in an emulsion liquid membrane process., Ultrasonics sonochemistry 20, 373 (2013). - p.29.

[14] C. Fang, N. Tong, and J. Lin, in Spe international symposium on oilfield chemistry (Society of Petroleum Engineers, 1991). — p.29.

[15] H. Yotsumoto and R.-H. Yoon, Application of Extended DLVO Theory II. Stability of Silica Suspensions, Journal of Colloid and Interface Science 157, 434 (1993). - p.32.

[16] H. Yotsumoto and R.-H. Yoon, Application of Extended DLVO Theory I. Stability of Rutile Suspensions, Journal of Colloid and Interface Science 157, 426 (1993). - p.32.

[17] B. P. Binks and S. O. Lumsdon, Stability of oil-in-water emulsions stabilised by silica particles, Physical Chemistry Chemical Physics 1, 3007 (1999). p.32.

[18] R. P. W. M. Jacobs, R. O. H. Grant, J. Kwant, J. M. Marquenie, and E. Mentzer, in Produced water: Technological/environmental issues and solutions, edited by J. Ray and F. Engelhardt (Plenum Publishing Corp., New York, 1992), pp. 13-21. - p.33.

[19] P. Ghosh and M. Banik, Effects of Salts Containing Mono-, Di-, and Trivalent Ions on Electrical and Rheological Properties of Oil-Water Interface in Presence of Cationic Surfactant: Importance in the Stability of Oil-in-Water Emulsions, Journal of Dispersion Science and Technology 35, 471 (2014). p.34.

[20] P. Taylor and R. Ottewill, The formation and ageing rates of oil-in-water miniemulsions, Colloids and Surfaces A: Physicochemical and Engineering Aspects 88, 303 (1994). - p.34.

[21] Z. Mei, J. Xu, and D. Sun, O/W nano-emulsions with tunable PIT induced by inorganic salts, Colloids and Surfaces A: Physicochemical and Engineering Aspects 375, 102 (2011). — p.34.

[22] B. P. Binks, J. A. Rodrigues, and W. J. Frith, Synergistic interaction in emulsions stabilized by a mixture of silica nanoparticles and cationic surfactant., Langmuir : the ACS journal of surfaces and colloids 23, 3626 (2007). - p.34.

[23] E. Vignati, R. Piazza, and T. P. Lockhart, Pickering Emulsions: Interfacial Tension, Colloidal Layer Morphology, and Trapped-Particle Motion, Langmuir 19, 6650 (2003). - p.34, 35.

[24] J. Legrand, M. Chamerois, F. Placin, J. E. Poirier, J. Bibette, and F. LealCalderon, Solid colloidal particles inducing coalescence in bitumen-in-water 
emulsions., Langmuir : the ACS journal of surfaces and colloids 21, 64 (2005). - p.34.

[25] K. Demetriades, J. Coupland, and D. J. McClements, Physical Properties of Whey Protein Stabilized Emulsions as Related to $\mathrm{pH}$ and $\mathrm{NaCl}$, Journal of Food Science 62, 342 (1997). - p.35, 36.

[26] C. Webb, C. North, A. Exploration, L. Nagghappan, and V. N. a. Water, Desalination of Oilfield-Produced Water at the San Ardo Water Reclamation Facility , CA, SPE 1215201 (2009). — p.35, 47.

[27] J. Bibette, F. L. Calderon, and P. Poulin, Emulsions: basic principles, Reports on Progress in Physics 62, 969 (1999). - p.36.

[28] F. Leal-Calderon and P. Poulin, Progress in understanding emulsion metastability and surface forces, Current Opinion in Colloid \& Interface Science 4, 223 (1999). - p.36.

[29] M. Cheryan and N. Rajagopalan, Membrane processing of oily streams. Wastewater treatment and waste reduction, Journal of Membrane Science 151, 13 (1998). - p.36.

[30] S. Judd, The MBR book: principles and applications of membrane bioreactors for water and wastewater treatment (Elsevier, 2010). — p.37.

[31] A. Deriszadeh, M. M. Husein, and T. G. Harding, Produced water treatment by micellar-enhanced ultrafiltration., Environmental science \& technology 44, 1767 (2010). - p.37.

[32] A. Alpatova, E.-S. Kim, S. Dong, N. Sun, P. Chelme-Ayala, and M. Gamal El-Din, Treatment of oil sands process-affected water with ceramic ultrafiltration membrane: Effects of operating conditions on membrane performance, Separation and Purification Technology 122, 170 (2014). — p.37.

[33] S. Emani, R. Uppaluri, and M. K. Purkait, Microfiltration of oilwater emulsions using low cost ceramic membranes prepared with the uniaxial dry compaction method, Ceramics International 40, 1155 (2014). — p.37.

[34] I. Barukčić, R. Božanić, and U. Kulozik, Effect of pore size and process temperature on flux, microbial reduction and fouling mechanisms during sweet whey cross-flow microfiltration by ceramic membranes, International Dairy Journal 39, 8 (2014). - p.37.

[35] A. Murić, I. Petrinić, and M. L. Christensen, Comparison of ceramic and polymeric ultrafiltration membranes for treating wastewater from metalworking industry, Chemical Engineering Journal 255, 403 (2014). — p.37.

[36] S. Zeidler, P. Puhlfürß, U. Kätzel, and I. Voigt, Preparation and characterization of new low MWCO ceramic nanofiltration membranes for organic solvents, Journal of Membrane Science 470, 421 (2014). — p.37.

[37] B. S. Lalia, V. Kochkodan, R. Hashaikeh, and N. Hilal, A review on membrane fabrication: Structure, properties and performance relationship, Desalination 326, 77 (2013). - p.38.

[38] K. C. Khulbe, C. Feng, and T. Matsuura, The art of surface modification 
of synthetic polymeric membranes, Journal of Applied Polymer Science 115, 855 (2010). - p.38.

[39] M. Hadidi and A. L. Zydney, Fouling behavior of zwitterionic membranes: Impact of electrostatic and hydrophobic interactions, Journal of Membrane Science 452, 97 (2014). — p.38, 42.

[40] R. J. Good, Contact angle, wetting, and adhesion: a critical review, Journal of Adhesion Science and Technology 6, 1269 (1992). — p.39.

[41] Y. Ko, B. Ratner, and A. Hoffman, Characterization of hydrophilichydrophobic polymeric surfaces by contact angle measurements, Journal of Colloid and Interface Science 82, 25 (1981). - p.39.

[42] S. Agarwal, V. von Arnim, T. Stegmaier, H. Planck, and A. Agarwal, Role of surface wettability and roughness in emulsion separation, Separation and Purification Technology 107, 19 (2013). - p.39.

[43] D. M. Dresselhuis, G. A. van Aken, E. H. A. de Hoog, and M. A. Cohen Stuart, Direct observation of adhesion and spreading of emulsion droplets at solid surfaces, Soft Matter 4, 1079 (2008). — p.39, 40.

[44] W. Essafi, K. Wong, J. Bibette, and P. Poulin, Oil coating of hydrophobic surfaces from aqueous media: Formation and kinetic study, Journal of Colloid and Interface Science 286, 730 (2005). - p.39.

[45] D. M. Jones, J. S. Watson, W. Meredith, M. Chen, and B. Bennett, Determination of Naphthenic Acids in Crude Oils Using Nonaqueous Ion Exchange Solid-Phase Extraction, Analytical Chemistry 73, 703 (2001). — p.40.

[46] A. I. Schäfer, R. Mauch, T. D. Waite, and A. G. Fane, Charge Effects in the Fractionation of Natural Organics Using Ultrafiltration, Environmental Science \& Technology 36, 2572 (2002). - p.40.

[47] E. M. Vrijenhoek, S. Hong, and M. Elimelech, Influence of membrane surface properties on initial rate of colloidal fouling of reverse osmosis and nanofiltration membranes, Journal of Membrane Science 188, 115 (2001). - p.40.

[48] M. Abbasi and A. Taheri, Modeling of permeation flux decline during oily wastewaters treatment by MF PAC hybrid process using mullite ceramic membranes, Indian Journal of Chemical Technology 21, 49 (2014). — p.41.

[49] Y. Zhu, D. Wang, L. Jiang, and J. Jin, Recent progress in developing advanced membranes for emulsified oil/water separation, NPG Asia Materials 6, 1 (2014). - p.42, 43, 45.

[50] A. Pagidi, R. Saranya, G. Arthanareeswaran, A. Ismail, and T. Matsuura, Enhanced oilwater separation using polysulfone membranes modified with polymeric additives, Desalination 344, 280 (2014). — p.42.

[51] X. Zhao, W. Chen, Y. Su, W. Zhu, J. Peng, Z. Jiang, L. Kong, Y. Li, and J. Liu, Hierarchically engineered membrane surfaces with superior antifouling and self-cleaning properties, Journal of Membrane Science 441, 93 (2013). - p.42. 
[52] X. Zhu, H.-E. Loo, and R. Bai, A novel membrane showing both hydrophilic and oleophobic surface properties and its non-fouling performances for potential water treatment applications, Journal of Membrane Science 436, 47 (2013). - p.42.

[53] Q. Liu, A. A. Patel, and L. Liu, Superhydrophilic and underwater superoleophobic poly(sulfobetaine methacrylate)-grafted glass fiber filters for oil-water separation., ACS applied materials \& interfaces 6, 8996 (2014). — p.42.

[54] P. Mittal, S. Jana, and K. Mohanty, Synthesis of low-cost hydrophilic ceramicpolymeric composite membrane for treatment of oily wastewater, Desalination 282, 54 (2011). - p.42.

[55] B. Chakrabarty, A. K. Ghoshal, and M. K. Purkait, Ultrafiltration of stable oil-in-water emulsion by polysulfone membrane, Journal of Membrane Science 325, 427 (2008). - p.43, 46.

[56] B. Chakrabarty, A. Ghoshal, and M. Purkait, Cross-flow ultrafiltration of stable oil-in-water emulsion using polysulfone membranes, Chemical Engineering Journal 165, 447 (2010). - p.43, 46.

[57] M. Hesampour, A. Krzyzaniak, and M. Nyström, The influence of different factors on the stability and ultrafiltration of emulsified oil in water, Journal of Membrane Science 325, 199 (2008). - p.43.

[58] A. Lobo, A. Cambiella, J. M. Benito, C. Pazos, and J. Coca, Ultrafiltration of oil-in-water emulsions with ceramic membranes: Influence of $p H$ and crossflow velocity, Journal of Membrane Science 278, 328 (2006). — p.44.

[59] H. Li, A. Fane, H. Coster, and S. Vigneswaran, Direct observation of particle deposition on the membrane surface during crossflow microfiltration, Journal of Membrane Science 149, 83 (1998). - p.44.

[60] T. Mohammadi, A. Kohpeyma, and M. Sadrzadeh, Mathematical modeling of flux decline in ultrafiltration, Desalination 184, 367 (2005). — p.44.

[61] A. Ullah, R. Holdich, M. Naeem, S. Khan, and V. Starov, Prediction of size distribution of crude oil drops in the permeate using a slotted pore membrane, Chemical Engineering Research and Design 92, 2775 (2014). — p.44.

[62] T. Mohammadi and A. Esmaeelifar, Wastewater treatment of a vegetable oil factory by a hybrid ultrafiltration-activated carbon process, Journal of Membrane Science 254, 129 (2005). - p.45.

[63] M. V. Sarfaraz, E. Ahmadpour, A. Salahi, F. Rekabdar, and B. Mirza, Experimental investigation and modeling hybrid nano-porous membrane process for industrial oily wastewater treatment, Chemical Engineering Research and Design 90, 1642 (2012). - p.45.

[64] N. A. Ochoa, M. Masuelli, and J. Marchese, Effect of hydrophilicity on fouling of an emulsified oil wastewater with PVDF/PMMA membranes, Journal of Membrane Science 226, 203 (2003). - p.45.

[65] Y. S. Li, L. Yan, C. B. Xiang, and L. J. Hong, Treatment of oily wastewater by organicinorganic composite tubular ultrafiltration (UF) membranes, 
Desalination 196, 76 (2006). - p.46.

[66] S. R. H. Abadi, M. R. Sebzari, M. Hemati, F. Rekabdar, and T. Mohammadi, Ceramic membrane performance in microfiltration of oily wastewater, Desalination 265, 222 (2011). - p.46.

[67] S. S. Madaeni, A. Gheshlaghi, and F. Rekabdar, Membrane treatment of oily wastewater from refinery processes, Asia-Pacific Journal of Chemical Engineering 8, 45 (2013). - p.47.

[68] H. Ozgun, M. E. Ersahin, S. Erdem, B. Atay, B. Kose, R. Kaya, M. Altinbas, S. Sayili, P. Hoshan, D. Atay, E. Eren, C. Kinaci, and I. Koyuncu, Effects of the pre-treatment alternatives on the treatment of oil-gas field produced water by nanofiltration and reverse osmosis membranes, Journal of Chemical Technology and Biotechnology 88, 1576 (2013). — p.47.

[69] T. Bilstad, Espedal, and E, Membrane separation of produced water, Water Science and Technology 34, 239 (1996). - p.47.

[70] C. Visvanathan, P. Svenstrup, and P. Ariyamethee, Volume reduction of produced water generated from natural gas productionprocess using membrane technology, Water Science and Technology 41, 117 (2000). — p.47.

[71] J. M. Lee and T. Frankiewicz, SPE 95735 Treatment of Produced Water With an Ultrafiltration ( UF ) Membrane A Field Trial, SPE 957351 (2005). - p.47.

[72] C. Yong and O. Wu, Re-injecting Produced Water into Tight Oil Reservoirs, SPE 1628631 (2012). - p.47. 


\section{CHAPTER 3}

\section{Adhesion of emulsified oil droplets to hydrophilic and hydrophobic surfaces - effect of surfactant charge, surfactant concentration and ionic strength}

Adhesion of emulsified oil droplets to a surface plays an important role in processes such as crossflow membrane filtration, where the oil causes fouling. We present a novel technique, in which we study oil droplets on a model surface in a flow cell under shear force to determine the adhesive force between droplets and surface. We prepared an emulsion of hexadecane and used hydrophilic and hydrophobic glass slides as model surfaces. Different surfactants were used as emulsifiers: negatively charged sodium dodecyl sulphate (SDS), positively charged hexadecyltrimethylammonium bromide (CTAB) and nonionic Triton ${ }^{T M} \mathrm{X}-100$. We evaluate the role of the surfactant, the glass surface properties and the ionic strength of the emulsion. We found a minimum in the adhesion force between droplets and surface as a function of surfactant concentration. The charged surfactants cause a lower droplet adhesion compared to the nonionic surfactant. The flow cell technique presented here proved to be very useful in understanding the interaction between oil droplets and a surface.

This chapter has been published as: Adhesion of emulsified oil droplets to hydrophilic and hydrophobic surfaces - effect of surfactant charge, surfactant concentration and ionic strength, J.M. Dickhout, J.M. Kleijn, R.G.H. Lammertink, W.M. de Vos, Soft Matter (2018) 


\subsection{Introduction}

Oil-in-water emulsions make up many day-to-day products, and are essential for a multitude of industrial processes. However, these emulsions also form some of the largest waste streams from industry. Vegetable oil mills [1], metal working facilities [2], fish processing facilities, the leather industry, the dairy industry and the petrochemical industry [3] produce large volumes of oil contaminated water that have to be treated before they can be disposed of. This oily waste water comes into contact with surfaces all through this process, causing problems such as clogging [4], and fouling in the case of membrane treatment [5].

The static adhesion of oil droplets, stabilized by a surfactant in water, to a surface has been studied extensively. These fundamental studies mainly concern single droplets with a focus on wetting properties, in order to accurately describe the forces that play a role in droplet adhesion. Early computational models have described the motion of a solid sphere near a wall with an applied flow [6, 7]. Recently Ramon et al. developed a model describing the motion and deposition of a rigid particle near a permeable surface, such as a membrane [8]. The model describes the hydrodynamic force on the particle and calculates a possible equilibrium position of the particle in terms of the electrostatic and lubrication forces on the particle. These models can describe the behavior of a particle very close to a surface, but are not able to describe the behavior of a particle or droplet touching the surface. Experimental studies can macroscopically describe the interaction between oil droplets and a surface. Chae Yung et al. measured the contact angle of oil droplets on a superoleophobic surface in both an air and water environment [9]. Based upon their measurements of this contact angle for various oleophobic surfaces with different interfacial tensions they proposed a model for the spreading of oil on a surface. Dresselhuis et al. [10] studied the spreading of oil droplets stabilized by protein on glass surfaces using microscopy. From the appearance of the droplets at the surface, they could discern between adhered droplets and spread droplets. They found that electrostatic, steric and hydrophobic interactions are the main factors for droplet adhesion and subsequent spreading. Fux and Ramon studied droplet deformation in the presence of permeation through a membrane [11]. They discovered that smaller droplets have a lower deformation propensity compared to bigger oil droplets. When applying crossflow cleaning to remove the oil from the surface, the smaller, spherical droplets could be removed whereas the biger, deformed droplets remained attached to the surface.

In contrast to studies that focused on a small number of droplets, work also has been done on emulsions containing large numbers of droplets. The adhesion behavior of emulsified oil droplets is of particular interest in membrane science, where fouling is a major problem [12]. Essafi et al. studied the coating of a surface with a monolayer of oil droplets by adding salt to a surfactant stabilized 
emulsion [13]. By using a flow cell they measured the surface interactions between glass and oil, showing a good agreement between experimental observations and the Langmuir adsorption model, where the adsorption of oil droplets to the surface is treated as a first-order reaction. Malmsten et al. studied the formation of a monolayer of droplets on a surface from an emulsion with ellipsometry [14]. In their system, all layers that were formed consisted of droplets with very limited droplet spreading. By considering electrostatic and van der Waals interactions, they could explain the results obtained when varying ionic strength and surfactant type. De Vos et al. studied the adhesion of polystyrene particles on a surface covered with polymer brushes under shear force [15]. They used a flow cell, and by applying a shear force they determined the amount of force needed to remove $50 \%$ of the adhered particles from the surface. They measured different adhesion strengths for surfaces with different coatings, proving the effectiveness of this setup for studying particle-surface interactions.

In this paper, we aim to combine the fundamentals of surface-droplet interactions with an understanding of what these interactions mean for a large number of droplets as found in emulsions. By studying single droplets and droplets as a population under exactly the same conditions, we can draw a more detailed picture of what happens between droplet and surface. We perform flow cell measurements, in which we let oil droplets adhere to a surface, followed by application of a shear force. Detachment occurs when the shear force becomes larger than the adhesive force. We combine these flow cell measurements with analytical techniques such as reflectometry, contact angle measurements and interfacial tension measurements. By varying the surfactant concentration, surfactant charge and the salt concentration of the emulsion, as well as the hydrophilicity of the surface, we determine the influence of each factor on the adhesion force between the oil droplets and the surface.

\subsection{Materials and methods}

\subsubsection{Materials}

For preparation of the emulsions and flush solutions, we used DI water, sodium dodecyl sulfate (SDS, Sigma Aldrich 75746), hexadecyltrimethylammonium bromide (CTAB, Sigma Aldrich H6269), Triton ${ }^{\text {TM }}$ X-100 (TX, Sigma Aldrich 9284), n-hexadecane (Merck Schuchardt OHG 820633) as the oil and sodium chloride ( $\mathrm{NaCl}$, Boom 51275). For glass surface modification we used $1 \mathrm{M}$ sodium hydroxide $(\mathrm{NaOH}, \mathrm{VWR} 31627.290)$ and trichloro $(1 \mathrm{H}, 1 \mathrm{H}, 2 \mathrm{H}, 2 \mathrm{H}$-perfluorooctyl)silane (FOTS, Sigma Aldrich 448931). All chemicals were used without further purification steps. 


\subsubsection{Emulsion preparation and characterization}

To ensure all emulsions have the same characteristics, a stock emulsion was prepared, which was then further diluted to obtain the desired salt and surfactant concentration. The stock emulsions were prepared by dissolving a surfactant (463 mg/L SDS; $346 \mathrm{mg} / \mathrm{L}$ CTAB; $298 \mathrm{mg} / \mathrm{L} \mathrm{TX)}$ in $1 \mathrm{~L}$ of DI water in a Duran ${ }^{\circledR}$ bottle (Duran 21801545) by mixing with a dispersing mixer (IKA ${ }^{\circledR}$ T25 digital Ultra-Turrax with S25N 18G element) for 2 minutes at $14000 \mathrm{rpm}$. Then, 2 or $4 \mathrm{~g}$ of n-hexadecane was injected near the mixer head and mixed for 10 minutes at $14000 \mathrm{rpm}$. After resting overnight, the stock emulsion was diluted to contain $1 \mathrm{~g} / \mathrm{L}$ hexadecane and the desired surfactant and $\mathrm{NaCl}$ concentration. The concentrations of surfactant were chosen to be very close or below the critical micelle concentration (CMC) to avoid formation of micelles. The CMC for SDS is $2400 \mathrm{mg} / \mathrm{L}$, for CTAB $340 \mathrm{mg} / \mathrm{L}$ and for TX $140 \mathrm{mg} / \mathrm{L}$. The particle size distribution was determined with a DIPA 2000 - Particle Analyzer (Prolyse). The mean droplet diameter in the diluted emulsions was 3-4 $\mu \mathrm{m}$ and was constant for all conditions.

Surfactant solutions used for rinsing and for applying shear were prepared the same as the emulsions, but without hexadecane and mixing for only 4 minutes. The concentrations of surfactant and $\mathrm{NaCl}$ were identical to the emulsion used in each experiment. After preparation, the surfactant solutions were degassed under vacuum and ultrasonic sonication for 15 minutes, followed by 15 minutes of only vacuum. The emulsions were not degassed, as they did not contain as much air bubbles. Furthermore, surfactant solutions were also used for all surfactant adsorption, contact angle and interfacial tension measurements.

\subsubsection{Glass modification and characterization}

Glass slides for the flow cell were prepared from microscope glass slides (VWR 631-1552). For the contact angle measurements, the slides were cut to fit the holder for the captive bubble measurement of the contact angle meter before treatment. The silica wafers used for reflectometry (WaferNet S64135) were treated in the same way as the glass after a $70 \mathrm{~nm}$ layer of silica oxide was grown on top. This ensures the glass and wafer surfaces are chemically similar. All glass slides were first put in a $1 \mathrm{M} \mathrm{NaOH}$ bath for one hour. Afterwards, the glass was flushed with DI water and dried with nitrogen. The dry glass was treated with a Harrick plasma cleaner (Harrick Plasma Cleaner model PDC-002) at the highest setting for one minute. This treatment yielded hydrophilic glass slides with a water contact angle of $<5^{\circ}$.

Hydrophobic slides were prepared by vapor deposition of FOTS (a fluorinated trichlorosilane) on hydrophilic glass slides. For this treatment we used a home built vapor deposition setup consisting of three connected glass chambers (Appendix 3.A). The first is a gas washing bottle which serves as evaporation cham- 
ber. The inlet of the bottle has an injection gate and is connected to a nitrogen flow. The outlet of the evaporation chamber is connected to the reaction chamber where the glass slides are placed. This reaction chamber is connected to a second gas washing bottle filled with water, where the released $\mathrm{HCl}$ gas is neutralized. Both evaporation chamber and reaction chamber can be heated. First, the hydrophilic glass slides were placed in the reaction chamber at $60^{\circ} \mathrm{C}$ under a nitrogen flow to dry for at least five hours. After drying, the reaction chamber was left to cool to room temperature. Then, approximately $0.3 \mathrm{~mL}$ of FOTS was injected into the evaporation chamber, which was heated to $60^{\circ} \mathrm{C}$. The FOTS was left to evaporate overnight under very low nitrogen flow. In the morning, the nitrogen flow was stopped, the evaporation chamber was left to cool down and the reaction chamber was heated to $60^{\circ} \mathrm{C}$ to speed up the reaction of the FOTS with the glass. After one hour, the reaction chamber was left to cool down again, the nitrogen flow was started and about $1 \mathrm{~mL}$ of water was injected into the evaporation chamber to neutralize leftover FOTS. After this, the glass slides were removed from the reaction chamber. The contact angle of the hydrophobic glass slides was $108 \pm 2^{\circ}$.

\subsubsection{Contact angle and interfacial tension measurements}

Both types of measurements were performed on a contact angle and contour analysis instrument (Dataphysics OCA 35). The contact angle measurements were performed in captive bubble mode, where a droplet of hexadecane is captured under a modified glass slide in the aqueous phase. The interfacial tension measurements were performed with the pendant droplet technique, where a droplet of aqueous solution is suspended in hexadecane. Image analysis of the droplet shapes from both contact angle and interfacial tension measurements was performed with the software provided with the measuring instrument, taking into account the density change of the water upon addition of $\mathrm{NaCl}$.

\subsubsection{Reflectometry measurements}

The adsorption of surfactant molecules to the surface was measured with reflectometry as described elsewhere [16]. We used solutions with the same concentration of surfactant and $\mathrm{NaCl}$ as used for all other experiments. The surfactant molecules were allowed to adsorb to the wafer surface. In between adsorption cycles the cell was flushed with a $\mathrm{NaCl}$ solution of the same ionic strength as the surfactant solution. The mass $\Gamma$ of the surfactant adsorbed to the surface can be calculated as

$$
\Gamma=\frac{\Delta S}{S_{0}} Q
$$


where $\Delta S=S-S_{0}$, with $S$ the ratio between the p- and s polarized components of the reflected laser beam, $S_{0}$ is the starting output signal of the silicon wafer and $Q$ is a sensitivity factor which depends on the angle of incidence of the laser $(\theta)$, the refractive indices (n), the thicknesses $(\mathrm{d})$ of the layers of the silicon wafer, and the refractive index increment $(\mathrm{dn} / \mathrm{dc})$ of the adsorbate. This factor is $0.100 \mathrm{mg} / \mathrm{m}^{2}$ for SDS [17], $0.151 \mathrm{mg} / \mathrm{m}^{2}$ for CTAB [17] and $0.154 \mathrm{mg} / \mathrm{m}^{2}$ for TX [18] and a silica layer thickness of $75 \mathrm{~nm}$. The Q-factor thus obtained for these surfactants is $40 \mathrm{mg} / \mathrm{m}^{2}$ for SDS, $27 \mathrm{mg} / \mathrm{m}^{2}$ for CTAB and $27 \mathrm{mg} / \mathrm{m}^{2}$ for TX.

\subsubsection{Flow cell setup}

To measure the adhesion of oil droplets in the emulsion to the glass surfaces, a flow cell setup with two parallel plates was used. This flow cell has been used before in the experiments of Dresselhuis, but in their experiments no shear force was applied [10]. A pulseless pump (Micropump serie 200, Axel Johnson International, Almere, The Netherlands) feeds the emulsion and flow solution into the flow chamber, which was placed under a microscope (Figure 3.1). By varying the distance between the plates of the flow cell and the flow of the pump, the hydrodynamic shear-induced force $F$ exerted on the oil droplets in the flow cell is increased and can be calculated as $[7,15]$

$$
F=10.2 \pi R^{2} \tau(\mathrm{N}) \quad \tau=\frac{6 \eta Q}{r h^{2}}\left(\mathrm{~N} / \mathrm{m}^{2}\right)
$$

Where $R$ is the droplet diameter, $\tau$ is the shear stress at the glass surface, $\eta$ is the viscosity of the continuous phase, $Q$ is the flow rate of the pump, which varied between 6 and $36 \mathrm{l} / \mathrm{h} ; r$ is the channel width and $h$ is the channel height, which varied between 0.7 and $2.3 \mathrm{~mm}$ [7] (Appendix 3.B). The flow cell was placed under a home built microscope, consisting of a $470 \mathrm{~nm}$ LED light source, polkadot beam splitter (Thorlabs BSW10R), 10x objective (Olympus, 10x/0.25), 2x magnification tube lens (Thorlabs ITL200) and a high speed camera (PointGrey GS2-GE-20S4M-C).

\subsubsection{Flow cell operation}

Before each experiment, the setup was cleaned by flushing with a $2 \%$ ethanol solution at $45^{\circ} \mathrm{C}$ for 15 minutes. After this, the system was flushed with DI water at room temperature for 15 minutes. A new modified glass slide was placed in the flow cell and the system was filled with degassed surfactant solution. Then 5 $\mathrm{mL}$ of emulsion was injected in the flow cell and left stagnant for 30 minutes to let the droplets float up against the glass. After 30 minutes, the cell was flushed with surfactant solution at the lowest pump setting to remove all oil droplets that did not adhere to the glass surface. After flushing, the channel depth of the 


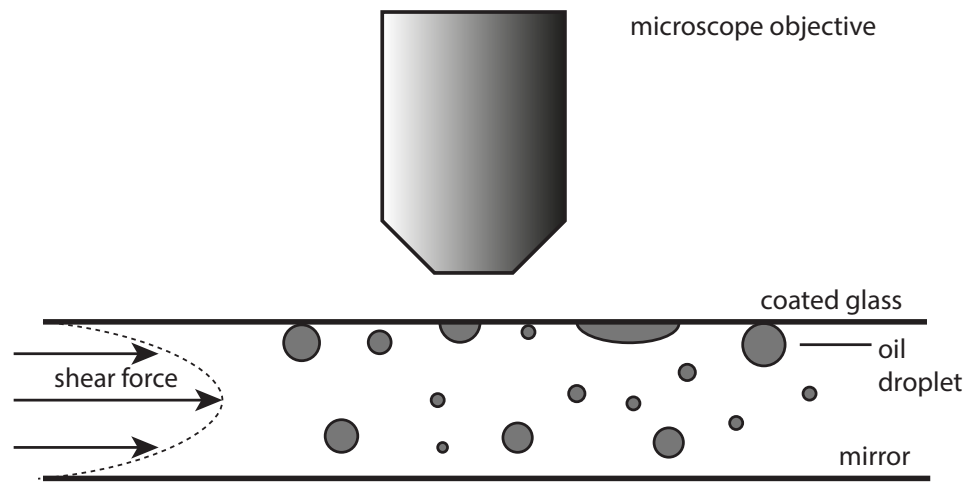

Figure 3.1: Schematic representation of the flow cell setup under the microscope. The distance between the mirror and the replaceable upper glass slide can be changed. The shear force is obtained by pumping a solution through the flow cell channel.

flow cell was decreased and the pump speed increased in steps to increase the shear force on the droplets. After each force increment an image of the droplets at the glass surface was captured. All images were taken at the same location in the cell and in the middle of the flow channel to ensure a fully-developed flow.

\subsubsection{Image analysis}

The images taken after each force increment were analyzed with ImageJ to determine the number of droplets adhered to the surface, as well as their mean diameter. Before analysis, the scale of the microscope images was set using a scale grid. First, the background was subtracted (sliding paraboloid, rolling ball radius 50 pixels). Then, the image was sharpened and finally a threshold was applied (default settings). Finally the amount of droplets was counted with a circularity of $0.35-1$, which is defined as $4 \pi \times$ area/perimeter ${ }^{2}$, and a minimum size of $1 \mu \mathrm{m}$ to exclude dust particles and other artifacts.

After droplet counting, the mean radius was determined from the image taken before flushing. This radius was used to calculate via equation 3.2 the force on the droplets in all subsequent images. The picture after initial flushing of the cell was considered the starting point of the experiment. The fraction of droplets adhering to the surface are all calculated from the number of droplets in this image. 


\subsection{Results and discussion}

In this work we have used a range of techniques to study the interaction between oil droplets and a glass surface at different salt and surfactant concentrations, for hydrophilic and hydrophobic surfaces. With reflectometry we measured the adsorption of surfactant molecules from the solution to a silica surface treated similar to the glass surface in the absence of oil. Interfacial tension measurements quantify the amount of surfactant molecules adsorbed to the oil-water interface, without a solid surface present. The contact angle of oil droplets on the surface depends on the hydrophilicity of the surface, which can change in the presence of surfactant molecules. It was measured in a system containing all the components present in the flow cell system, but in the absence of shear force. With these background measurements, we then moved on to our flow cell approach. Our subsequent observations on droplet adhesion in the flow cell provide a measure of the strength of droplet-surface interactions, and also allow direct visual observation.

\subsubsection{Surfactant adsorption}

Reflectometry is widely used to study the adsorption of molecules to surfaces [19-22]. In this section, we discuss the adsorption of SDS, CTAB and TX to a hydrophilic, negatively charged silica surface and to an uncharged hydrophobic surface. As expected, SDS, which is negatively charged, shows low adsorption to the hydrophilic, negatively charged surface (Figure 3.2a,b) [23]. The little adsorption that is measured is probably due to impurities in the solution. SDS is sensitive to hydrolysis of the head group from the dodecane tail, leading to minute amounts of dodecanol in the solution, especially below the CMC [24]. The hydrophobic tails of SDS molecules do adsorb to the hydrophobic surface to form a monolayer. Therefore, the hydrophobic surface becomes negatively charged in the presence of SDS [25].

Firstly, we measured the SDS adsorption at three different surfactant concentrations: $115 \mathrm{mg} / \mathrm{L}, 231 \mathrm{mg} / \mathrm{L}$ and $463 \mathrm{mg} / \mathrm{L}$ (Figure 3.2a) with $10 \mathrm{mM} \mathrm{NaCl}$ added. No significant difference in the amount of surfactant adsorbed to the hydrophobic surface was observed, indicating that the surface is saturated with surfactant molecules, giving it a constant negative charge.

Secondly, we varied the salt concentration of the solution with $231 \mathrm{mg} / \mathrm{L} \mathrm{SDS}$, adding 1, 10 and $100 \mathrm{mM} \mathrm{NaCl}$. There seems to be a maximum in the adsorbed amount of surfactant at $10 \mathrm{mM} \mathrm{NaCl}$ for both hydrophilic and hydrophobic surfaces (Figure 3.2b). It has been observed that the amount of surfactant adsorbed to a surface increases until concentrations close to the CMC of the surfactant. At higher concentrations the amount of adsorbed surfactant decreases again [25]. This effect is attributed to impurities in the used surfactant. Dodecanol is ex- 

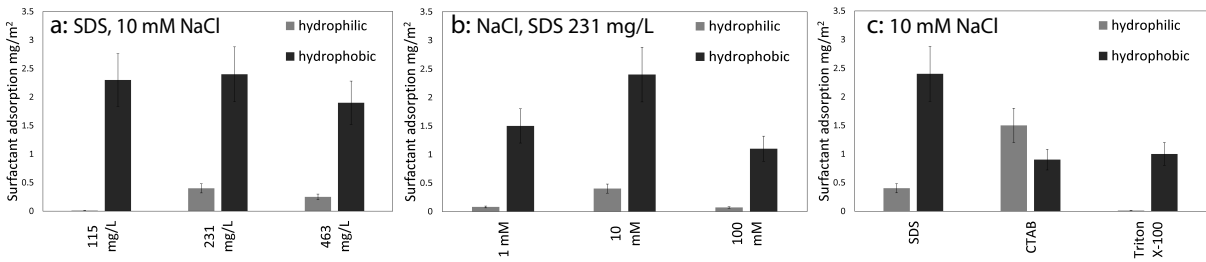

Figure 3.2: Surfactant adsorption to hydrophilic and hydrophobic surfaces for (a) different SDS concentrations and $10 \mathrm{mM} \mathrm{NaCl}$; (b) different $\mathrm{NaCl}$ concentrations and 231 $\mathrm{mg} / \mathrm{L} \mathrm{SDS}$; (c) surfactants with different properties at $10 \mathrm{mM} \mathrm{NaCl}$ and $231 \mathrm{mg} / \mathrm{L} \mathrm{SDS}$, $176 \mathrm{mg} / \mathrm{L} \mathrm{CTAB}$ and $149 \mathrm{mg} / \mathrm{L}$ TX. Error bars are $15 \%$ of the measured mean after three repetitions.

pected to adsorb stronger to the silica-water interface than SDS, forming dense monolayers [26]. The increased salt concentration possibly influences this adsorption, for instance by influencing the adsorption strength of dodecanol to the interface. The exact mechanism however is not clear. Generally speaking, it can be stated that at different salt concentrations both the hydrophilic and the hydrophobic surfaces are negatively charged, the latter due to SDS adsorption. Finally we compared the adsorption of anionic SDS to cationic CTAB and nonionic TX to study the influence of surfactant head group charge (Figure 3.2c). CTAB, which is positively charged, forms a double layer on the hydrophilic, negatively charged surface, resulting in a positively charged surface [27]. On the hydrophobic surface, CTAB forms a monolayer, also resulting in a positively charged surface. This means that for charged surfactants, the hydrophobic surface will possess the same charge as the surfactant present. The nonionic surfactant TX however, does not adsorb to the hydrophilic surface, but does adsorb to the hydrophobic surface. The hydrophobic surface becomes more hydrophilic because of the polar headgroups pointing outwards into the aqueous phase [28]. The hydrophilic head group of TX consists of a short polyethylene oxide (PEO) tail. The adsorption of PEO to silica is strongly dependent on $\mathrm{pH}[29,30]$. At increasing $\mathrm{pH}$ the adsorption of $\mathrm{PEO}$ on silica decreases, especially above $\mathrm{pH} 8$.

\subsubsection{Interfacial tension surfactant solution/oil}

The interfacial tension between the surfactant solution and oil, which correlates to the adsorption of surfactant in the oil-water interface, was measured using the pendant droplet technique, in which a droplet of surfactant solution was suspended in hexadecane. From the interfacial tension it is possible to estimate the amount of surfactant adsorbed to the oil interface using the generalized form 
of the Gibbs adsorption isotherm

$$
-\mathrm{d} \gamma=R T \sum \Gamma_{i} \mathrm{~d} \ln a_{i}
$$

where $\gamma$ represents the interfacial tension, and $\Gamma_{i}$ and $a_{i}$ the surface excess and the activity of the $i$ th ionic species in solution respectively [31].

With increasing surfactant concentration, the interfacial tension (at $10 \mathrm{mM} \mathrm{NaCl}$ ) lowers from $22 \mathrm{mN} / \mathrm{m}$ for $115 \mathrm{mg} / \mathrm{L}$ SDS and $18 \mathrm{mN} / \mathrm{m}$ for $231 \mathrm{mg} / \mathrm{L}$ SDS to $14 \mathrm{mN} / \mathrm{m}$ for $463 \mathrm{mg} / \mathrm{L}$ SDS (Figure $3.3 \mathrm{I}$, III, V). The amount of surfactant adsorbed to the interface was estimated to be $1.6 \mu \mathrm{mol} / \mathrm{m}^{2}, 3.1 \mu \mathrm{mol} / \mathrm{m}^{2}$ and $4.0 \mu \mathrm{mol} / \mathrm{m}^{2}$ respectively. This behavior indicates that the interface between oil and water is not saturated and more surfactant molecules adsorb at increasing surfactant concentration. This is expected as the used surfactant concentrations are below the CMC [32].

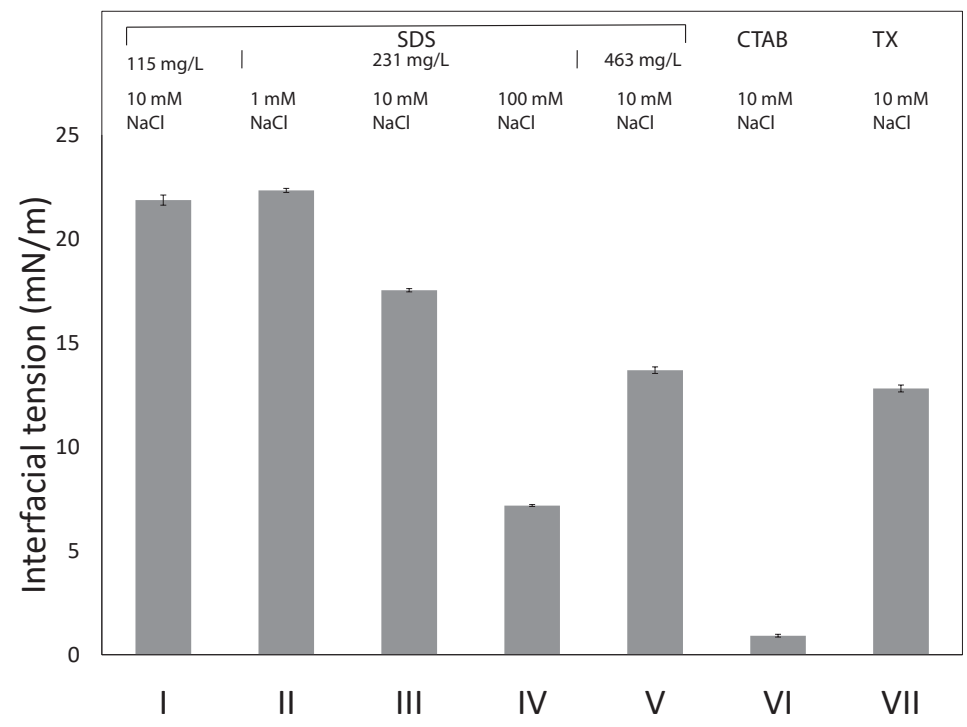

Figure 3.3: Interfacial tension of the oil-water interface in presence of surfactant. I) $115 \mathrm{mg} / \mathrm{L}$ SDS $10 \mathrm{mM} \mathrm{NaCl}$; II) $231 \mathrm{mg} / \mathrm{L}$ SDS, $1 \mathrm{mM} \mathrm{NaCl}$; III) $231 \mathrm{mg} / \mathrm{L}$ SDS, 10mM NaCl; IV) $231 \mathrm{mg} / \mathrm{L}$ SDS, 100mM NaCl V) $463 \mathrm{mg} / \mathrm{L}$ SDS, $10 \mathrm{mM} \mathrm{NaCl}$; VI) $176 \mathrm{mg} / \mathrm{L}$ CTAB, $10 \mathrm{mM} \mathrm{NaCl}$; VII) $149 \mathrm{mg} / \mathrm{L}$ TX, $10 \mathrm{mM} \mathrm{NaCl}$. Error bars represent the standard deviation after duplicates.

At increasing $\mathrm{NaCl}$ concentration in the presence of $231 \mathrm{mg} / \mathrm{L}$ SDS, the interfacial tension lowers (Figure 3.3 II, III, IV). The positively charged sodium ions screen the charge of the negatively charged SDS head groups. This lowers the electro- 
static repulsion between the head groups, allowing more surfactant molecules to adsorb, thus lowering the interfacial tension from $22 \mathrm{mN} / \mathrm{m}$ for $1 \mathrm{mM} \mathrm{NaCl}$ and $18 \mathrm{mN} / \mathrm{m}$ for $10 \mathrm{mM} \mathrm{NaCl}$ to $7 \mathrm{mN} / \mathrm{m}$ for $100 \mathrm{mM} \mathrm{NaCl}$. From these values, we estimated the amount of surfactant on the interface to be $2.5 \mu \mathrm{mol} / \mathrm{m}^{2}, 3.1$ $\mu \mathrm{mol} / \mathrm{m}^{2}$ and $3.3 \mu \mathrm{mol} / \mathrm{m}^{2}$ respectively. In addition to this, the colloidal stability of the emulsion might go down as the electrostatic repulsion between the droplets is also screened by the sodium ions. When comparing SDS at $231 \mathrm{mg} / \mathrm{L}$, CTAB at $176 \mathrm{mg} / \mathrm{L}$ and TX at $149 \mathrm{mg} / \mathrm{L}$, all in the presence of $10 \mathrm{mM} \mathrm{NaCl}$, it is evident that $\mathrm{CTAB}$ results in the lowest interfacial tension at $1 \mathrm{mN} / \mathrm{m}$, followed by $\operatorname{TX}(13 \mathrm{mN} / \mathrm{m})$ and $\operatorname{SDS}(18 \mathrm{mN} / \mathrm{m})$.

\subsubsection{Contact angle measurements}

The contact angle between an oil droplet and the glass surface immersed in surfactant solution was measured with the captive droplet technique, where the oil droplet is trapped under the glass.

On a hydrophilic surface, the oil droplet has a contact angle of about $150^{\circ}$ for all surfactant and $\mathrm{NaCl}$ concentrations (Figure 3.4). In the case of SDS the surface of the oil droplet is covered by negatively charged surfactant molecules, whereas the surface is negatively charged by itself causing electrostatic repulsion and avoiding contact. The droplet retains its spherical shape and rolls over the surface, indicating no real attachment. Because the oil droplets roll away, the contact angle was measured directly after touching the surface. For hydrophobic surfaces however, the droplet collapses into a hemispherical shape with a contact angle of about $60^{\circ}$ upon contact with the surface. The contact angles after 30 minutes can be found in Appendix 3.C. In these circumstances, the repulsive force between the glass surface covered by a monolayer of SDS molecules and the droplet covered in SDS molecules is overcome by the hydrophobic interactions between the surface and the oil. An exception we observed was the measured contact angle at an SDS concentration of $231 \mathrm{mg} / \mathrm{L}, 100 \mathrm{mM} \mathrm{NaCl}$ and the hydrophobic surface (Figure 3.4IV). In this experiment, we observed that the oil droplet retained its spherical shape upon contact with the surface. After 2-3 seconds the droplet collapsed, like observed in all other experiments with SDS on the hydrophobic surface. This indicates that at sufficiently high surfactant adsorption to both surface and oil-water interface, a barrier is formed that can avoid immediate droplet collapse.

When comparing SDS with CTAB and TX at $10 \mathrm{mM} \mathrm{NaCl}$, it becomes immediately clear that droplets stabilized by CTAB and TX do not collapse on a hydrophilic surface and retain their spherical shape. In the case of CTAB, the repulsive electrostatic force between droplet and the glass surface covered in either a mono- or bilayer of surfactant is sufficient to keep the droplet from collapsing on the surface. For TX, which is a surfactant without charge, the repulsion is 
caused by only sterical hindrance between the surface and the oil droplet.

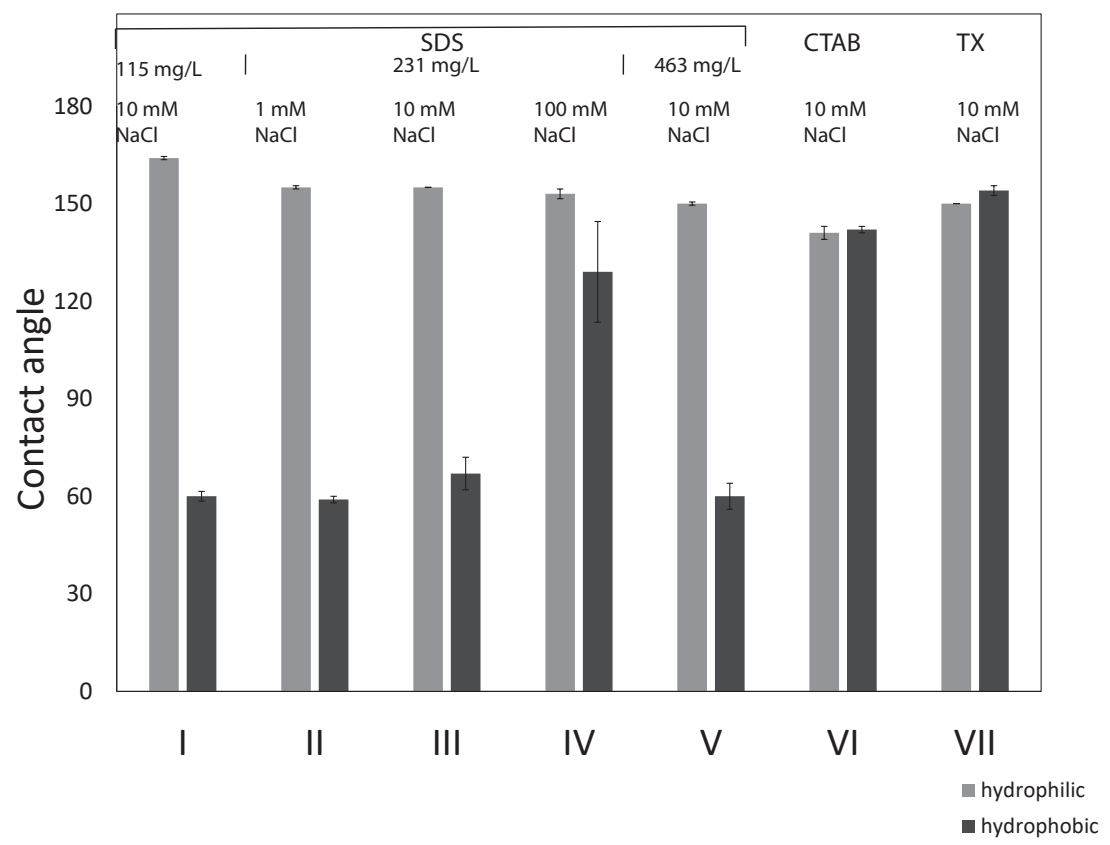

Figure 3.4: Contact angles of surfactant stabilized hexadecane droplets on glass measured with the captive bubble method. Contact angle was measured through the droplet upon contact with the surface. I) $115 \mathrm{mg} / \mathrm{L} \mathrm{SDS} 10 \mathrm{mM} \mathrm{NaCl}$; II) $231 \mathrm{mg} / \mathrm{L} \mathrm{SDS}, 1 \mathrm{mM}$ $\mathrm{NaCl}$; III) $231 \mathrm{mg} / \mathrm{L}$ SDS, 10mM NaCl; IV) $231 \mathrm{mg} / \mathrm{L}$ SDS, 100mM NaCl V) $463 \mathrm{mg} / \mathrm{L}$ SDS, $10 \mathrm{mM} \mathrm{NaCl}$; VI) $176 \mathrm{mg} / \mathrm{L} \mathrm{CTAB,} 10 \mathrm{mM} \mathrm{NaCl}$; VII) $149 \mathrm{mg} / \mathrm{L}$ TX, $10 \mathrm{mM}$ $\mathrm{NaCl}$. Error bars represent the standard deviation after duplicates.

\subsubsection{Flow cell}

The flow cell is used to visually observe droplet adhesion to the surface. In contrast to the contact angle measurements in Figure 3.4, the droplets are seen from above rather than from the side. The oil droplets studied in the flow cell are much smaller, leading to less deformable droplets. The components present in both contact angle measurements and flow cell experiments are the same.

When the emulsion is injected in the cell, due to buoyancy the droplets float up and attach to the top glass plate of the cell (Figure 3.1). With a light microscope, we can observe the droplets on this glass surface (Figure 3.5). After 30 minutes without any flow, the surface is covered in oil droplets (Figure 3.5, first column). We then remove the droplets that are not attached to the surface by gently 
flushing the flow cell with surfactant solution until only the droplets remain that have truly attached to the surface (Figure 3.5, second column).

In contrast to the contact angle measurements from section 3.3.3, adhesion of droplets is observed on both the hydrophilic and the hydrophobic surface, which we attribute to a longer contact time. The state after flushing is the starting point of the experiment. Then, by increasing the shear force on the droplets, we wash away a fraction of the attached droplets, until we reach maximum pump capacity and minimum plate distance (Figure 3.5, third and fourth column). In our experiments, we did not observe coalescence of droplets on the surface. In addition, due to sufficiently high shear force, removed droplets were immediately flushed away. We also observed that on the hydrophobic surface, a small number of oil droplets stabilized by SDS or CTAB spread out on the surface. After this happens, it is impossible to wash the oil from the surface. We did not observe this behavior on the hydrophilic surface for the charged surfactants, but oil droplets stabilized by TX spread out on both hydrophilic and hydrophobic surfaces. This indicates that electrostatic repulsion plays an important role in the force balance of the interaction between surface and oil droplet.

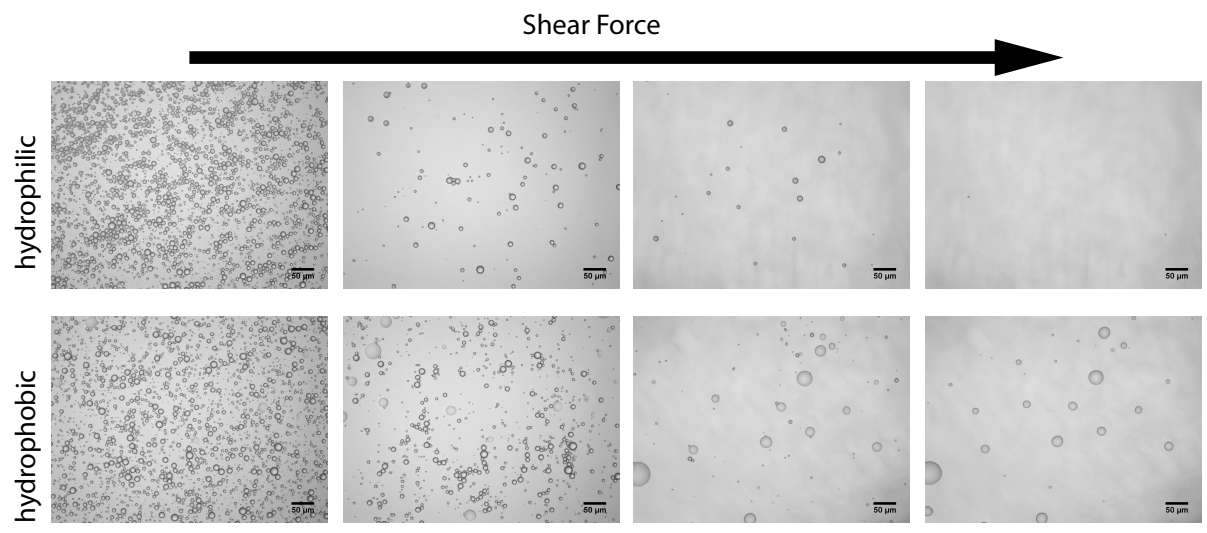

Figure 3.5: Photos from the flow cell setup showing droplets stabilized by SDS (231 $\mathrm{mg} / \mathrm{L}$ ) on a hydrophilic and hydrophobic surface under increasing shear force. The pictures are taken after the stagnant phase, flushing, in the middle of the experiment and after the experiment. Note the spreading of droplets on the hydrophobic surface.

\section{Surfactant concentration}

The fraction of droplets adhering to the hydrophilic and hydrophobic glass surface at different SDS concentrations and $10 \mathrm{mM} \mathrm{NaCl}$ is plotted in Figure 3.6. At higher applied shear forces, droplets detach from the surface. We performed 
the experiment for three different SDS concentrations with $10 \mathrm{mM} \mathrm{NaCl}$. On the hydrophilic surface, we observed comparable detachment behavior for 115 $\mathrm{mg} / \mathrm{L}$ and $463 \mathrm{mg} / \mathrm{L}$ of SDS. At $231 \mathrm{mg} / \mathrm{L} \mathrm{SDS}$, the detachment of droplets from the surface is much faster. On the hydrophobic surface, we observed the fastest droplet detachment for $231 \mathrm{mg} / \mathrm{L}$ SDS, a slightly slower detachment for $115 \mathrm{mg} / \mathrm{L}$ SDS and the least droplet detachment for $463 \mathrm{mg} / \mathrm{L}$ SDS. This indicates that the droplet adhesion at $231 \mathrm{mg} / \mathrm{L}$ SDS is the weakest, both on the hydrophilic and the hydrophobic surface, and we observe a minimum in the adhesive force between droplet and surface at this surfactant concentration. As shown before in Figure 3.2, SDS adsorbs to the hydrophobic surface, providing the surface with a negative charge, and the hydrophilic surface is negatively charged due to dissociation of silanol groups. In addition, a small amount of surfactant also adsorbs on the hydrophilic surface at $231 \mathrm{mg} / \mathrm{L}$ SDS. The droplet surface is also covered by SDS molecules, so electrostatic repulsion prevents droplets from adhering. The minimum in droplet-surface interaction can be explained by a balance of various processes taking place at the surface. At increasing surfactant concentration, the interfacial tension of the oil droplet decreases, as discussed in section 3.3.2. This means more surfactant molecules are adsorbed to the oilwater interface and a higher surface charge density, increasing the electrostatic repulsion between droplet and surface. In contrast to what we expected, a higher amount of surfactant did not yield a lower adhesion force to the surface, so other factors play a role in this adhesion behavior. The deformability of oil droplets can be described by the capillary number $C a=\tau R / \gamma[33]$. As shown by Gupta and Basu, deformation of oil droplets occurs at capillary numbers in the order of $1 \times 10^{-2}$ and higher [34]. The capillary number of our droplets is lower, in the order of $1 \times 10^{-3}$ indicating that droplet deformation does not play a role in the adhesion behavior of our system. Finally, the viscosity of the aqueous phase does not change significantly at our concentrations of surfactant, so the effects of shear thinning can be omitted [35]. However, we did observe that at $231 \mathrm{mg} / \mathrm{L}$ SDS there is a maximum in surfactant adsorption to both the hydrophilic and the hydrophobic surface, which can explain the decreased interaction between surface and droplets. Thus, it remains unclear why the droplet adhesion increases with increasing SDS concentration.

\section{$\mathrm{NaCl}$ concentration}

As shown in section 3.3.1, both the hydrophilic and hydrophobic surface are negatively charged at all $\mathrm{NaCl}$ concentrations, because of the properties of the silica itself and the adsorption of SDS respectively (Figure 3.2a). At increasing $\mathrm{NaCl}$ concentration, the surface tension decreases, because more surfactant molecules adsorb to the oil-water interface, thus increasing the charge density of the droplet surface, as discussed in section 3.3.2. 

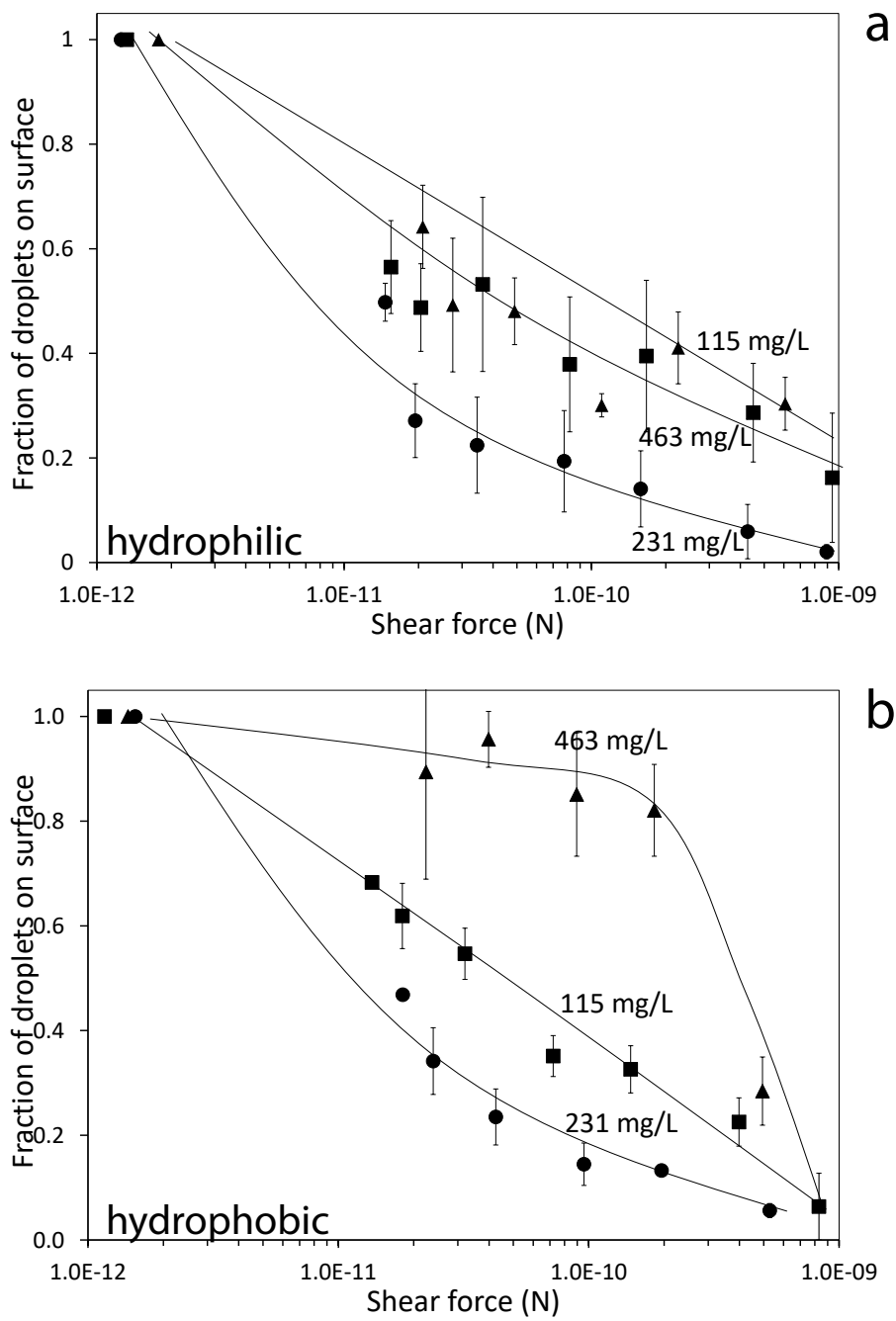

Figure 3.6: fraction of droplets that sticks to a hydrophilic (a) and hydrophobic (b) surface for different SDS concentrations and a $\mathrm{NaCl}$ concentration of $10 \mathrm{mM}$. Error bars represent standard deviation after duplicates. Lines are a guide to the eye. 
For both surfaces, droplet adhesion at 1 and $10 \mathrm{mM}$ is comparable. At $100 \mathrm{mM}$, however, the adhesion of droplets to the surfaces increases. More shear force is required to wash away the oil droplets. At high salt concentrations, the counterions (in this case sodium) allow for more SDS adsorption on the oil-water interface, but also screen the resulting surface charge of the droplet and the glass surface. The repulsive force between droplet and surface decreases and droplets can adhere to the surface more strongly. Calculating the electrostatic repulsion of the system with the DLVO equation indicates that the van der Waals and electrostatic forces are in the same order of magnitude as the shear force applied to the droplets, which indicates that electrostatic interactions play a significant role in the droplet adhesion. The force at which droplets detach from the surface is about $2 \times 10^{-10} \mathrm{~N}$ for the hydrophilic surface, and $3 \times 10^{-11} \mathrm{~N}$ for the hydrophobic surface. This means the interaction between the droplets and the surface is stronger for the hydrophilic surface. This suggests that the presence of a surfactant layer on the surface, as in the hydrophobic case, is better at preventing droplets to adhere to the surface at this salt concentration. As shown by Tadros and Lyklema, the surface charge of glass at neutral $\mathrm{pH}$ and $10 \mathrm{mM}$ $\mathrm{NaCl}$ is $-0.05 \mathrm{C} / \mathrm{m}^{2}$ [36], whereas the adsorption of surfactant yields a surface charge of $-0.8 \mathrm{C} / \mathrm{m}^{2}$. In addition two layers of surfactant (one of the droplet and one on the surface) form a better barrier than just one layer of surfactant. We did observe, however, that a small fraction of droplets spreads out on the hydrophobic surface. These droplets make contact with the surface and collapse to form spread out patches of oil, see also Figure 3.5. These patches of oil cannot be removed from the surface by washing with surfactant solution. This behavior was not observed on the hydrophilic surface for SDS.

\section{Surfactant type}

The charge of the surfactant used to stabilize the emulsion influences the behavior of oil droplets on the surface. We compared three surfactants, anionic SDS, cationic CTAB and nonionic TX (Figure 3.8). For both the hydrophilic and hydrophobic surface similar trends were observed. Both SDS and CTAB result in equal sign charge for surface and droplet, allowing for droplets to be washed away. TX however behaves differently. Oil droplets adhere to the surface in aggregates and have a high tendency to spread on both the hydrophilic and the hydrophobic surface (Appendix 3.D). Images taken in the experiments with TX were not suitable for image analysis because of very high droplet coverage, therefore the line in the graph is based on this general observation rather than data from the images. The lack of ionic repulsion between the interface and the oil droplets allows for higher adhesion, and much easier spreading. 

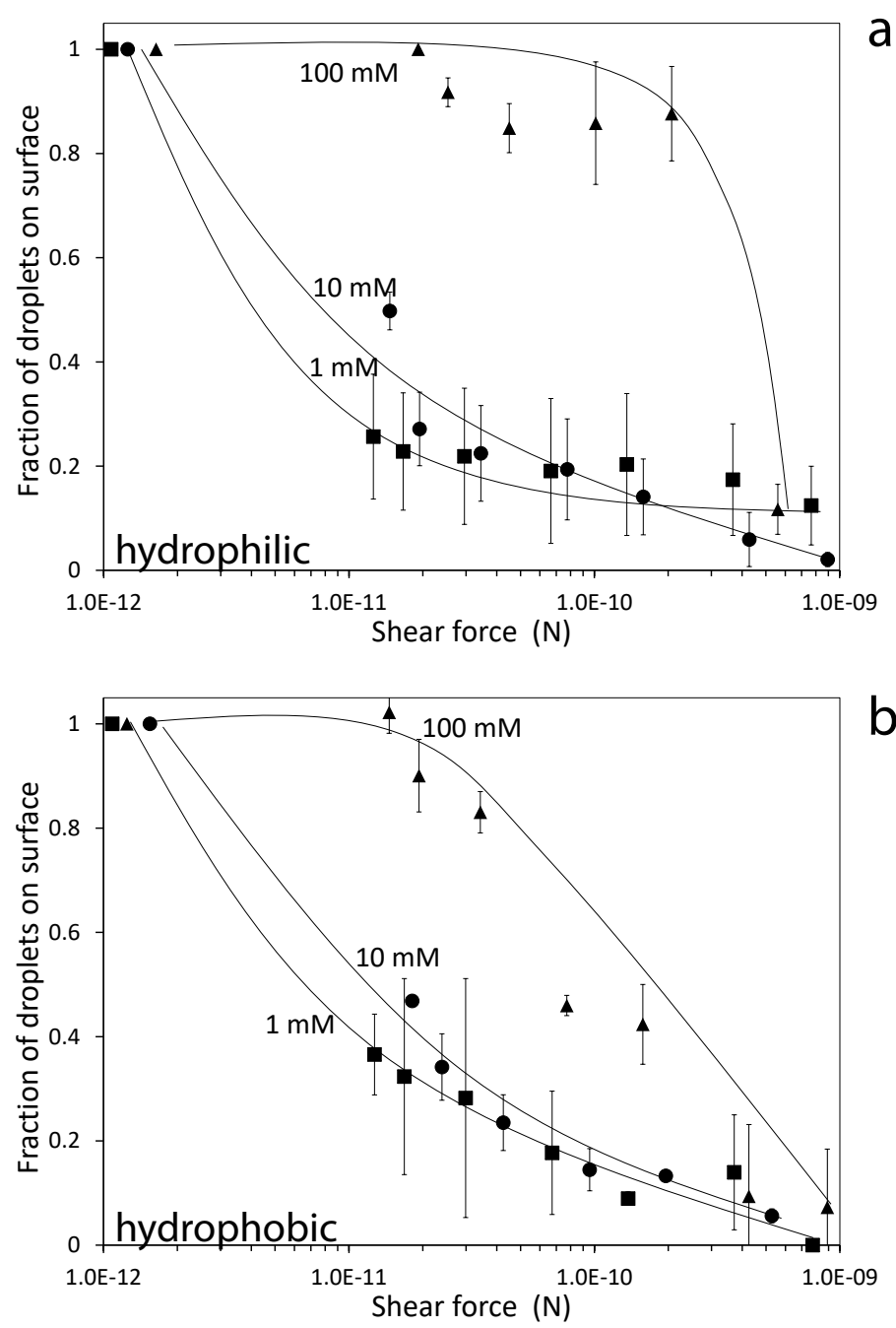

Figure 3.7: fraction of droplets that sticks to a hydrophilic (a) and hydrophobic (b) surface for different $\mathrm{NaCl}$ concentrations and an SDS concentration of $231 \mathrm{mg} / \mathrm{L}$. Error bars represent standard deviation after duplicates. Lines are a guide to the eye. 

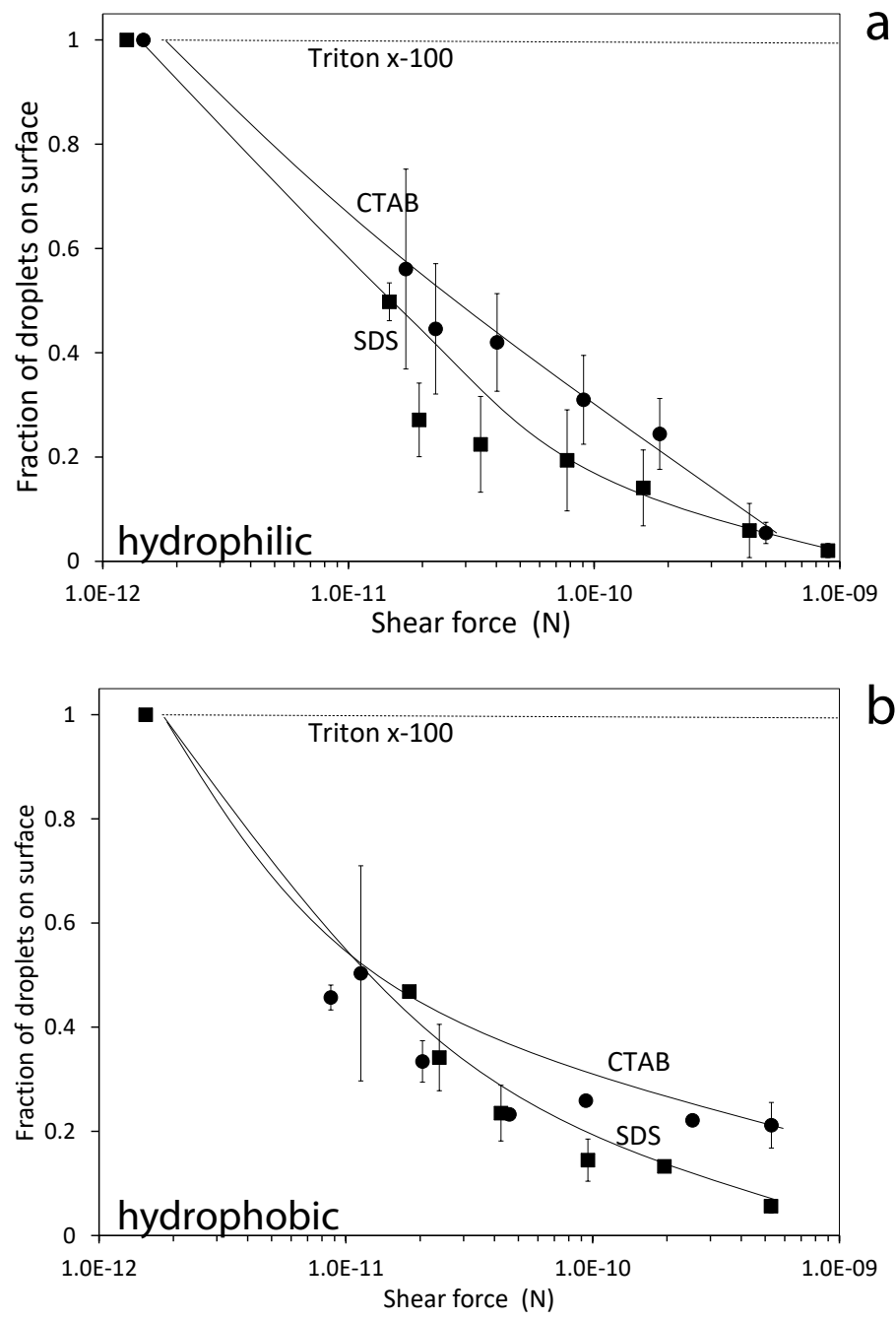

Figure 3.8: fraction of droplets that sticks to a hydrophilic (a) and hydrophobic (b) surface for different surfactants and $10 \mathrm{mM} \mathrm{NaCl}$. Error bars represent standard deviation after duplicates. Lines are a guide to the eye. 


\subsection{Conclusion}

In this article we used a novel flow cell technique to study the adhesion strength between a glass surface by applying a shear force. Because the flow cell allowed us to visually observe the droplets, we could also see the behavior of the individual oil droplets on the surface. By using hydrophilic and hydrophobic surface modifications, the role of the surface in droplet adhesion could be studied. In addition to these flow cell measurements, we performed interfacial tension, surfactant adsorption and contact angle measurements under similar conditions. With these techniques, we were able to study the influence of surfactant concentration, $\mathrm{NaCl}$ concentration and surfactant charge on the adhesion behavior of droplets to hydrophilic and hydrophobic surfaces.

Firstly, there appears to be an ideal surfactant concentration for SDS to prevent droplet adhesion to both hydrophilic and hydrophobic surfaces. Secondly, at increasing salt concentrations, droplets adhere to both the hydrophilic and the hydrophobic surface. At $100 \mathrm{mM} \mathrm{NaCl}$, droplets adhere even stronger to the hydrophilic than to the hydrophobic surface. In addition, droplets also tend to spread out on the hydrophobic surface. Finally, we compared two charged surfactants, SDS and CTAB, to an uncharged surfactant. TX. Where the charged surfactants showed similar behavior, where droplets could be washed away from the surface, the droplets stabilized with uncharged surfactant either aggregated or spreaded on both the hydrophilic and the hydrophobic surface. The results presented in this paper show that the flow cell gives us an adequate technique to study the interaction of oil droplets and surfaces, and should be used to study more complex droplet-surface systems. 


\section{A The vapor despostion setup}

The injection gate of this setup was created by placing a piece of silicon tubing just before the inlet of the reaction chamber, as can be seen in the picture.

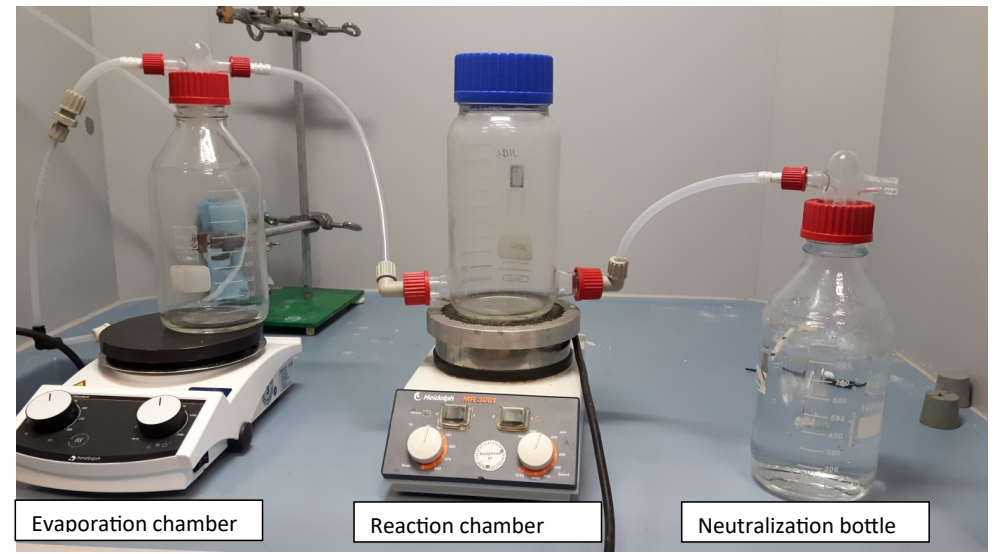

Figure 3.9: The setup used for vapor deposition of the FOTS.

\section{B Exact settings of flow cell and pump}

\begin{tabular}{|l|l|l|l|}
\hline Action & $\begin{array}{l}\text { Duration } \\
(\mathrm{min})\end{array}$ & $\begin{array}{l}\text { Channel } \\
\text { depth cell } \\
(\mathrm{mm})\end{array}$ & $\begin{array}{l}\text { Pump speed } \\
(\mathrm{l} / \mathrm{h})\end{array}$ \\
\hline $\begin{array}{l}\text { Inject emulsion and } \\
\text { settling }\end{array}$ & 30 & 2.3 & 0 \\
\hline Flushing & 30 & 2.3 & 1.5 \\
\hline Shearing & 1 & 2.3 & 6 \\
\hline Shearing & 1 & 2.0 & 6 \\
\hline Shearing & 1 & 1.5 & 6 \\
\hline Shearing & 1 & 1.0 & 6 \\
\hline Shearing & 1 & 0.7 & 16.2 \\
\hline Shearing & 1 & 0.7 & 25.3 \\
\hline Shearing & 1 & 0.7 & 34.5 \\
\hline
\end{tabular}




\section{C Contact angles after $\mathbf{3 0}$ minutes}

\begin{tabular}{|c|c|c|c|c|c|}
\hline & & $\begin{array}{l}\text { contact } \\
\text { angle } t=0\end{array}$ & $\begin{array}{l}\text { stdev } \\
\mathrm{t}=0\end{array}$ & $\begin{array}{l}\text { contact } \\
\text { angle } \\
\mathrm{t}=30\end{array}$ & $\begin{array}{l}\text { stdev } \\
\mathrm{t}=30\end{array}$ \\
\hline \multirow{2}{*}{$\begin{array}{l}\text { SDS } 115 \mathrm{mg} / \mathrm{L} \\
10 \mathrm{mM} \mathrm{NaCl}\end{array}$} & hydrophilic & 164.45 & 1.9 & $\mathrm{R}$ & $\mathrm{x}$ \\
\hline & hydrophobic & 59 & 1.4 & 57 & 0.3 \\
\hline \multirow{2}{*}{$\begin{array}{l}\mathrm{SDS} 231 \mathrm{mg} / \mathrm{L} 1 \\
\mathrm{mM} \mathrm{NaCl}\end{array}$} & hydrophilic & 155.45 & 1.3 & $\mathrm{R}$ & $\mathrm{x}$ \\
\hline & hydrophobic & 58.95 & 1.6 & 53.2 & 3.0 \\
\hline \multirow{2}{*}{$\begin{array}{l}\text { SDS } 231 \mathrm{mg} / \mathrm{L} \\
10 \mathrm{mM} \mathrm{NaCl}\end{array}$} & hydrophilic & 155.1 & 0.3 & $\mathrm{R}$ & $\mathrm{x}$ \\
\hline & hydrophobic & 67.1 & 10.2 & 59.15 & 5.9 \\
\hline \multirow{2}{*}{$\begin{array}{l}\text { SDS } 231 \mathrm{mg} / \mathrm{L} \\
100 \mathrm{mM} \mathrm{NaCl}\end{array}$} & hydrophilic & 153 & 2.5 & $\mathrm{R}$ & $\mathrm{x}$ \\
\hline & hydrophobic & 151 & 1.0 & 59.35 & 5.7 \\
\hline \multirow{2}{*}{$\begin{array}{l}\text { SDS } 463 \mathrm{mg} / \mathrm{L} \\
10 \mathrm{mM} \mathrm{NaCl}\end{array}$} & hydrophilic & 150.35 & 0.9 & $\mathrm{R}$ & $\mathrm{x}$ \\
\hline & hydrophobic & 59.6 & 7.8 & 53.3 & 3.1 \\
\hline \multirow{2}{*}{$\begin{array}{lll}\text { CTAB } & & 176 \\
\mathrm{mg} / \mathrm{L} & 10 & \mathrm{mM} \\
\mathrm{NaCl} & & \end{array}$} & hydrophilic & 140.5 & 3.5 & $\mathrm{R}$ & $\mathrm{x}$ \\
\hline & hydrophobic & 141.5 & 2.1 & $\mathrm{R}$ & $\mathrm{x}$ \\
\hline \multirow{2}{*}{ 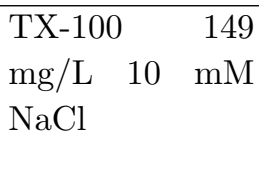 } & hydrophilic & 150.15 & 0.2 & $\mathrm{R}$ & $\mathrm{x}$ \\
\hline & hydrophobic & 154.2 & 2.7 & 94.95 & 10 \\
\hline
\end{tabular}

Table 3.1: Contact angles at the $\mathrm{t}=0$ and $\mathrm{t}=30 \mathrm{~min}$. An $\mathrm{R}$ indicates a droplet that rolled off the surface, of which the contact angle was not measured. 


\section{D Images of TX in flow cell}

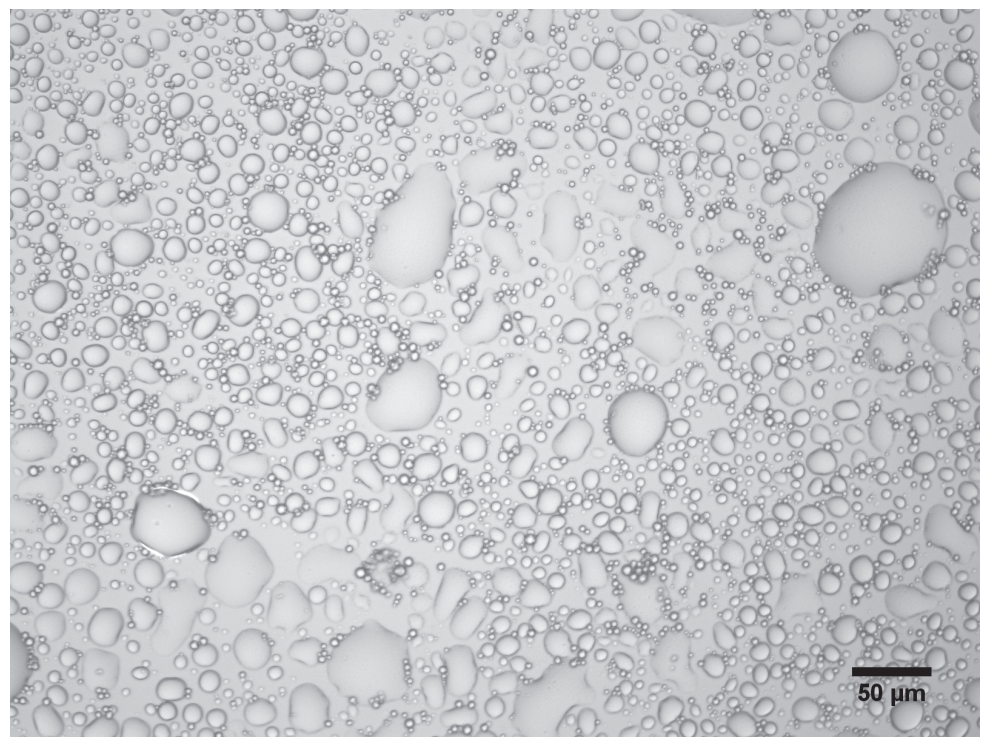

Figure 3.10: Oil droplets stabilized with TX on a hydrophilic surface during flushing.

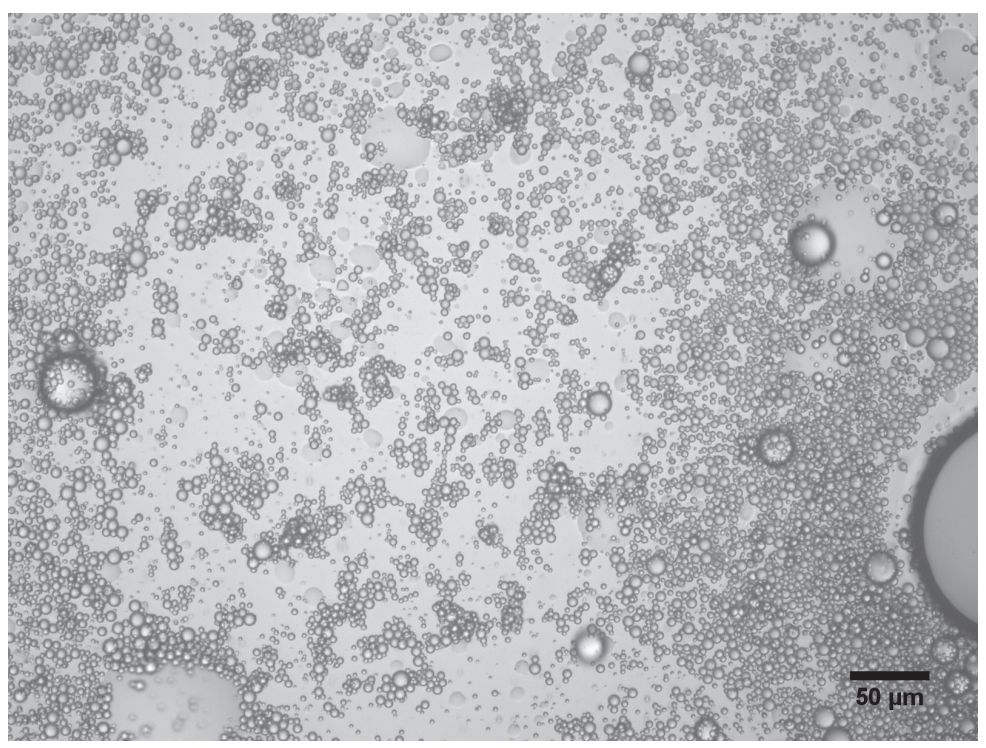

Figure 3.11: Oil droplets stabilized with TX on a hydrophobic surface during flushing. 


\section{Bibliography}

[1] X. Zhu, W. Tu, K.-H. Wee, and R. Bai, Effective and low fouling oil/water separation by a novel hollow fiber membrane with both hydrophilic and oleophobic surface properties, Journal of Membrane Science 466, 36 (2014). p.56.

[2] A. Murić, I. Petrinić, and M. L. Christensen, Comparison of ceramic and polymeric ultrafiltration membranes for treating wastewater from metalworking industry, Chemical Engineering Journal 255, 403 (2014). — p.56.

[3] J. Zheng, B. Chen, W. Thanyamanta, K. Hawboldt, B. Zhang, and B. Liu, Offshore produced water management: A review of current practice and challenges in harsh/Arctic environments, MPB 104, 7 (2016). — p.56.

[4] T. Wallace, D. Gibbons, M. O'Dwyer, and T. P. Curran, International evolution of fat, oil and grease (FOG) waste management $A$ review, Journal of Environmental Management 187, 424 (2017). — p.56.

[5] S. Alzahrani and A. W. Mohammad, Challenges and trends in membrane technology implementation for produced water treatment: A review, Journal of Water Process Engineering 4, 107 (2014). — p.56.

[6] A. Goldman, R. Cox, and H. Brenner, Slow viscous motion of a sphere parallel to a plane wallI Motion through a quiescent fluid, Chemical Engineering Science 22, 637 (1967). - p.56.

[7] A. Goldman, R. Cox, and H. Brenner, Slow viscous motion of a sphere parallel to a plane wallII Couette flow, Chemical Engineering Science 22, 653 (1967). - p.56, 60.

[8] G. Z. Ramon, H. E. Huppert, J. R. Lister, and H. A. Stone, On the hydrodynamic interaction between a particle and a permeable surface, Physics of Fluids 25, 073103 (2013). - p.56.

[9] Y. Chae Jung and B. Bhushan, Wetting Behavior of Water and Oil Droplets in Three-Phase Interfaces for Hydrophobicity/philicity and Oleophobicity/philicity, Langmuir 25, 14165 (2009). - p.56.

[10] D. M. Dresselhuis, G. A. van Aken, E. H. A. de Hoog, and M. A. Cohen Stuart, Direct observation of adhesion and spreading of emulsion droplets at solid surfaces, Soft Matter 4, 1079 (2008). — p.56, 60.

[11] G. Fux and G. Z. Ramon, Microscale Dynamics of Oil Droplets at a Membrane Surface: Deformation, Reversibility, and Implications for Fouling, Environmental Science \& Technology 51, 13842 (2017). — p.56. 
[12] J. Dickhout, J. Moreno, P. Biesheuvel, L. Boels, R. Lammertink, and W. de Vos, Produced water treatment by membranes: A review from a colloidal perspective, Journal of Colloid and Interface Science (2016). — p.56.

[13] W. Essafi, K. Wong, J. Bibette, and P. Poulin, Oil coating of hydrophobic surfaces from aqueous media: Formation and kinetic study, Journal of Colloid and Interface Science 286, 730 (2005). — p.57.

[14] M. Malmsten, A.-L. Lindström, and T. Wärnheim, Electrostatic Effects on Interfacial Film Formation in Emulsion Systems, Journal of Colloid and Interface Science 179, 537 (1996). — p.57.

[15] W. M. de Vos, A. de Keizer, M. A. Cohen Stuart, and J. M. Kleijn, Thin polymer films as sacrificial layers for easier cleaning, Colloids and Surfaces A: Physicochemical and Engineering Aspects 358, 6 (2010). — p.57, 60.

[16] J. de Grooth, M. Dong, W. M. de Vos, and K. Nijmeijer, Building Polyzwitterion-Based Multilayers for Responsive Membranes, Langmuir 30, 5152 (2014). - p.59.

[17] T. Tumolo, L. Angnes, and M. S. Baptista, Determination of the refractive index increment $(d n / d c)$ of molecule and macromolecule solutions by surface plasmon resonance, Analytical Biochemistry 333, 273 (2004). — p.60.

[18] G. Csucs and J. J. Ramsden, Solubilization of planar bilayers with detergent, Biochimica et Biophysica Acta 1369, 304 (1998). — p.60.

[19] J. Dijt, M. A. Cohen Stuart, J. Hofman, and G. Fleer, Kinetics of polymer adsorption in stagnation point flow, Colloids and Surfaces 51, 141 (1990). - p.62.

[20] J. Dijt, M. A. Cohen Stuart, and G. Fleer, Reflectometry as a tool for adsorption studies, Advances in Colloid and Interface Science 50, 79 (1994). - p.62.

[21] W. M. de Vos, P. M. Biesheuvel, A. de Keizer, J. M. Kleijn, and M. A. Cohen Stuart, Adsorption of the Protein Bovine Serum Albumin in a Planar Poly(acrylic acid) Brush Layer As Measured by Optical Reflectometry, Langmuir 24, 6575 (2008). - p.62.

[22] M. Jiang, I. Popa, P. Maroni, and M. Borkovec, Adsorption of poly(l-lysine) on silica probed by optical reflectometry, Colloids and Surfaces A: Physicochemical and Engineering Aspects 360, 20 (2010). — p.62.

[23] M. Ishiguro and L. K. Koopal, Surfactant adsorption to soil components and soils, Advances in Colloid and Interface Science 231, 59 (2016). — p.62.

[24] D. A. Woods, J. Petkov, and C. D. Bain, Surfactant Adsorption Kinetics by Total Internal Reflection Raman Spectroscopy. 2. CTAB and Triton X-100 Mixtures on Silica, J. Phys. Chem. B 115, 7353 (2011). — p.62.

[25] K. Hu and A. J. Bard, Characterization of Adsorption of Sodium Dodecyl Sulfate on Charge-Regulated Substrates by Atomic Force Microscopy Force Measurements, Langmuir 13, 5418 (1997). — p.62.

[26] R. N. Ward, D. C. Duffy, P. B. Davies, and C. D. Bain, Sum-Frequency 
Spectroscopy of Surfactants Adsorbed at a Flat Hydrophobic Surface, J. Phys. Chem 98, 8536 (1994). — p.63.

[27] E. Tyrode, M. W. Rutland, and C. D. Bain, Adsorption of CTAB on Hydrophilic Silica Studied by Linear and Nonlinear Optical Spectroscopy, Journal of the American Chemical Society 130, 17434 (2008). — p.63.

[28] H. Tang, L. Zhao, W. Sun, Y. Hu, and H. Han, Surface characteristics and wettability enhancement of respirable sintering dust by nonionic surfactant, Colloids and Surfaces A: Physicochemical and Engineering Aspects 509, 323 (2016). - p.63.

[29] J. Rubio and J. Kitchener, The mechanism of adsorption of poly(ethylene oxide) flocculant on silica, Journal of Colloid and Interface Science 57, 132 (1976). - p.63.

[30] G. Van der Beek and M. A. Cohen Stuart, The hydrodynamic thickness of adsorbed polymer layers measured by dynamic light scattering : effects of polymer concentration and segmental binding strength, Journal de Physique 49, 1449 (1988). — p.63.

[31] K. Tajima, Radiotracer Studies on Adsorption of Surface Active Substance at Aqueous Surface. III. The Effects of Salt on the Adsorption of Sodium Dodecylsulfate, Bulletin of the Chemical Society of Japan 44, 1767 (1971). - p.64.

[32] T. D. Gurkov, D. T. Dimitrova, K. G. Marinova, C. Bilke-Crause, C. Gerber, and I. B. Ivanov, Ionic surfactants on fluid interfaces: determination of the adsorption; role of the salt and the type of the hydrophobic phase, Colloids and Surfaces A: Physicochemical and Engineering Aspects 261, 29 (2005). - p.64.

[33] N. Müller-Fischer, P. Tobler, M. Dressler, P. Fischer, and E. J. Windhab, Single bubble deformation and breakup in simple shear flow, Experiments in Fluids 45, 917 (2008). - p.68.

[34] A. K. Gupta and S. Basu, Deformation of an oil droplet on a solid substrate in simple shear flow, Chemical Engineering Science 63, 5496 (2008). p.68.

[35] A. M. Poskanzer and F. C. Goodrich, Surface viscosity of sodium dodecyl sulfate solutions with and without added dodecanol, The Journal of Physical Chemistry 79, 2122 (1975). — p.68.

[36] T. Tadros and J. Lyklema, Adsorption of potential-determining ions at the silica-aqueous electrolyte interface and the role of some cations, Journal of Electroanalytical Chemistry and Interfacial Electrochemistry 17, 267 (1968). - p.70. 



\section{CHAPTER 4}

\section{Membrane filtration of anionic surfactant stabilized emulsions: Effect of ionic strength on fouling and droplet adhesion}

Membranes hold great potential to be used for the successful treatment of oily waste water, but membrane fouling leads to substantial decreases in performance. Here we study the impact of ionic strength on membrane fouling from an emulsion stabilized by the anionic surfactant sodium dodecyl sulfonate (SDS). For this we use a unique combinatorial approach where droplet adhesion to a cellulose surface in a flow cell is compared to membrane fouling (flux decline) on a cellulose membrane. In the initial membrane fouling stages droplet adhesion dominates. While the flow cell demonstrates a high number of droplets adhering especially at high ionic strengths $(100 \mathrm{mM} \mathrm{NaCl})$, the strongest flux decline is observed at intermediate $(10 \mathrm{mM} \mathrm{NaCl})$ ionic strength. This suggests that the fouling mechanism must be different, with pore blocking expecting to dominate at intermediate ionic strength. At the later fouling stages the porosity of the cake layer plays a key role in the flux reduction. At low ionic strength, oil droplets repel each other strongly and an open, more permeable, cake layer is formed. However at higher ionic strength, a screening of charge interactions leads to a lower porosity and thereby a lower flux. This leads to a clear trend: with a higher ionic strength a higher flux decline is observed. Flux recovery is high at all ionic strengths, in line with the observation in the flow cell that oil droplets can easily be sheared of a cellulose surface at all ionic strengths. This work thus highlights the critical effect of the ionic strength on membrane fouling by anionically stabilized emulsions. Moreover it shows how the use of an optical flow cell can provide key insights to help explain observations in more standard membrane fouling experiments. 


\subsection{Introduction}

Membrane filtration of oil-in-water emulsions is a cost-effective and selective way of separating water from oil. This is especially the case for stable emulsions, with droplets $<10 \mu \mathrm{m}$, which cannot be separated efficiently by for instance flotation or other gravity-driven processes [1-5]. Membranes, however, suffer from fouling, which causes a decline in clean water production and an increase in energy consumption.

Membrane fouling has been studied extensively on a macroscopic level, mainly by correlating the flux decline of a filtration process with models [6-9]. The more microscopic interactions between particles or, in this case, oil droplets, and the membrane surface are harder to study in-situ. In the case of oil droplets on a membrane, the interaction between the oil droplets and the membrane surface will determine much of the fouling behavior. Droplets can deform, coalesce and spread out on the membrane surface. In contrast to hard particles, which form a dense but permeable cake layer on top of the membrane surface, oil droplets can also form a film of oil on the surface, with an even more detrimental effect on the flux [5]. Direct observation of oil droplets on a membrane surface is therefore an important step towards better understanding membrane fouling by oil-in-water emulsions. In addition, understanding the interactions between oil droplets and the membrane surface is a first step towards better tailoring membrane filtration processes to their feed stream in the future.

Many different optical and spectroscopic techniques have been used to investigate the process of membrane fouling [10]. Most of these techniques can be applied only in quite specific situations or systems, or require elaborate optical devices. Altmann and Rippeger used a laser triangulometer to measure the layer thickness of either diatomaceous earth or silica particles on a membrane during crossflow filtration [11]. Based on their model, they concluded that smaller particles attach easier to the fouling layer than larger particles or aggregates, and that the latter are the only particles that can be detached from the layer once attached. They also concluded that by changing the operating parameters of the filtration process, the layer characteristics can be changed. Li et al. used direct observation through the membrane (DOTM) to study the deposition of either yeast or latex beads on the membrane surface [12]. The membrane in this case was an anodized aluminum membrane with see-through pores, which allowed them to place the microscope on the permeate size. They determined that the particle deposition on the membrane was largely dependent on a critical flux, which depends on the crossflow velocity. In addition, they discovered that initial deposition of particles causes more particles to deposit on the membrane. Mores et al. performed direct visual observation of yeast deposition on membranes in a specialized membrane cell and with colored yeast on a cellulose acetate and an 
anodized alumina membrane [13]. By mounting the microscope on the feed side of the membrane, they could observe the yeast particles during filtration, but also during and after a backflush routine. Vanysacker et al. studied biofouling in a high throughput crossflow membrane filtration system by placing it in a confocal laser scanning microscope system [14]. They combined this technique with SEM and optical microscopy to study the formation of a biofilm. By running multiple experiments simultaneously in this setup, they yielded reproducible results for statistical analysis. Fux and Ramon studied the behavior of surfactant-stabilized oil droplets on a membrane surface in the presence of a transmembrane flow [15]. By studying the deformation of individual oil droplets on the membrane surface using a confocal microscope, they discovered that the transmembrane flow and the force exerted on the droplet determine the adhesion to the surface. To properly model this behavior, they proposed a modified capillary number. At higher forces and thus higher deformation, droplets are harder to remove, in some cases the adhesion is irreversible. Di et al. developed a microfluidic system in which a polyethersulfone membrane was mounted and subsequently fouled by latex microbeads [16]. The whole system was placed in a confocal microscope, enabling them to acquire 3D time-sequenced images of the fouling layer. They observed that at increasing ionic strength, less latex particles deposited, but they formed more aggregates than at lower ionic strengths [17].

In this chapter, we investigate the correlation between droplet adhesion on a model surface and fouling during crossflow membrane filtration. A recently developed flow-cell approach allows us to directly observe droplet adhesion to a model surface. The strength with which droplets are adhered to a surface can give an indication of the fouling potential of the oil droplets in an emulsion. Because the technique is relatively easy and fast, multiple parameters can be taken into account. In the case of produced water, which is a complex mixture of different components, this can prove useful to study the influence on fouling of each of those components. Membrane fouling by produced water, which fouls much more severe than other (less complex) oil-in-water emulsions, is still poorly studied, and this technique can attribute to extending our knowledge on the subject [5]. For produced water, where a complex emulsion is often stabilized by charged surfactants, especially the ionic strength of the solution is expected to be key to oil droplet adhesion at the interface and subsequent cake layer build-up. Indeed in a recent study, the strength of adhesion of surfactant stabilized oil droplets was found to be strongly affected by the ionic strength, both on a hydrophobic and charged hydrophilic surface [18].

Although the flow cell has no permeation interface, the membrane and model surface are chemically identical (cellulose). The emulsion used for both flow cell and membrane filtration is also identical, with well defined characteristics. We directly observe the adhesion between the oil droplets in feed stream and the cellulose surface in the flow cell. From this, we know how much droplets stick to 
the surface, but by increasing the shear force we can also determine how strong the droplet-surface interactions are. In the membrane filtration experiments we observe the flux decline caused by fouling. The kinetics of this fouling can tell us how the fouling is formed and what the characteristics of the layer are.

\subsection{Materials and methods}

For preparation of the emulsions and flush solutions, we used DI water, sodium dodecyl sulfate (SDS, Sigma Aldrich 75746), n-hexadecane (Merck Schuchardt OHG 820633), and sodium chloride ( $\mathrm{NaCl}$, Boom 51275). For the glass surface modification we used trichloromethylsilane (Sigma Aldrich M85301) and trimethylsilylcellulose (TMSC, Artecs bv Hengelo), prepared via the protocol in [19], but without addition of the catalyst. The membranes we used were regenerated cellulose membranes on a PET support with a molecular weight cutoff of 500kDa (Microdyn Nadir UC500). All chemicals were used without further purification steps.

\subsubsection{Emulsion preparation}

To ensure all emulsions have the same characteristics, a stock emulsion was prepared under standard conditions, which was then diluted with carefully chosen concentrations to obtain the desired oil, salt and surfactant concentration for the membrane experiments and the flow cell. The stock emulsions were prepared by dissolving $463 \mathrm{mg} / \mathrm{L}$ SDS in 1 L of DI water in a Duran ${ }^{\circledR}$ bottle (Duran 21801545 ) by mixing with a dispersing mixer (IKA ${ }^{\circledR}$ T25 digital Ultra-Turrax with S25N 18G element) for 2 minutes at $14000 \mathrm{rpm}$. Then, $2 \mathrm{~g}$ of n-hexadecane was injected near the mixer head and mixed for 10 minutes at $14000 \mathrm{rpm}$. For the membrane filtration experiments, the stock emulsion was diluted to make up $20 \mathrm{~L}$ of emulsion with $100 \mathrm{mg} / \mathrm{L}$ hexadecane, $463 \mathrm{mg} / \mathrm{L}$ SDS and 1, 10 or 100 $\mathrm{mM} \mathrm{NaCl}$, which was then stored in a glass $20 \mathrm{~L}$ bottle.

For the flow cell, the stock emulsion was diluted to contain $1 \mathrm{~g} / \mathrm{L}$ hexadecane, $463 \mathrm{mg} / \mathrm{L}$ SDS and 1, 10 or $100 \mathrm{mM} \mathrm{NaCl}$. The concentration of hexadecane in the emulsions for the flow cell was chosen higher than the concentration of oil in the membrane filtration experiments to ensure enough droplets would be visible in the flow cell. Surfactant solutions used for rinsing and for applying shear were prepared the same as the emulsions, but without hexadecane. The concentrations of surfactant and $\mathrm{NaCl}$ were identical to the emulsion used in each experiment. After preparation, the surfactant solutions were degassed under vacuum and ultrasonic sonication for 15 minutes, followed by 15 minutes of only vacuum. The emulsions were not degassed, as this was not to be found necessary. Furthermore, 
surfactant solutions were also used for all contact angle and interfacial tension measurements.

\subsubsection{Glass preparation for flow cell}

Microscope glass slides (VWR 631-1552) were washed with DI water and ethanol, dried in an oven and placed in a desiccator with $0.2 \mathrm{~mL}$ of trichloromethylsilane in a glass bottle. The glass slides were left overnight so the trichloromethylsilane could deposit on the glass slides to make them hydrophobic. A $20 \mathrm{mg} / \mathrm{L}$ solution of TMSC in chloroform was prepared by stirring overnight. To remove any solids, the solution was filtered over a steel filter with $15 \mu \mathrm{m}$ pores. The TMSC was spincoated on the hydrophobic glass slides by spinning at $2500 \mathrm{rpm}$ for 20 seconds. The TMSC was then regenerated to cellulose by exposing the glass slides to a hydrochloric acid vapor by placing them in a desiccator above $37 \%$ hydrochloric acid for 15 minutes [19]. After regeneration, the layer thickness was determined to be $115 \pm 2 \mathrm{~nm}$ with a roughness of $30 \pm 2 \mathrm{~nm}$ by ellipsometry.

\subsubsection{Contact angle and interfacial tension measurements}

Measurements were performed on a contact angle and contour analysis instrument (Dataphysics OCA 35). The contact angle measurements were performed in captive bubble mode, where a droplet of hexadecane is captured under a cellulose coated glass slide or a piece of membrane in the aqueous solution with surfactant and salt. The interfacial tension measurements were performed with the pendant droplet technique, where a droplet of aqueous solution with surfactant and salt is suspended in hexadecane. Image analysis of the droplet shapes from both contact angle and interfacial tension measurements was performed with the software provided with the measuring instrument, taking into account the density change of the water upon addition of $\mathrm{NaCl}$.

\subsubsection{Flow cell setup}

To measure the adhesion of oil droplets in the emulsion to the model cellulose surface, a flow cell setup with two parallel plates was used. This flow cell has been used before in the experiments of Dresselhuis, but in their experiments no shear force was applied [20]. A pulseless pump (Micropump serie 200, Axel Johnson International, Almere, The Netherlands) feeds the emulsion and flow solution into the flow chamber, which was placed under a microscope (Figure 4.1). By varying the distance between the plates of the flow cell and the flow of the pump, the hydrodynamic shear-induced force $F$ exerted on the oil droplets in the flow cell is increased and can be calculated as [21, 22]

$$
F=10.2 \pi R^{2} \tau(\mathrm{N}) \quad \tau=\frac{6 \eta Q}{r h^{2}}\left(\mathrm{~N} / \mathrm{m}^{2}\right)
$$




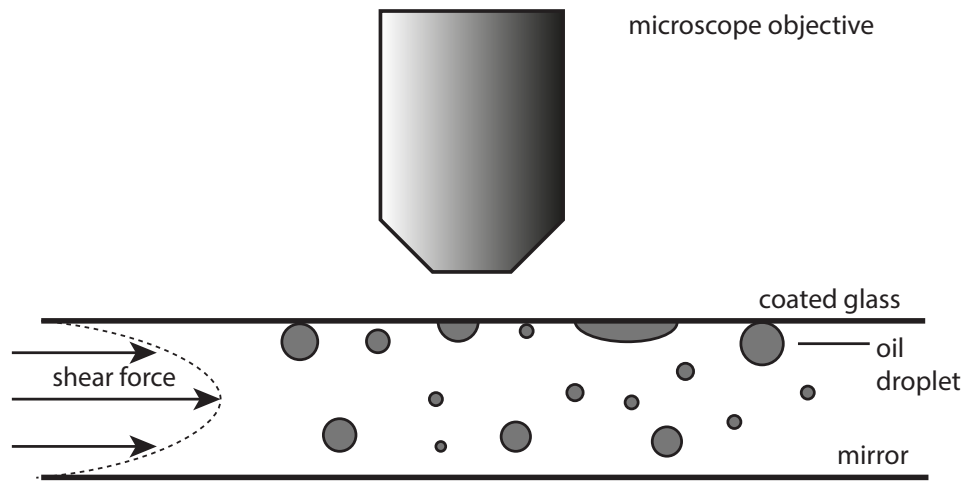

Figure 4.1: Schematic representation of the flow cell setup under the microscope. The distance between the mirror and the replaceable upper glass slide can be changed. The shear force is obtained by pumping a solution through the flow cell channel.

where $R$ is the droplet diameter, $\tau$ is the shear stress at the glass surface, $\eta$ is the viscosity of the continuous phase, $Q$ is the flow rate of the pump, which varied between 6 and $36 \mathrm{l} / \mathrm{h} ; r$ is the channel width and $h$ is the channel height, which varied between 0.7 and $2.3 \mathrm{~mm}$ [21]. The flow cell was placed under a home built microscope, consisting of a $470 \mathrm{~nm}$ LED light source, polkadot beam splitter (Thorlabs BSW10R), 10x objective (Olympus, 10x/0.25), 2x magnification tube lens (Thorlabs ITL200) and a high speed camera (PointGrey GS2-GE-20S4M-C).

\subsubsection{Flow cell operation}

Before each experiment, the setup was cleaned by flushing with a $2 \%$ ethanol solution at $45^{\circ} \mathrm{C}$ for 15 minutes. After this, the system was flushed with DI water at room temperature for 15 minutes. A newly coated glass slide was placed in the flow cell and the system was filled with degassed surfactant solution. Then $5 \mathrm{~mL}$ of emulsion was injected in the flow cell, taking care not to inject any air bubbles, and left stagnant for 30 minutes to let the droplets float up against the glass. After 30 minutes, the cell was flushed with surfactant solution at the lowest pump setting to remove all oil droplets that did not adhere to the glass surface. In case air droplets were observed, the experiment was aborted. For each step in the experiment, the channel depth of the flow cell was decreased and the pump speed increased in steps to increase the shear force on the droplets. After each force increment an image of the droplets at the glass surface was captured. 


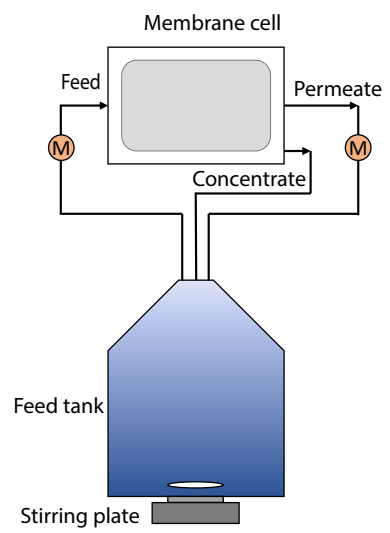

Figure 4.2: Schematic representation of the membrane filtration setup. The feed, concentrate and permeate flows are all regulated by the Con-Vergence OSMO setup, the feed and permeate mass flow are measured by mass flow meters (M).

\subsubsection{Membrane filtration}

The membrane filtration experiments were performed using an OSMO-inspector crossflow membrane filtration system built by Con-Vergence (Figure 4.2). The membrane was mounted in a flat sheet crossflow membrane cell with an effective surface of $240 \mathrm{~cm}^{2}$, using a feed spacer with a thickness of $700 \mu \mathrm{m}$, a filament angle of $90^{\circ}$ and a maze size of $2.5 \times 2.5 \mathrm{~mm}$. The volume and density of the feed and permeate streams were measured by Bronckhorst M15 mass flow meters. The $20 \mathrm{~L}$ glass feed bottle was constantly stirred to prevent creaming of the feed. Both concentrate and permeate were recycled to the feed bottle to ensure a consistent feed quality. Before mounting the membrane, it was soaked in DI water overnight to remove production chemicals and glycerine from the membrane. Then, the clean water flux was measured under experimental conditions because the membrane sheets provided were not uniform (Appendix 4.A). A membrane filtration experiment consisted of filtering for 3 hours at a TMP of 1 bar and a flow rate of $48 \mathrm{~kg} / \mathrm{h}$, which corresponds to a crossflow velocity of $0.2 \mathrm{~m} / \mathrm{s}$. The permeate flux was constantly monitored. To clean the membrane, the cell was flushed with DI water for $1 \mathrm{~h}$ without applied pressure, then a backflush with DI water of 3 minutes at 0.2 bar, and then another flush. After the cleaning, the clean water flux was measured again to determine the flux recovery.

The amount of oil in the permeate was determined by liquid-liquid extraction with hexane followed by HPLC. The extraction protocol can be found in Appendix 4.B. 


\subsection{Results and discussion}

This results and discussion section is split into three distinct parts. First, emulsion characteristics and emulsion surface interactions are discussed from measurements on the the contact angle of oil droplets in a surfactant solution with the cellulose surfaces and the interfacial tension of oil in the surfactant solution. Secondly, a study of oil droplets attachment to the cellulose surface in the flow cell will give us an indication of the strength of adhesion between droplets and the model surface, which will be used in the third part to help explain fouling observed in an actual membrane filtration experiment.

\subsubsection{Contact angle measurements}

The contact angle measurements were performed in captive bubble mode, in which a droplet of oil is injected under the surface of interest. In this configuration, a large contact angle indicates a hydrophilic surface and a small contact angle a hydrophobic surface. The measured contact angles of the cellulose coated glass model surfaces and the membrane surfaces for 1, 10 and $100 \mathrm{mM} \mathrm{NaCl}$ are shown in Figure 4.3. On the membrane, the contact angle is $150 \pm 1$ for $1 \mathrm{mM}$ $\mathrm{NaCl}, 148 \pm 1$ for $10 \mathrm{mM} \mathrm{NaCl}$ and $141 \pm 4$ for $100 \mathrm{mM} \mathrm{NaCl}$. On the glass, the contact angles are $155 \pm 3,154 \pm 1$ and $148 \pm 3$ for 1,10 and $100 \mathrm{mM}$ respectively. All measured contact angles are above $140^{\circ}$, which indicates the surfaces are all hydrophilic [23]. This is to be expected, because cellulose has hydrophilic $\mathrm{OH}$ groups. Even after 10 minutes of contact time with the surface, the droplet displayed a stable contact angle. The contact angles measured on the membrane is in all cases about 5 degrees lower than the contact angles measured on the cellulose model surface. This might indicate that the membrane surface is more hydrophobic, but is more likely due to higher surface roughness and air pockets trapped in the membrane pores [24]. At increasing ionic strength, there seems to be a very small decrease of the contact angle on both surfaces, indicating a tiny increase in hydrophobic interactions. The cellulose surface will be slightly negatively charged due to dissociation of surface $\mathrm{OH}$ groups, while the droplets are also negatively charged because of the anionic surfactant. At higher salt concentrations the repulsion between droplet and surface is decreasing, allowing a small decrease in contact angle.

\subsubsection{Interfacial tension measurements}

The interfacial tension was measured by suspending an aqueous droplet in hexadecane and using the Laplace equation for contour analysis. The results are shown in Figure 4.4. The interfacial tension of the droplets goes down with increasing ionic strength, because the ions screen the charge repulsion between the SDS headgroups. This allows more SDS to adsorb on the interface, lowering the 


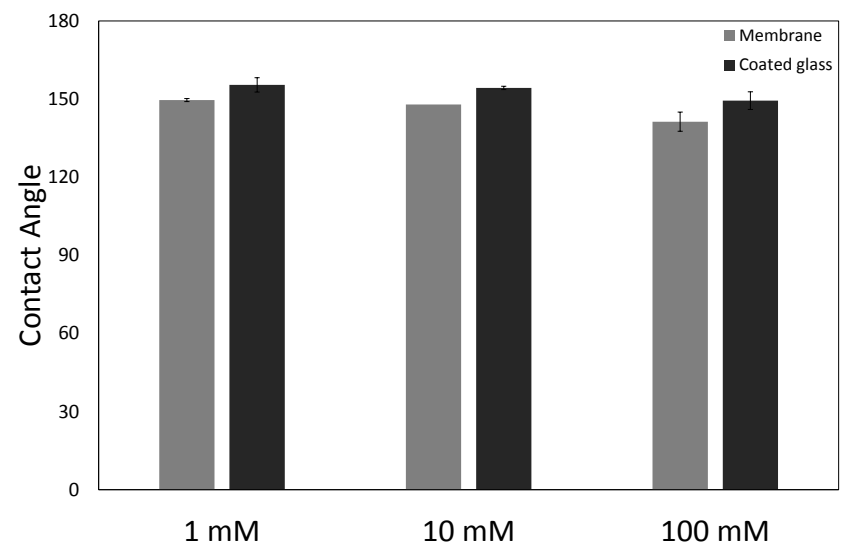

Figure 4.3: Contact angles of SDS stabilized hexadecane droplets on cellulose coated glass and cellulose based UF membranes as measured with the captive bubble method with 1, 10 and $100 \mathrm{mM} \mathrm{NaCl}$. Error bars represent the standard deviation after duplicates.

interfacial tension. By using the Gibbs adsorption equation, $\Gamma=-\frac{C}{R T} \frac{d \gamma}{d C}$, we can make an estimate of the amount of surfactant adsorbed to the surface. By fitting the interfacial tension data with the Szyszkowski-Langmuir adsorption isotherm and inserting the obtained $\frac{d \gamma}{d C}$ into the Gibbs-equation, we find $0.5 \mu \mathrm{mol} / \mathrm{m}^{2}$ for 1 $\mathrm{mM} \mathrm{NaCl}, 1.5 \mu \mathrm{mol} / \mathrm{m}^{2}$ for $10 \mathrm{mM} \mathrm{NaCl}$ and $2.0 \mu \mathrm{mol} / \mathrm{m}^{2}$ for $100 \mathrm{mM} \mathrm{NaCl}$. An increase in surfactant on the surface gives an increasing surface charge, but since the salt concentration in the aqueous phase is also higher, electrostatic screening increases at the same time. Overall, this means the electrostatic repulsion between droplets and droplets and the model surface goes down with increasing ionic strength.

\subsubsection{Flow cell}

As shown in Chapter 3 and [18], the amount of droplets attached to the surface of the flow cell is an indication of the adhesion force between droplets and surface. In this chapter, we coated the glass surface of the flow cell with a thin cellulose layer. In Figure 4.5, microscopic images are shown from the flow cell setup. As can been seen, the cellulose layer is optically transparent and flat. For 1 and $10 \mathrm{mM}$ of $\mathrm{NaCl}$, not many droplets stick to the cellulose surface, which can be observed all over the flow cell window. At $100 \mathrm{mM} \mathrm{NaCl}$, the amount of adsorbed droplets is significantly higher. 


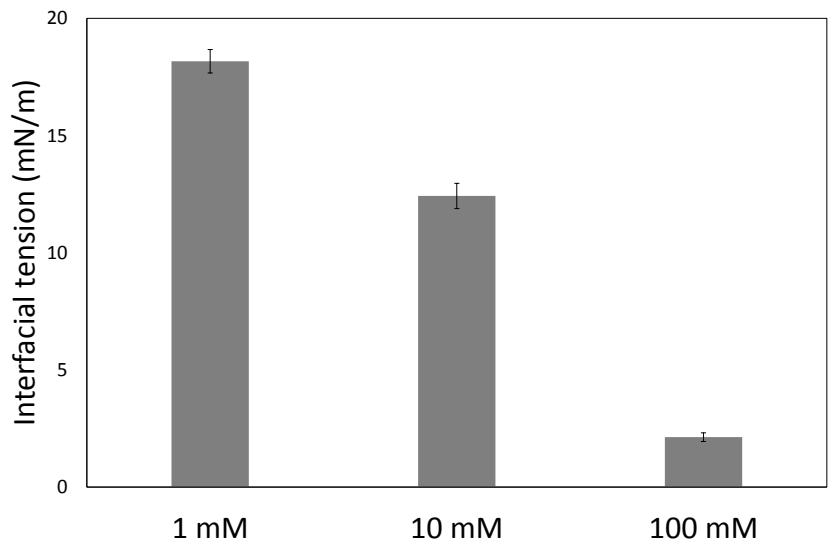

Figure 4.4: Interfacial tension of the oil-water interface in presence of SDS for 1,10 and $100 \mathrm{mM}$ of $\mathrm{NaCl}$ and $463 \mathrm{mg} / \mathrm{L}$ SDS. Error bars represent the standard deviation after duplicates.

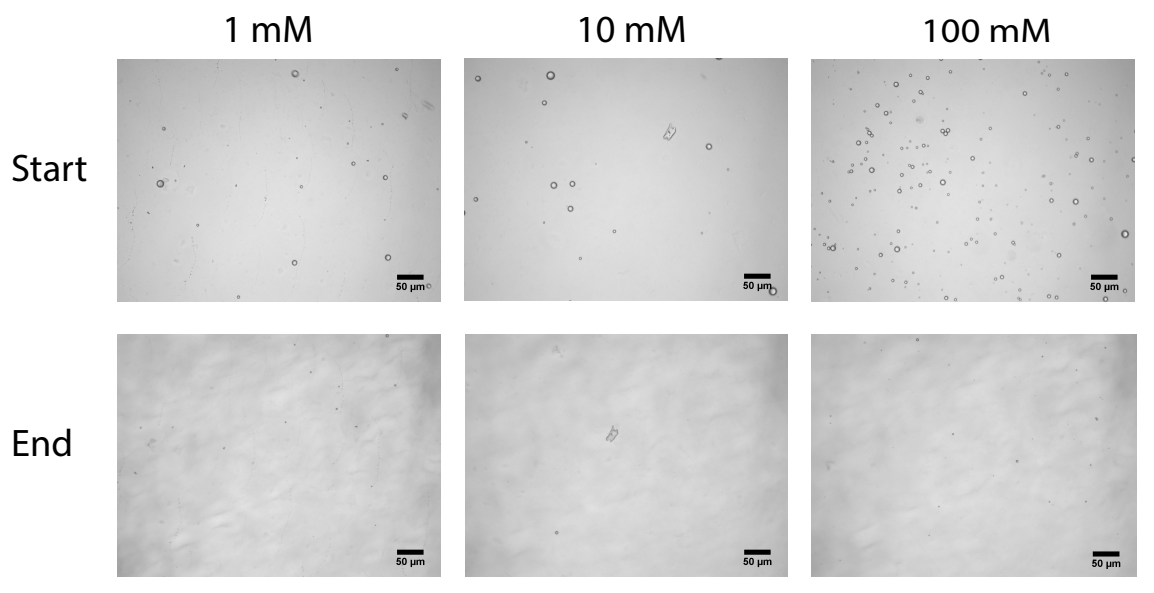

Figure 4.5: Images of the cellulose coated glass with attached droplets in the flow cell at 1, 10 and $100 \mathrm{mM} \mathrm{NaCl}$ and $463 \mathrm{mg} / \mathrm{L}$ SDS. The Start images were taken after flushing of the flow cell at the lowest possible speed, the End images were taken after the maximum shear force was applied. 
The fraction of droplets attached to the surface as a function of shear force is plotted in Figure 4.6. The fraction of droplets adhered tot the surface with applied shear force is comparable for the three different salt concentrations. This means that the force required to wash away droplets from the surface does not change significantly with an increasing salt concentration, in line with the rather constant contact angle of these droplets (Figure 4.3). These observations are however quite different from the effect of ionic strength observed for the adhesion of SDS stabilized emulsion droplets to a strongly negative hydrophilic surface (glass) and a hydrophobic surface (Chapter 3). For both surfaces a higher ionic strength was found to lead to a stronger adhesion. For these surfaces, charge, and thus the ionic strength plays a much more significant role. A glass surface is strongly negatively charged (at the studied $\mathrm{pH}$ ), while also the hydrophobic surface obtains a strong negative charge due to the adsorption of surfactant. At higher salt concentration, charge repulsion between the negatively charged droplet and the negatively charged surfaces is screened, allowing stronger adhesion forces. For cellulose, only weakly charged and too hydrophilic to facilitate surfactant adsorption, this effect is not present and a relatively constant adhesion force is observed. The force of adhesion for the three different salt concentration is thus quite constant for our weakly negative hydrophilic surface. When we look at the absolute number of droplets adhered to the model surface, however, we do observe a difference (Figure 4.7). At a salt concentration of 1 and $10 \mathrm{mM}$, only a few oil droplets adhere to the surface (see also Figure 4.5). At a salt concentration of $100 \mathrm{mM}$ however, significantly more droplets adhere to the surface. At the end of the experiment, at maximum shear force, the largest number of droplets adheres to the surface at the highest salt concentration. The initial adhesion phase, when the fluid in the cell is stagnant, determines the amount of droplets that adheres to the surface. At 1 and $10 \mathrm{mM} \mathrm{NaCl}$, the repulsive force between the slightly negatively charged cellulose surface and the negatively charged oil droplets is just sufficient to act as a kinetic barrier, decreasing the rate at which droplets adhere. At $100 \mathrm{mM}$ however, due to electrostatic screening the repulsion between the droplets and the surface is slightly less, allowing the droplets to approach the surface more easily. This increases the chance for adhesion, and therefore the number of droplets that stick to the surface.

\subsubsection{Membrane filtration}

\section{Flux decline}

An emulsion with $100 \mathrm{ppm}$ oil, $463 \mathrm{mg} / \mathrm{L}$ SDS and 1, 10 or $100 \mathrm{mM} \mathrm{NaCl}$ was filtered over a UF regenerated cellulose membrane for 3 hours. The crossflow velocity was $0.2 \mathrm{~m} / \mathrm{s}$ and the transmembrane pressure was kept constant at 1 bar. The permeate flux was measured every 10 seconds. In Figure 4.8, the 


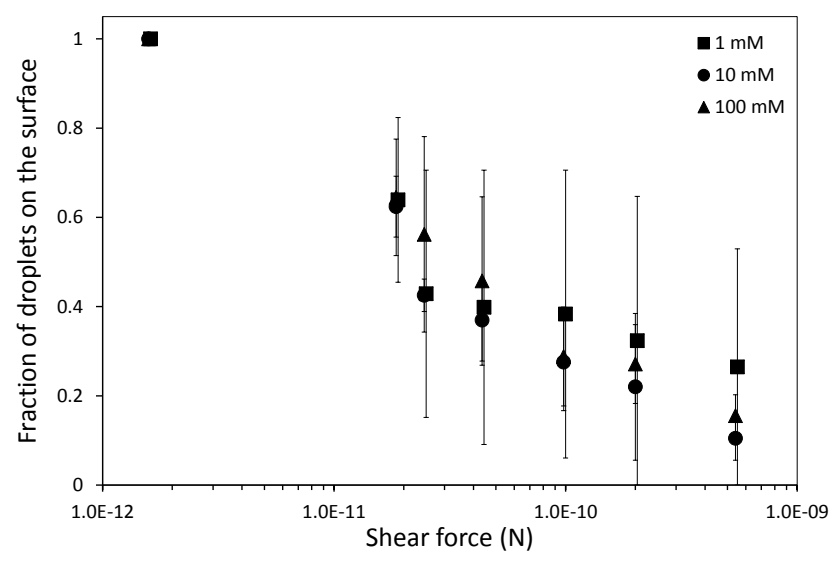

Figure 4.6: Fraction of droplets that sticks to a cellulose surface for different $\mathrm{NaCl}$ concentrations and $463 \mathrm{mg} / \mathrm{L}$ SDS. Error bars represent standard deviation after duplicates.

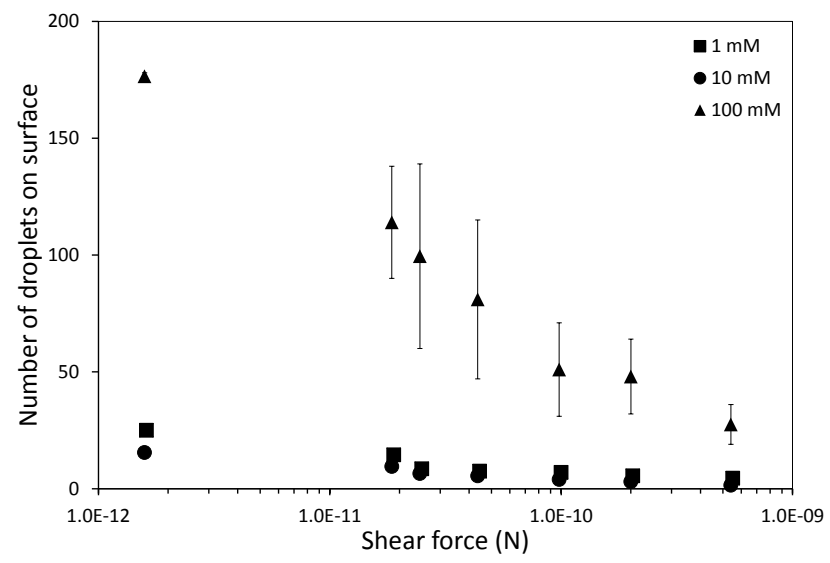

Figure 4.7: Number of droplets that sticks to a cellulose surface for different $\mathrm{NaCl}$ concentrations and $463 \mathrm{mg} / \mathrm{L}$ SDS. Error bars represent standard deviation after duplicates. 
normalized permeate flux is plotted as a function of the total permeate volume. At $1 \mathrm{mM} \mathrm{NaCl}$, the flux decline is gradual and reaches $50 \pm 3 \%$ of the initial flux at the end of the experiment. At $10 \mathrm{mM} \mathrm{NaCl}$, the initial flux decline is very steep, but after this initial stage the flux slowly declines until $37 \pm 6 \%$ at the end of the experiment. For $100 \mathrm{mM} \mathrm{NaCl}$, the flux decline is initially steep and then slows down, until at the end of the experiment the flux is $23 \pm 3 \%$ of the initial flux. These effects of ionic strength are reproducible and are also observed at a lower crossflow velocity of $0.14 \mathrm{~m} / \mathrm{s}$ (Figure 4.9 ), where the final flux decline is $40 \pm 0 \%$ for $1 \mathrm{mM}, 32 \pm 5 \%$ for $10 \mathrm{mM}$ and $22 \pm 8 \%$ for $100 \mathrm{mM}$. For the flux decline at the initial stages of filtration a strong correlation is expected with the flow cell experiments, especially regarding the initial number of droplets attached to the surface. Indeed, for 1 and $100 \mathrm{mM}$ the flow cell demonstrates a much larger degree of adsorbed droplets at the high ionic strength, and a much stronger flux decline is observed in the membrane fouling experiments. However, for $10 \mathrm{mM}$ of salt the fouling rate at the initials stages is much higher than can be expected on the basis of the amount of adhered droplets observed in the flow cell experiments. We expect that the fouling mechanism for $10 \mathrm{mM}$ of salt is different with pore blocking leading to a very rapid decrease in flux during the initial stages. Clearly, the flow cell approach provides useful insights relevant to membrane fouling, but cannot by itself explain all intricacies of fouling, as in the current flow cell design no pores are present and no permeation is taking place.

After initial droplet adhesion on the surface, the flux decline is mainly determined by droplet-droplet adhesion and the formation of a cake layer on the surface. This means that subsequent adhesion of oil droplets is mainly influenced by repulsive forces between negatively charged oil droplets. This repulsive force will also influence the characteristics of the cake layer and possibly prevent the adhesion of oil droplets to the cake layer, leading to a steady state.

The resistance of the cake layer can be given by the Kozeny Carman term:

$$
R_{c}=\frac{150 l_{c}\left(1-\varepsilon_{c}\right)^{2}}{D_{v}^{2} \varepsilon_{c}^{3}}
$$

where $l_{c}$ is the thickness of the cake layer, $\varepsilon_{c}$ the porosity of the cake layer and $D_{v}$ the effective diameter of the oil droplets. As can be seen from this equation, the resistance of the cake layer is heavily dependent on the porosity of the layer. According to Song and Elimelech, the maximum packing of a cake layer of monodisperse rigid particles arises at a porosity of 0.36 [25]. If we however assume a close cubic packing of spheres (ccp), the porosity has a mimimum of 0.26. This means that for a cake layer of monodisperse particles the maximum radius of a particle that can pass through the spaces in between the particles of radius $a$ is approximately $0.12 a$. In our case the membrane has an expected pore size of around 40-80 nm, while the open space between our large oil droplets will be in the order of 0.5 to $1 \mathrm{um}$. The cake layer thus remains very open compared 


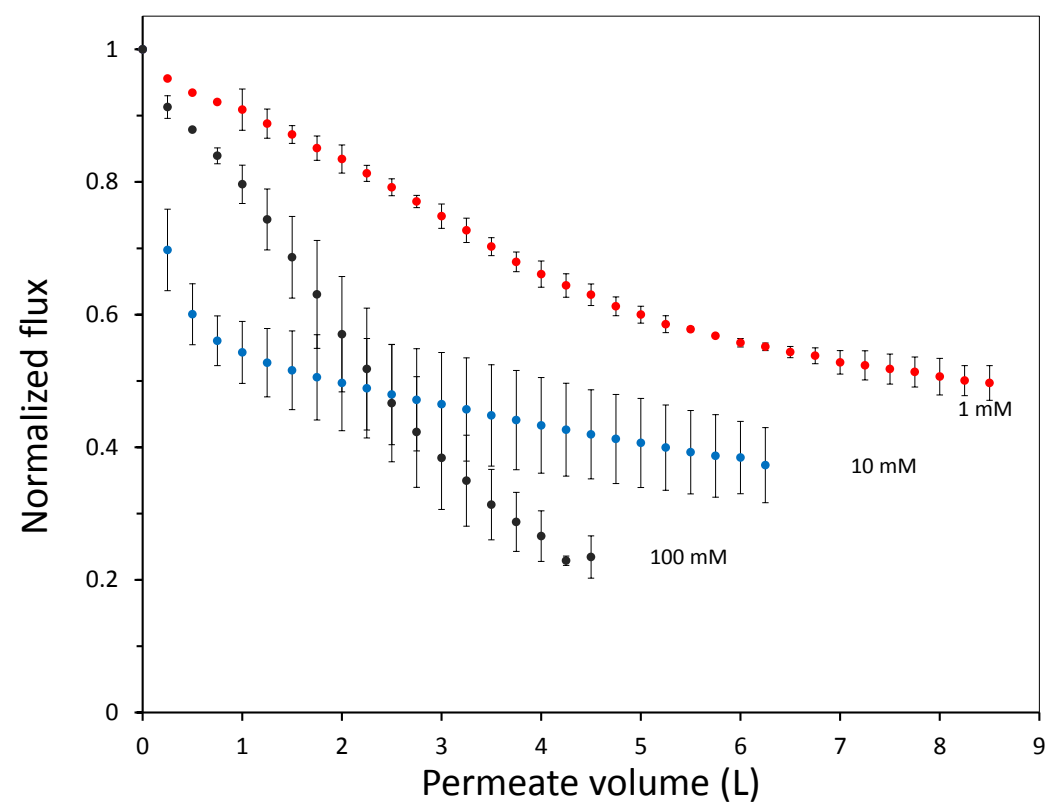

Figure 4.8: Normalized membrane flux as a function of the permeated volume for different concentrations of $\mathrm{NaCl}$ and $463 \mathrm{mg} / \mathrm{L} \mathrm{SDS} .48 \mathrm{~kg} / \mathrm{h} \mathrm{TMP}=1 \mathrm{bar}$

to the pore size of the membrane. Naturally, the porosity of the cake layer will be determined by more parameters, such as the flux through the membrane. At higher flux, we have higher shear forces, that push the droplets closer together. Still as in this work we worked at constant pressure, and thus a constant initial flux, this is not taken into account here.

For charged fouling species, the porosity of the cake layer is strongly linked to the ionic strength. At low ionic strength, the negatively charged droplets repel each other leading to a open cake layer with a relatively high flux. At increasing ionic strength the cake layer becomes denser (lower porosity), leading to a much higher resistance and thus lower fluxes. The same ionic strength effects on the cake layer porosity, and thus the extend of flux decline was recently also observed for negatively charged silica nanoparticles [26]. Clearly the ionic strength has a massive effect on the successful filtration of emulsions stabilized by anionic surfactants. A low ionic strength is preferred to avoid the formation of a dense cake layer. 


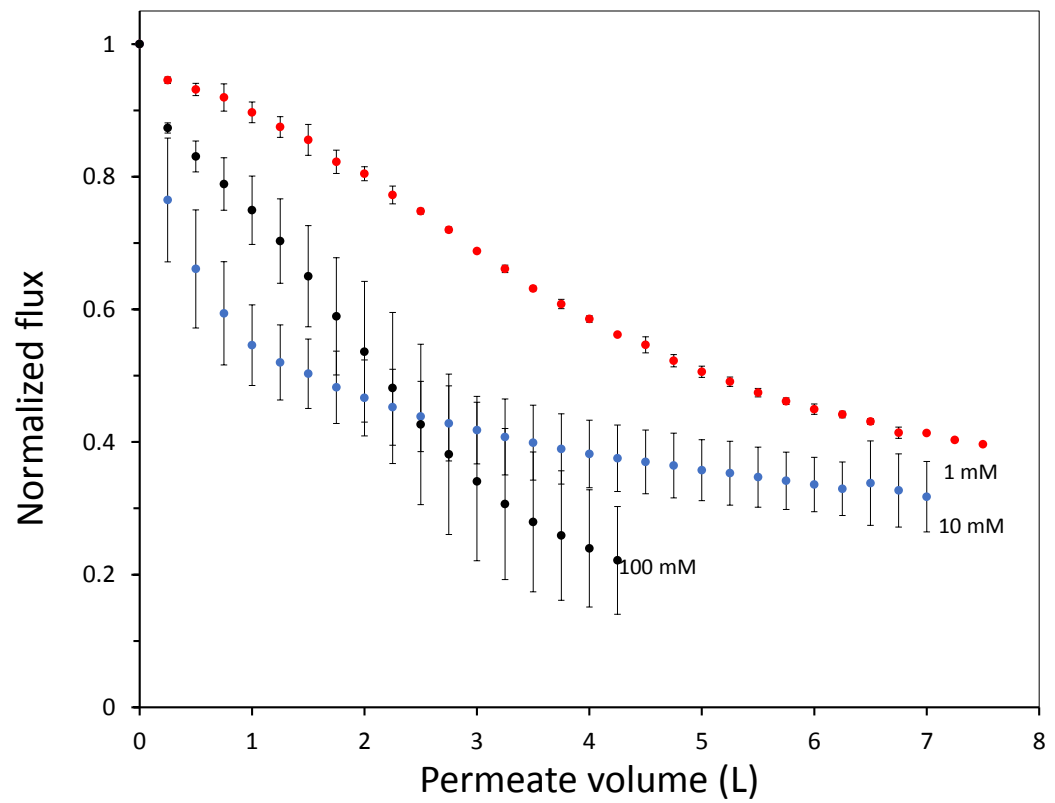

Figure 4.9: Normalized membrane flux as a function of the permeated volume for different concentrations of $\mathrm{NaCl}$ and $463 \mathrm{mg} / \mathrm{L}$ SDS. $32 \mathrm{~kg} / \mathrm{h}$ TMP $=1$ bar 


\begin{tabular}{|l|l|l|l|}
\hline Salt concentration & Flux recovery & Oil retention start & Oil retention end \\
\hline $1 \mathrm{mM}$ & $74 \%$ & $98 \pm 6 \%$ & $88 \pm 6 \%$ \\
\hline $10 \mathrm{mM}$ & $78 \%$ & $97 \pm 4 \%$ & $97 \pm 4 \%$ \\
\hline $100 \mathrm{mM}$ & $95 \%$ & $92 \pm 1 \%$ & $93 \pm 1 \%$ \\
\hline
\end{tabular}

Table 4.1: Flux recovery and oil retention at $48 \mathrm{~kg} / \mathrm{h}$ and 1 bar TMP.

\section{Flux recovery and oil retention}

In addition to the flux decline, we also determined the oil retention and the flux recovery after a forward flush and a backwash. As can be seen from Table 4.1, the flux recovery is high for all concentrations. This is in line with the flow cell experiments that indicated that the oil droplets could be easily rinsed of the cellulose surface by applying shear forces. Still, there is an effect of ionic strength visible, where at the higher salt concentration a better flux recovery is found. One possibility is that the denser cake layers formed at higher ionic strength are easier to remove as a whole, while a more open cake layer is just partly removed [11]. Another possibility is that there is a more kinetic origin. When flushed with water, the bulk surfactant concentration drops and surfactant desorbs from the interface of the emulsion droplets. The rinsing step could thus also have a destabilizing effect on the emulsion droplets. However, at high ionic strength much more surfactant molecules are adsorbed to the droplet interface (see paragraph 4.3.2), keeping the droplets stable for longer, possibly allowing a more complete droplet removal from the surface. This could be studied by follow-up experiments in which we flush with a surfactant solution instead of water.

For all salt concentrations, the oil retention is around $90 \%$ and does not change significantly during the experiment. As discussed in section 4.3.4, this suggests the cake layer is indeed an ineffective filtration layer, as the rejection does not go up over time, in contrast to observations made on silica nanoparticles [26]. Most likely only the smallest droplets in the emulsion pass through the largest pores of the membrane. The theoretical critical pressure for an oil droplet to pass through a membrane pore in the absence of crossflow is:

$$
P_{\text {crit }}=\frac{\gamma O_{p} \cos \theta}{A_{p}} \text { (bar) }
$$

where $\gamma$ is the interfacial tension between the oil and the aqueous phase, $O_{p}$ the circumference of the pore, $\theta$ the contact angle of the droplet on the surface and $A_{p}$ the surface area of the membrane pore. For membrane pores of $60 \mathrm{~nm}$, the critical pressure at the measured interfacial tensions and contact angles is predicted to be 10.5 bar for $1 \mathrm{mM} \mathrm{NaCl}, 7.0$ bar for $10 \mathrm{mM} \mathrm{NaCl}$ and 1.1 bar 
for $100 \mathrm{mM} \mathrm{NaCl}$. This means that at 1 and $10 \mathrm{mM} \mathrm{NaCl}$ droplets will not be pushed through the membrane. At $100 \mathrm{mM}$ we expect to be close to the critical pressure, but clearly the oil retention is still quite high, indicating that we have not gone over the critical pressure.

\subsection{Conclusion}

In this work we have used a unique combinatorial approach to study membrane fouling by surfactant stabilized oil droplets at different ionic strengths. We do not only study fouling by looking at indirect measurements, such as flux decline of the membrane and oil permeation, but also more directly by observing oil droplet adhesion on a chemically identical surface using a flow cell approach. On a weakly negative cellulose surface the force of adhesion between the surface and SDS stabilized oil droplets is found to be independent on the ionic strength. The low degree of charge, and thus low charge repulsion between surface and droplet means that the addition of ions has no significant effect on the strength of adhesion. In all cases, the attached droplets can nearly completely be removed from the cellulose surface using shear forces. Still the number of droplets that adhere to the surface before applying shear is clearly affected by the ionic strength, with many more droplets adhering especially at the high ionic strength of $100 \mathrm{mM}$ $\mathrm{NaCl}$. The weak negative charge on the surface does seem to provide a kinetic barrier that slows down droplet adhesion, but this effect disappears at higher ionic strength leading to many more adhered droplets. Membrane fouling on cellulose membranes was subsequently studied over time-scales of a few hours. Here we can distinguish two regimes, initially the rate of flux decline is coupled to droplets adhering to the membrane surface, while for longer times the build up of a cake layer will dominate the flux decline. At the start of the experiment, the flux decline is higher at $100 \mathrm{mM}$ than at $1 \mathrm{mM}$, which can be coupled to the higher droplet adhesion expected at high salt concentration on the basis of the flow-cell results. However, at $10 \mathrm{mM}$ the flux decline is even stronger than for $100 \mathrm{mM}$, indicating that at $10 \mathrm{mM}$ another fouling mechanism is occurring, most likely pore blocking. For the flux decline at the later stages of the experiment, there is a clear trend, with a greater flux decline at increasing ionic strength. The porosity of the cake layer plays a key role in the flux reduction. At low ionic strength, oil droplets repel each other strongly and an open, more permeable, cake layer is formed. However at higher ionic strength, a screening of charge interactions leads to a lower porosity and thereby a lower flux. Flux recovery after a forward flush and backwash is high at all ionic strengths, in line with the flow cell observation that droplets can easily be sheared off. The flux recovery is highest at high ionic strength, possibly due to the more compact cake layer, or due to the much higher amount of surfactant molecules at the interface of the oil droplets. 
Overall this work highlights the key role that ionic strength plays in the fouling of membranes by emulsions stabilized with an anionic surfactant. Moreover the work demonstrates the potential of our combinatorial approach, where insights from a flow-cell, where droplets adhesion can be directly observed, are combined with standard membrane fouling experiments. While the flow cell approach will not show all intricacies of membrane fouling (no pores, no permeation), it provides valuable insights that help in the interpretation of the more indirect flux decline data. 


\section{A Clean water fluxes membrane sheets}

Clean water fluxes for the membrane sheets used in the membrane filtration experiments.

\begin{tabular}{|l|l|l|}
\hline $\mathrm{NaCl}$ concentration & Experiment $1\left(\mathrm{~L} / \mathrm{m}^{2} \mathrm{~h}\right)$ & Experiment $2\left(\mathrm{~L} / \mathrm{m}^{2} \mathrm{~h}\right)$ \\
\hline $1 \mathrm{mM}$ & 251 & 209 \\
\hline $10 \mathrm{mM}$ & 227 & 232 \\
\hline $100 \mathrm{mM}$ & 174 & 179 \\
\hline
\end{tabular}

Table 4.2: Flux recovery and oil retention at $48 \mathrm{~kg} / \mathrm{h}$ and 1 bar TMP.

\section{B Extraction protocol permeate analysis}

\section{Materials}

- Separating funnel, glass, $50 \mathrm{~mL}$, with stopper

- Collection bottle, glass, 10-20 mL, with screw cap

- Beaker, glass, $50 \mathrm{~mL}$

- Funnel, glass

- Folding filters, $110 \mathrm{~mm}, 595$

- Custom made funnel rack, polypropylene

- LC/GC vials, amber glass, $1.5 \mathrm{~mL}$, with screw cap

- Multipette, Eppendorf

- Multipette tips, $25 \mathrm{~mL}$, with adapter

- Pipette, Eppendorf, $10 \mathrm{~mL}$ and $5000 \mu \mathrm{L}$

- Pipette tips, $10 \mathrm{~mL}$ and $5000 \mu \mathrm{L}$

\section{Chemicals}

- n-Hexane

- Pentadecane (C15) stock solution, 996 ppm in hexane

- Milli-Q water

- Silica 


\section{Procedure}

1. Rinse as many separating funnels as needed with n-hexane. Collect the waste in waste category 3 (organic chemicals).

2. Place the separating funnels in the custom made funnel rack and mark the funnels.

3. Pipette $5 \mathrm{~mL}$ of sample in a separating funnel. Add $1 \mathrm{~mL}$ of C15 stock solution using a pipette and homogenize through gentle mixing. Then add $4 \mathrm{~mL}$ of MQ-water and homogenize again.

4. Attach a tip to the Multipette using the adapter and fill the tip with nhexane. Set the dispensing volume to $4 \mathrm{~mL}$ using the numbered dial (setting number 8). Dispense the first amount into the waste or back into the $\mathrm{n}$ hexane.

5. Dispense $4 \mathrm{~mL}$ in each separating funnel and close the funnels using the stopper.

6. Invert the stoppered funnel and shake for approximately 5-10 seconds. While in inverted position, slowly open the valve of the funnel to release excess pressure. Close the valve after venting.

7. Repeat step 6 another two times.

8. Place the funnel upright in the rack and leave for a few minutes, allowing phase separation to occur. Foam may be present on the top layer but this will not harm the result in the end.

9. Upon completion of phase separation, place a marked clean glass beaker under each funnel and collect the lower (aqueous) liquid phase by slowly opening the valve of the funnel.

10. Collect the remaining extract - including the foam - in a marked bottle and close the bottle.

11. Transfer the collected aqueous phase from the glass beaker to the separating funnel, add $3 \mathrm{~mL}$ (dial setting number 6 ) of n-hexane and close the funnel using the stopper. Repeat steps 6 to 10 using the previously used glassware.

12. Repeat step 11 once more to complete the extraction.

13. Put the used separating funnels and beakers aside for cleaning.

14. Fold a paper filter and place in a funnel. Fill the filter with silica. Repeat as needed for all samples. 
15. Place a clean marked bottle under each funnel and gently pour the extract over the silica filter to remove any polar contaminants. Close the bottle upon completion of the filtration.

16. Transfer approximately $1000-1500 \mu \mathrm{L}$ of the filtrate to an amber glass LC/GC vial and cap using a screw cap. The sample is now ready for further GC analysis. 



\section{Bibliography}

[1] M. Cheryan and N. Rajagopalan, Membrane processing of oily streams. Wastewater treatment and waste reduction, Journal of Membrane Science 151, 13 (1998). - p.82.

[2] A. Fakhru'l-Razi, A. Pendashteh, L. C. Abdullah, D. R. A. Biak, S. S. Madaeni, and Z. Z. Abidin, Review of technologies for oil and gas produced water treatment, Journal of Hazardous Materials 170, 530 (2009). — p.82.

[3] Y. Zhu, D. Wang, L. Jiang, and J. Jin, Recent progress in developing advanced membranes for emulsified oil/water separation, NPG Asia Materials 6, e101 (2014). - p.82.

[4] M. Padaki, R. Surya Murali, M. Abdullah, N. Misdan, A. Moslehyani, M. Kassim, N. Hilal, and A. Ismail, Membrane technology enhancement in oilwater separation. A review, Desalination 357, 197 (2015). — p.82.

[5] J. Dickhout, J. Moreno, P. Biesheuvel, L. Boels, R. Lammertink, and W. de Vos, Produced water treatment by membranes: A review from a colloidal perspective, Journal of Colloid and Interface Science (2016). — p.82, 83.

[6] T. Mohammadi, M. Kazemimoghadam, and M. Saadabadi, Modeling of membrane fouling and flux decline in reverse osmosis during separation of oil in water emulsions, Desalination 157, 369 (2003). — p.82.

[7] K.-J. Hwang, C.-Y. Liao, and K.-L. Tung, Analysis of particle fouling during microfiltration by use of blocking models, Journal of Membrane Science 287, 287 (2007). - p.82.

[8] M. C. V. Vela, S. Á. Blanco, J. L. García, and E. B. Rodríguez, Analysis of membrane pore blocking models applied to the ultrafiltration of PEG, Separation and Purification Technology 62, 489 (2008). — p.82.

[9] A. Salahi, M. Abbasi, and T. Mohammadi, Permeate flux decline during UF of oily wastewater: Experimental and modeling, Desalination 251, 153 (2010). - p.82.

[10] J. C. Chen, Q. Li, and M. Elimelech, In situ monitoring techniques for concentration polarization and fouling phenomena in membrane filtration, Advances in Colloid and Interface Science 107, 83 (2004). — p.82.

[11] J. Altmann and S. Ripperger, Particle deposition and layer formation at the crossflow microfiltration, Journal of Membrane Science 124, 119 (1997). - p.82, 96 .

[12] H. Li, A. Fane, H. Coster, and S. Vigneswaran, Direct observation of particle 
deposition on the membrane surface during crossflow microfiltration, Journal of Membrane Science 149, 83 (1998). — p.82.

[13] W. D. Mores and R. H. Davis, Direct visual observation of yeast deposition and removal during microfiltration, Journal of Membrane Science 189, 217 (2001). - p.83.

[14] L. Vanysacker, P. Declerck, and I. Vankelecom, Development of a high throughput cross-flow filtration system for detailed investigation of fouling processes, Journal of Membrane Science 442, 168 (2013). — p.83.

[15] G. Fux and G. Z. Ramon, Microscale Dynamics of Oil Droplets at a Membrane Surface: Deformation, Reversibility, and Implications for Fouling, Environmental Science \& Technology 51, 13842 (2017). - p.83.

[16] H. Di, G. J. Martin, and D. E. Dunstan, A microfluidic system for studying particle deposition during ultrafiltration, Journal of Membrane Science 532, 68 (2017). - p.83.

[17] H. Di, G. J. Martin, Q. Sun, D. Xie, and D. E. Dunstan, Detailed, real-time characterization of particle deposition during crossflow filtration as influenced by solution properties, Journal of Membrane Science 555, 115 (2018). - p.83.

[18] J. M. Dickhout, J. M. Kleijn, R. G. H. Lammertink, and W. M. de Vos, Adhesion of emulsified oil droplets to hydrophilic and hydrophobic surfaces effect of surfactant charge, surfactant concentration and ionic strength, Soft Matter 14, 5452 (2018). - p.83, 89.

[19] G. K. Cooper, K. R. Sandberg, and J. F. Hinck, Trimethylsilyl cellulose as precursor to regenerated cellulose fiber, Journal of Applied Polymer Science 26, 3827 (1981). - p.84, 85.

[20] D. M. Dresselhuis, G. A. van Aken, E. H. A. de Hoog, and M. A. Cohen Stuart, Direct observation of adhesion and spreading of emulsion droplets at solid surfaces, Soft Matter 4, 1079 (2008). — p.85.

[21] A. Goldman, R. Cox, and H. Brenner, Slow viscous motion of a sphere parallel to a plane wallII Couette flow, Chemical Engineering Science 22, 653 (1967). - p.85, 86.

[22] W. M. de Vos, A. de Keizer, M. A. Cohen Stuart, and J. M. Kleijn, Thin polymer films as sacrificial layers for easier cleaning, Colloids and Surfaces A: Physicochemical and Engineering Aspects 358, 6 (2010). — p.85.

[23] K. Grundke, T. Bogumil, C. Werner, A. Janke, K. Pöschel, and H.-J. Jacobasch, Liquid-fluid contact angle measurements on hydrophilic cellulosic materials, Colloids and Surfaces A: Physicochemical and Engineering Aspects 116, 79 (1996). - p.88.

[24] K. Grundke, K. Pöschel, A. Synytska, R. Frenzel, A. Drechsler, M. Nitschke, A. Cordeiro, P. Uhlmann, and P. Welzel, Experimental studies of contact angle hysteresis phenomena on polymer surfaces Toward the understanding and control of wettability for different applications, Advances in Colloid and 
Interface Science 222, 350 (2015). - p.88.

[25] L. Song and M. Eiimelech, Theory of Concentration Polarization in Crossflow Filtration, J. CHEM. SOC. FARADAY TRANS 91, 3389 (1995). p.93.

[26] K. W. Trzaskus, W. M. de Vos, A. Kemperman, and K. Nijmeijer, Towards controlled fouling and rejection in dead-end microfiltration of nanoparticles Role of electrostatic interactions, Journal of Membrane Science 496, 174 (2015). - p.94, 96. 



\section{CHAPTER 5}

\section{Comparing the effects of ionic strength for various surfactant types on membrane fouling during produced water treatment}

Membrane filtration is a technique that can be successfully applied to remove oil from stable oil-in-water emulsions. This is especially interesting for produced water (PW), a massive waste stream from the petrochemical industry, which contains dispersed oil, surface-active components and often has a high ionic strength. Due to the complexity of this emulsion, membrane fouling by produced water is more severe and less understood than membrane fouling by more simple oil-in-water emulsions. In this Chapter, we study the relation between surfactant type and the effect of the ionic strength on membrane filtration of an artificial produced water emulsion. As surfactants, we use anionic sodium dodecyl sulphate (SDS), cationic hexadecyltrimethylammonium bromide (CTAB), nonionic Triton TM X-100 (TX) and zwitterionic N-dodecyl-N,N-dimethyl-3ammonio-1-propanesulfonate (DDAPS), and 1, 10 and $100 \mathrm{mM}$ sodium chloride ( $\mathrm{NaCl}$ ). Membrane filtration experiments showed a pronounced effect of the ionic strength for the charged surfactants SDS and CTAB, although the nature of the effect was quite different. For anionic SDS, an increasing ionic strength leads to less droplet-droplet repulsion, allowing a denser cake layer to form, resulting in a much more pronounced flux decline. CTAB, on the other hand leads to a lower interfacial tension than observed for SDS, and thus more deformable oil droplets. At high ionic strength, increased surfactant adsorption leads to such a low oil-water surface tension that the oil droplets can permeate through the much smaller membrane pores. For the nonionic surfactant TX, no clear effect of the ionic strength was observed, but the flux decline is very high compared to the other surfactants. For the zwitterionic surfactant DDAPS, the flux decline decreased with increasing ionic strength, suggesting that membrane fouling decreases with increasing ionic strength. More strikingly is that the flux decline is extremely low for the zwitterionic surfactant, coming to a decline of just $3 \%$ after 3 hours of filtration at an ionic strength of $10 \mathrm{mM}$.

From our results, it becomes clear that the type of the surfactant used is crucial for a successful application of membrane filtration for PW treatment, especially at high ionic strengths. In addition, they point out that the application of zwitterionic surfactants can be beneficial for PW treatment with membranes. 


\subsection{Introduction}

Membrane filtration is an increasingly important technique for the treatment of a wide spectrum of waste waters from a large variety of sources [1-6]. Membranes are, for example, used for municipal waste water treatment in combination with bioreactors [7], and in the food industry both in the processes themselves $[1,8]$ and as waste water treatment for factory effluents $[9,10]$. Moreover, membrane filtration is used to remove harmful chemicals and particles, such as heavy metals or oil and grease, from industrial waste streams. Treating these wastewaters sufficiently brings the water to such quality that it also allows re-use of the water, thereby decreasing the fresh water demand. This large variety of applications and feed streams means that membrane filtration has to be tailored to each specific process. The membrane material, process parameters and pretreatment all influence the performance of the membrane system and therefore have to be carefully chosen. This is especially important, as virtually all membrane processes suffer from fouling, the building up of retained material on the feed side of the membrane [6]. This blocks the pores, builds into a cake layer and thereby reduces the membrane flux and increases operation costs. In some cases, however, this cake layer on top of the membrane forms a new active layer and improves the filtration characteristics of the membrane [11].

A current focus area of membrane science is the use of membranes to treat the challenging waste stream of so-called produced water $(\mathrm{PW})$, the largest waste stream of the petrochemical industry. Quite some research has now shown that PW can be effectively treated using membrane filtration, but that membrane fouling remains a critical problem $[6,12]$. PW contains dissolved and dispersed hydrocarbons, salts, heavy metals and solid particles, as well as production chemicals. Before this water can be re-used or disposed, those components have to be removed. The dispersed oil can be removed largely by conventional techniques such as gas flotation, adsorption, evaporation and hydrocyclones, but the smallest oil droplets with a size $<10 \mu \mathrm{m}$ are less efficiently removed by these techniques [13]. Membrane filtration can remove those droplets, but, as mentioned, the fouling of the membrane by these oil droplets is often severe. Moreover, the membrane fouling by produced water is typically more severe than membrane fouling by many other oil-in-water emulsions such as food emulsions or other industrial waste waters containing oils [14]. A key parameter that is different in most produced waters, compared to more standard oily waste waters, is the high salinity [6]. This high salinity stems from the use of sea-water for enhanced oil recovery, or due to the presence of salt in the oil reservoir. The high salinity can have a detrimental effect of the stability of the stabilized oil droplets, which in turn can lead to more detrimental fouling (Chapter 4). It is good to mention that produced water is a waste stream with varying properties. The composition of produced water changes from well to well but also over the lifetime of an oil 
reservoir. Therefore, there is no universally applicable solution or method for all sources of produced water.

In order to control membrane fouling by produced water, it is important to understand the interaction of the oil droplets with the membrane surface, as was studied in previous Chapters. Here the presence of surfactants is believed to play a key role. The surfactant adsorbs to the oil-water interface of the droplets, but also often adsorbs to the membrane surface. The surfactant will thus determine much of the interactions between droplet and membrane surface, and naturally the droplet-droplet interactions. Since PW contains such a variety in components, it is important to understand what the influence of each component is on the membrane fouling, but also how one component might affect the fouling propensity of another component. For example, the effective stabilization of an oil droplet by a charged surfactant will be strongly influenced by the ionic strength, while for an uncharged surfactant the ionic strength might play only a small role. In literature, many examples of oil-water separation with membranes can be found, as well as studies on the kinetics of fouling (Chapter 2). Here, we will discuss a few examples in which the influence of emulsion components or process parameters was studied systematically.

Li et al. developed a cellulose UF hollow fiber membrane for oil-water separation [15]. They chose cellulose for its high resistance against swelling from organic compounds and its hydrophilic nature. The retention was $99 \%$ for an emulsion of machine oil in water while showing only minimal fouling, showing the potential for this membrane material. Lipp et al. also tested a cellulose membrane for oil-in-water emulsion separation. Their emulsion contained a mixture of oil and surface-active components [16]. They found evidence of coalescence in the cake layer, and proposed a loss of surfactant to the permeate due to this coalescence, thereby changing the properties of the cake layer, making it more dense. Out of a range of membranes, however, the regenerated cellulose membrane showed excellent oil rejection and flux recovery after cleaning. Lu et al. studied the filtration of oil-in-water emulsions with three different surfactants on a ceramic membrane [17]. Interestingly enough, they found that an emulsion with surfactant oppositely charged to the membrane surface charge showed less irreversible fouling than a surfactant with similar charge. They attributed this effect to the adsorption of surfactant molecules to the surface and the inside of the membrane pores, hindering the entrance of oil into the membrane. The exact mechanism however was not understood well and requires further investigation. Singh et al. studied the influence of the ionic strength on membrane fouling during aqueous filtration of silica particles [18]. They found that the fouling potential of the feed water was linearly related to the double layer thickness. In their experiments and model, a 10-fold increase in ionic strength had the same effect as a 2-fold increase in colloid concentration of the feed.

What becomes apparent from the discussed studies, is that the effect of many 
parameters, such as type of surfactant, type of membrane surface, ionic strength etc., have received prior interest. However, all studies look at just a single parameter at the same time, while it is clear that a parameter such as surfactant type, could strongly influence the effect for the ionic strength. In this Chapter, we chose four different model surfactants with different properties. We used an anionic, cationic, nonionic and zwitterionic surfactant and compare their behavior when used in membrane filtration experiments. In addition, we varied the salt concentration of the feed emulsion to study the effect of ionic strength on membrane fouling, and how that is affected by the type of surfactant. The emulsions used in this study are synthetic model emulsions with carefully chosen components, so we are able to control the properties of the emulsions.

\subsubsection{Theory}

Here we provide the theoretical background that is the basis for all interpretation of the experimental data. After prolonged filtration of oily waste water, the membrane fouling will be dominated by the cake layer that has formed on the membrane surface $[19,20]$. Here we study the effect of increasing ionic strength on membrane fouling by oil-in-water emulsions stabilized by four different surfactants. Since the properties, and especially the charge of the head group of those surfactants are different, we expect to see an influence on the formed cake layer and thus the observed flux decline. Here we link the expected properties of the cake layer, described by the Kozeny-Carman term, to the DLVO theory. We also discuss the critical pressure required to push an oil droplet through a membrane pore.

The resistance of a cake layer on the membrane can be described by the KozenyCarman term

$$
R_{c}=\frac{150 l_{c}\left(1-\varepsilon_{c}\right)^{2}}{D_{v}^{2} \varepsilon_{c}^{3}},
$$

where $l_{c}$ is the thickness of the cake layer, $\varepsilon_{c}$ the porosity of the cake layer and $D_{v}$ the effective diameter of the oil droplets [21]. This resistance is heavily dependent on the porosity of the cake layer, and therefore of the interaction between the droplets in the cake layer. As shown in Chapter 4 the pores in a cake layer of monodisperse particles is not effective in rejecting oil droplets based on pore size, as the pores in the layer are larger than the membrane pores.

At fixed oil concentrations, droplet sizes, crossflow velocities and initial fluxes, the properties of the cake layer will to a large extend be governed by droplet-droplet interactions. The interaction between two particles, or in our case oil droplets, can be described by the DLVO theory. This theory adds the attractive interaction 
energy $V_{A}$ and the repulsive interaction energy $V_{R}$ in the total potential

$$
V_{T}=V_{A}+V_{R}
$$

The attractive van der Waals potential, caused by the alignment of dipoles in adjacent molecules, can be found by calculating the interaction of one atom in a droplet with all the atoms in a second droplet, leading to a long-range interaction. When the particle separation distance $h$ is small compared to the droplet radius $a(h<<2 a)$, the potential is given by the equation

$$
V_{A}=-\frac{A a}{12 h}(\mathrm{~J})
$$

where $A$ is the Hamaker constant, which depends on the polarizability of the material of the droplet. Thus, the attractive potential between two oil droplets is inversely dependent of the separation distance between the droplets. While the used surfactant will have some influence on the attractive van der Waals potential, it will be dominated by the droplets bulk material. The surfactant type and the ionic strength will therefore have limited influence on the attractive interaction between droplets.

The electrostatic repulsion is an important stabilizing factor in oil-in-water emulsions. When the oil droplets carry a surface charge, the repulsion will prevent collision between the droplets. For short distances $h$, the electrostatic repulsion can be written as

$$
V_{R}=2 \pi \epsilon_{0} \epsilon_{r} a \psi_{\delta}^{2} e^{(-\kappa h)}(\mathrm{J}),
$$

where $\psi_{\delta}$ is the surface potential of the oil droplet. This electrostatic repulsion is dependent on the thickness of the electrostatic double layer or the Debye length $(1 / \kappa)$, which is given by

$$
\kappa^{-1}=\sqrt{\frac{\epsilon_{r} \epsilon_{0} k_{B} T}{2 N_{A} e^{2} I}}(\mathrm{~m}),
$$

where $\epsilon_{0}$ is the permittivity of vacuum, $\epsilon_{r}$ the dielectric constant of the medium, $k_{B}$ is the Boltzmann constant, $T$ is the temperature in Kelvin, $N_{A}$ Avogadro's number, $e$ the elementary charge and $I$ the ionic strength of the emulsion. The total interaction energy, as stated in equation 5.2, gives a potential curve with a maximum which has to be overcome for droplets to come in close contact. As can be seen from equations 5.4 and 5.5, the repulsive force is dependent on the ionic strength of the emulsion. At increasing ionic strength, the repulsive forces between charged droplets decreases, allowing the droplets to come into much closer contact, or even to coalesce. At higher ionic strength more surfactant will adsorb to the droplet surfaces, thereby increasing surface charge density. The screening effect of salt that lowers the electrostatic repulsion between droplets is, 
however, stronger than the increased repulsion due to the additional surfactant on the surface [22].

Droplets stabilized by nonionic surfactants however do not carry a surface charge. They stabilize the oil droplets by steric hindrance of a large, hydrophilic head group [23]. As this interaction is not charge based, the ionic strength will have little effect on the strength of steric stabilization.

Zwitterionic surfactants stabilize by hydration of the head group. In contrast to charged surfactants, the water molecules around the head group are ordered in the same manner as in the bulk phase of water instead of reordering the water around the single charge of an ionic surfactant [24]. In this unperturbed state, the water molecules around the zwitterionic group are in a H-bonded structure, which takes a considerable amount of energy to disturb.

When a cake layer is formed on the membrane surface, we expect that the repulsive forces between oil droplets with charged surfactants contribute to the porosity of the cake layer. Because the surface charge of the droplets and the resulting electrostatic repulsion, we expect a more open cake layer and less flux decline. However, at increasing ionic strength, the electrostatic repulsion decreases and the cake layer is expected to become more dense because of electrostatic screening of the surface charge. For nonionic and zwitterionic surfactants, which suffer less from electrostatic screening, we expect that increasing the ionic strength has a less pronounced effect on the flux decline. For these surfactants especially the steric repulsion and head group hydration will dominate. It is important to mention that for zwitterionic surfactants, the hydration of the headgroup typically does depend on the ionic strength. At higher ionic strength, the headgroup will be more hydrated and a larger repulsion could follow. So for zwitterionic surfactants, a higher ionic strength might even lead to a more open cake layer and thus a lower flux decline [25].

Apart from the membrane flux, a key membrane performance parameter is the retention of oil droplets. While in this study the membrane pores are much smaller than the oil droplets, oil droplets can deform to flow through the pore if the applied pressure is large enough. The critical pressure difference at which oil transport through the membrane starts to occur can be estimated by:

$$
P_{\text {crit }}=\frac{\gamma O_{p} \cos \theta}{A_{p}}(\text { bar }),
$$

where $\gamma$ is the interfacial tension between the oil and the aqueous phase, $O_{p}$ the circumference of the pore, $\theta$ the advancing contact angle of the droplet on the surface and $A_{p}$ the surface area of the membrane pore. As can be seen, a key parameter here is the oil-water interfacial tension. For charged surfactants the interfacial tension is a function of the ionic strength. The higher the ionic strength, the lower the repulsion between headgroups, allowing more surfactant molecules to adsorb. Ideally, the contact angle used to calculate the critical 
pressure should be measured on a smooth polymer film, to exclude any effects of roughness. Here we used the contact angle on a rougher interface (the membrane) as in the previous chapter no significant difference in contact angle was observed between the cellulose membrane and a spincoated cellulose film. The adsorbed amount of surfactant on the surface can be derived from the interfacial tension via

$$
\Gamma_{s}=-\frac{C}{R T}\left(\frac{\delta \gamma}{\delta C}\right)_{T, p}\left(\mathrm{~mol} / \mathrm{m}^{2}\right),
$$

Where $R$ is the ideal gas constant, $T$ is the temperature, $\gamma$ is the interfacial tension and $C$ is the salt concentration. For charged surfactants, a higher ionic strength thus leads to a lower interfacial tension, thereby also lowering the critical pressure at which the oil droplets can be pushed through the membrane. For nonionic and zwitterionic surfactants this effect is not expected.

\subsection{Materials and methods}

\subsubsection{Materials}

For preparation of the emulsions, we used DI water, sodium dodecyl sulfate (SDS, Sigma Aldrich 75746), hexadecyltrimethylammonium bromide (CTAB, Sigma Aldrich H6269), Triton ${ }^{T M}$ X-100 (TX, Sigma Aldrich 9284), N-dodecyl-N,Ndimethyl-3-ammonio-1-propanesulfonate (DDAPS), n-hexadecane (Merck Schuchardt OHG 820633) as the oil, Coumarin 6/ Neeliglow Yellow 196 (Neelikon) as fluorescent dye, and sodium chloride ( $\mathrm{NaCl}$, Boom 51275). The membrane used was a regenerated cellulose UF membrane with a pore size of $500 \mathrm{kDa}$ (Microdyn Nadir UC500T). All chemicals were used without further purification steps.

\subsubsection{Emulsion preparation and characterization}

To detect the amount of oil that permeates through the membrane, the hexadecane was colored with a dye. As fluorescent dyes bleach over time, the colored oil was prepared freshly before each experiment. Approximately $5 \mathrm{mg}$ of the dye powder was put in a test tube together with $8 \mathrm{~mL}$ of n-hexadecane and put in an ultrasonic bath for 10 minutes. Afterwards, the oil was filtered over a Millipore $.45 \mu \mathrm{m}$ filter to remove any solid particles left.

To ensure all emulsions have the same characteristics, a stock emulsion was prepared, which was then further diluted to obtain the desired salt and surfactant concentration. The surfactant concentrations were all chosen to be at or below the CMC, but high enough to ensure a stable emulsion and a reproducible droplet size distribution. The stock emulsions were prepared by dissolving a surfactant (463 mg/L SDS; $346 \mathrm{mg} / \mathrm{L}$ CTAB; $298 \mathrm{mg} / \mathrm{L}$ TX or $1009 \mathrm{mg} / \mathrm{L}$ DDAPS) in $1 \mathrm{~L}$ of DI water in a Duran ${ }^{\circledR}$ bottle (Duran 21801545 ) by mixing with a dispersing 
mixer (IKA ${ }^{\circledR}$ T25 digital Ultra-Turrax with S25N 18G element) for 2 minutes at $14000 \mathrm{rpm}$. Then, $2 \mathrm{~g}$ of colored oil was injected near the mixer head and mixed for 10 minutes at $14000 \mathrm{rpm}$. The stock emulsion was diluted to contain 100 $\mathrm{mg} / \mathrm{L}$ hexadecane and the desired surfactant and $\mathrm{NaCl}$ concentration to make up 20L of feed emulsion. The particle size distribution was determined with a DIPA 2000 - Particle Analyzer (Prolyse). The mean droplet size in the diluted emulsions was 3-5 $\pm 2-4 \mu \mathrm{m}$ and was constant for all conditions.

\subsubsection{Membrane filtration}

The membrane filtration experiments were performed using an OSMO-inspector crossflow membrane filtration system built by Con-Vergence (Figure 4.2). A fresh membrane sheet was used for each experiment. The membrane was mounted in a flat sheet crossflow membrane cell with an effective surface of $240 \mathrm{~cm}^{2}$, using a feed spacer with a thickness of $700 \mu \mathrm{m}$, a filament angle of $90^{\circ}$ and a maze size of $2.5 \times 2.5 \mathrm{~mm}$. The volume and density of the feed and permeate streams were measured by Bronckhorst M15 mass flow meters. The $20 \mathrm{~L}$ glass feed bottle was constantly stirred to prevent creaming of the feed. Both concentrate and permeate were recycled to the feed bottle to ensure a consistent feed quality. Before mounting the membrane, it was soaked in DI water overnight to remove production chemicals and glycerine from the membrane. Then, the clean water flux was measured. A membrane filtration experiment consisted of filtering for 3 hours at a TMP of 1 bar and a flow rate of $48 \mathrm{~kg} / \mathrm{h}$, which corresponds to a crossflow velocity of $0.2 \mathrm{~m} / \mathrm{s}$. The permeate flux was constantly monitored. To clean the membrane, the cell was flushed with DI water for $1 \mathrm{~h}$ without applied transmembrane pressure, then a backflush with DI water of 3 minutes at 0.2 bar, and then another flush. After the cleaning, the clean water flux was measured again to determine the flux recovery. Each experiment was repeated at least two times and an average and standard deviation were taken on the basis of these data.

\subsubsection{Permeate analysis}

The oil retention for SDS was measured by liquid-liquid extraction of the permeate and subsequent HPLC analysis as described in Chapter 4. For the other surfactants, the fluorescent dye method was used, because the presence of surfactants often caused excessive foaming, hindering the extraction. We repeated the fluorescence method for SDS and found good agreement with the results obtain by extraction. 
The oil retention is defined as

$$
R=\left(1-\frac{F_{p}}{F_{f}}\right) \cdot 100 \%
$$

where $F_{p}$ and $F_{f}$ are the oil concentrations in the permeate and the feed respectively. Therefore, we took a concentrate and permeate sample at the same time and used those for analysis. The concentrate with fluorescent oil was used to make a calibration line. The permeate was subsequently measured on the same sample plate to determine the oil concentration in the permeate using this calibration line. The fluorescence of the samples was measured in a Perkin Elmer Victor3 Multilabel Plate Reader, using a protocol for Fluorescein (465nm/510nm, 1.0s). The dilutions for the calibration line and permeate were injected in threefold in a 96-hole well plate. The volume of liquid in one hole was $200 \mu \mathrm{L}$. As shown in Chapter 3 , the rejection of oil does not change significantly over the course of the experiment, therefore we took the permeate sample only once, after 2 hours of filtration.

\subsubsection{Contact angle and interfacial tension measurements}

Both types of measurements were performed on a contact angle and contour analysis instrument (Dataphysics OCA 35). The contact angle measurements were performed in captive bubble mode, where a droplet of colored hexadecane is captured under a piece of membrane in the aqueous solution with surfactant and salt. The interfacial tension measurements were performed with the pendant droplet technique, where a droplet of aqueous solution with surfactant and salt is suspended in colored hexadecane in a cuvette. Image analysis of the droplet shapes from both contact angle and interfacial tension measurements was performed with the software provided with the measuring instrument, taking into account the density of the media. These experiments were repeated at least two times, and average and standard deviations were obtained from these data.

\subsection{Results}

In this section, we will first discuss background data on the contact angle and interfacial tensions for four different surfactant types, at three different salt concentrations. Membrane performance data regarding flux decline over time, oil retention and flux recovery after cleaning are then discussed per surfactant type.

\subsubsection{Interfacial tension}

The interfacial tension was measured using the pendant droplet technique, where a droplet of aqueous solution is suspended in a cuvette filled with colored oil. The 
results are plotted in Figure 5.1. It is immediately apparent that the four different surfactants show different behavior.

SDS, the anionic surfactant, has the highest interfacial tension at low ionic strength. At $1 \mathrm{mM} \mathrm{NaCl}$, the interfacial tension is $18.2 \pm 5 \mathrm{mN} / \mathrm{m}$, decreasing to $12.4 \pm 0.5 \mathrm{mN} / \mathrm{m}$ for $10 \mathrm{mM} \mathrm{NaCl}$ and $2.3 \pm 0.2 \mathrm{mN} / \mathrm{m}$ for $100 \mathrm{mM}$ $\mathrm{NaCl}$. This strong dependence on the ionic strength indicates that the adsorbed amount of surfactant depends on the ionic strength. Upon increasing the ionic strength, the charge of the head groups is screened, allowing more surfactant molecules to adsorb to the droplet surface, leading to a lower interfacial tension. CTAB, the cationic surfactant, shows the lowest interfacial tensions of the four. CTAB has the longest carbon tail of all surfactants studied here, leading to a higher adsorbed amount and thus a lower interfacial tension. At $1 \mathrm{mM} \mathrm{NaCl}$, the interfacial tension is $1.9 \pm 0.3 \mathrm{mN} / \mathrm{m}$, lowering to $0.4 \pm 0.1 \mathrm{mN} / \mathrm{m}$ and 0.3 $\pm 0.1 \mathrm{mN} / \mathrm{m}$ for 10 and $100 \mathrm{mM}$ respectively. These last two values are not accurate because the pendant droplet technique is not appropriate to study such low interfacial tensions. There is a clear decrease in interfacial tension between 1 and $10 \mathrm{mM}$ however, so we can assume that we have a similar situation as with SDS, where the screening of charges at the head group of the surfactant molecules allows more surfactant molecules to adsorb, leading to a lower interfacial tension at higher ionic strengths. Based on this data we cannot confirm that this trend continues from $10 \mathrm{mM}$ to $100 \mathrm{mM}$ of salt, but this would be expected.

As expected, for TX-100, the non-ionic surfactant, an increase in ionic strength does not influence the adsorption of surfactant to the droplet surface very much. The interfacial tensions for 1,10 and $100 \mathrm{mM}$ are $6.7 \pm 0.6 \mathrm{mN} / \mathrm{m}, 8.0 \pm 0.1$ $\mathrm{mN} / \mathrm{m}$ and $7.8 \pm 0.1 \mathrm{mN} / \mathrm{m}$ respectively. The small variation in interfacial tension could be caused by small changes in the solvent quality for the PEO tail of TX upon the addition of salt.

The interfacial tension of DDAPS stabilized droplets also does not change significantly with increasing salt concentration. The interfacial tension is $2.5 \pm 0.1$ $\mathrm{mN} / \mathrm{m}, 2.4 \pm 0.1 \mathrm{mN} / \mathrm{m}$ and $2.4 \pm 0.1 \mathrm{mN} / \mathrm{m}$ for 1,10 and $100 \mathrm{mM}$ respectively. As was the case with CTAB, these values are in a regime that is hard to measure accurately using the pedant drop technique. The head groups of DDAPS are neutral as a whole, but do have a positive and a negative charge on their head groups [25].

\subsubsection{Contact angle}

The contact angle was obtained from a captured droplet of colored hexadecane under the membrane in a cuvette filled with the aqueous phase. The results are shown in Figure 5.2. For all surfactants and ionic strenghts, there is a rather high contact angle, here indicating a rather hydrophilic surface and thus little spreading of the oil droplet. 


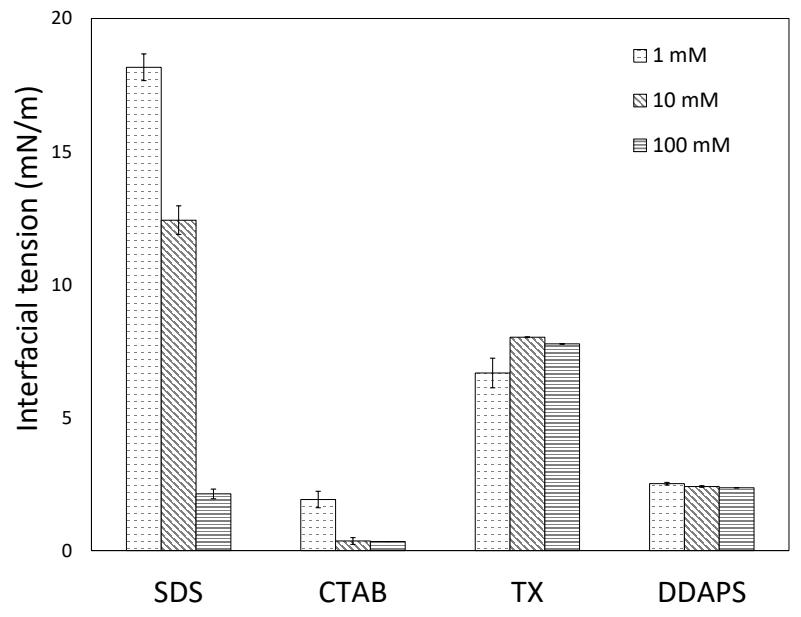

Figure 5.1: The interfacial tension of the water/oil interface for four different surfactants and three different salt concentrations as indicated.

For SDS, the contact angles are $150 \pm 0.5,140 \pm 0.5$ and $131 \pm 4$ for 1,10 and 100 $\mathrm{mM}$. There seems to be a slight decreasing trend, indicating increased hydrophobic interactions. Due to the dissociation of $\mathrm{OH}$ groups on the cellulose surface it is slightly negatively charged. At higher ionic strengths, the negatively charged droplet might interact more favourably with the negative membrane surface, allowing more spreading of the oil droplet. For CTAB we see a slighty increasing contact angle at increasing ionic strength. The contact angles measured are 148 $\pm 2,149 \pm 2$ and $151 \pm 1$ for 1,10 and $100 \mathrm{mM} \mathrm{NaCl}$ respectively. This might indicate an increase in hydrophilic interactions. The cationic surfactant CTAB will adsorb to the negatively charged cellulose. A higher ionic strength could lead to more CTAB adsorption and to the observed slight change in contact angle.

For TX, there is no influence on the contact angle, as the measured values are $148 \pm 0.4,149 \pm 0.4$ and $149 \pm 0.2$ for 1,10 and $100 \mathrm{mM}$ respectively. This is in line with expectations. Because TX has no charge, we also do not expect an influence of the ionic strength.

Similar behavior is observed for DDAPS. The contact angle was $150 \pm 2,152 \pm 1$ and $151 \pm 1$ for 1,10 and $100 \mathrm{mM}$ respectively. Just as with TX, we expected no significant influence of the ionic strength on the contact angle, as the head group has no net charge. 


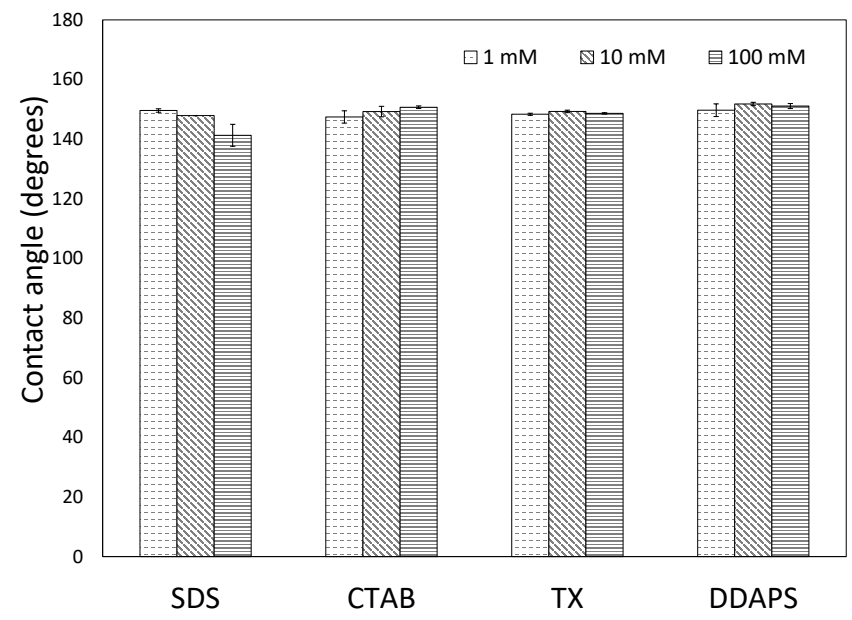

Figure 5.2: The contact angle of an oil droplet trapped under the membrane surface in the aqueous phase, for four different surfactants and three different salt concentrations as indicated

\subsubsection{SDS stabilized emulsions}

An emulsion with $100 \mathrm{ppm}$ hexadecane, $463 \mathrm{mg} / \mathrm{L}$ SDS and 1, 10 and $100 \mathrm{mM}$ $\mathrm{NaCl}$ was filtered in a crossflow membrane filtration system using a regenerated cellulose membrane. The crossflow velocity was $0.2 \mathrm{~m} / \mathrm{s}$ and the transmembrane pressure was kept constant at 1 bar. The flux decline as a function of permeate volume is plotted in Figure 5.3. At $1 \mathrm{mM} \mathrm{NaCl}$, the flux decline is gradual, and after three hours of filtration the flux decline reached $50 \pm 3 \%$ of the initial flux. At $10 \mathrm{mM} \mathrm{NaCl}$, the initial flux decline is very steep, after which the flux decline becomes more gradual. At the end of the experiment, the flux had dropped to $37 \pm 6 \%$ of the original flux. At $100 \mathrm{mM} \mathrm{NaCl}$, the flux first declines quite fast, and then slows down, reaching a permeate flux of $23 \pm 3 \%$ of the initial flux at the end of the experiment. From these results, it is clear that increasing the ionic strength has a strong influence on the flux decline, where a higher ionic strength gives more membrane fouling. As discussed in Chapter 4, The initial flux decline is associated with the direct adsorption of oil droplets to the membrane, whereas the more gradual flux decline later on in the experiment is associated with the formation of a cake layer. During cake layer formation however, the interaction between oil droplets dominates. For 1 and $100 \mathrm{mM} \mathrm{NaCl}$, the flux decline follows a similar trend, whereas the flux decline at $10 \mathrm{mM}$ shows a much steeper initial decline. This suggests there is a different fouling mechanism dominating the initial flux decline. 


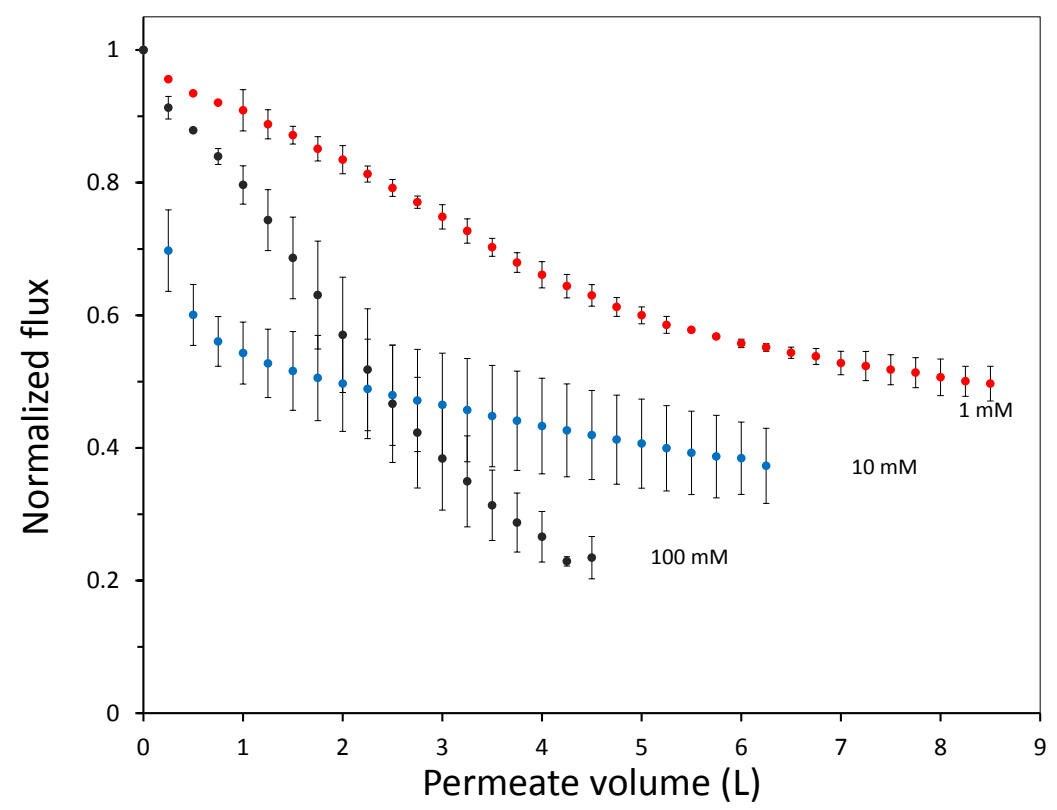

Figure 5.3: Flux decline of SDS stabilized emulsions at a crossflow velocity of $0.2 \mathrm{~m} / \mathrm{s}$ and a transmembrane pressure of 1 bar. Error bars represent standard deviation after duplicates. 


\begin{tabular}{|l|l|l|l|}
\hline Salt concentration & Flux recovery & Oil retention & Critical pressure (bar) \\
\hline $1 \mathrm{mM}$ & $74 \pm 8 \%$ & $93 \pm 5 \%$ & 10.5 \\
\hline $10 \mathrm{mM}$ & $78 \pm 5 \%$ & $94.5 \pm 2.5 \%$ & 7.0 \\
\hline $100 \mathrm{mM}$ & $95 \pm 8 \%$ & $90 \pm 6 \%$ & 1.1 \\
\hline
\end{tabular}

Table 5.1: Flux recovery, oil retention and critical pressure at $48 \mathrm{~kg} / \mathrm{h}$ and $1 \mathrm{bar}$ TMP for SDS stabilized emulsions. The theoretical critical pressure was calculated using equation 6 , and data from section 3.1 and 3.2. The error margin on the flux recovery is an approximation, as the membrane broke during cleaning after several experiments.

The flux recovery of the membrane was measured after a cleaning procedure including a forward flush, backwash and another forward flush of the membrane cell. The results are given in Table 5.1. At higher salt concentrations, the flux recovery increases, although we observed that the degree of fouling increases. In Chapter 4, we already proposed two possible mechanisms to explain this observation. Firstly, we expect the cake layer formed on the surface to become denser at high ionic strengths. A denser cake layer might be easier to remove as a whole, hence the increase in flux recovery at high ionic strengths. In literature, it was observed that larger particles and aggregates are indeed more prone to detach from a cake layer [26]. The second explanation is that at higher ionic strength, more surfactants are adsorbed to the droplet interface, as discussed in section 5.3.1. Upon flushing with pure water, the salt and surfactant is diluted and removed from the cake layer, which can have a destabilizing effect. However, because the initial concentration of surfactant was higher at high ionic strengths, the droplets might stay stable for a longer period of time, allowing for easier cleaning.

The oil retention for SDS stabilized emulsions is between 90 and $95 \%$ for all ionic strengths. High retentions were expected based on the theoretical critical pressure (equation 5.6) required to push an oil droplet through the membrane. This was calculated on the basis of the data from section 5.3.1 and 5.3.2 and is for all three ionic strengths predicted to be above the applied pressure of 1 bar. This means that the small amount of oil found in the permeate is probably made up of the smallest droplets present in the feed stream passing through the largest pores in the membrane.

\subsubsection{CTAB stabilized emulsions}

The same experimental conditions were used to filter an emulsion containing $100 \mathrm{ppm}$ oil, $346 \mathrm{mg} / \mathrm{L} \mathrm{CTAB}$ and 1, 10 or $100 \mathrm{mM} \mathrm{NaCl}$. The flux decline upon filtration of CTAB-stabilized emulsions is plotted in Figure 5.4. It is immediately apparent that the behavior is different from the results obtained with 


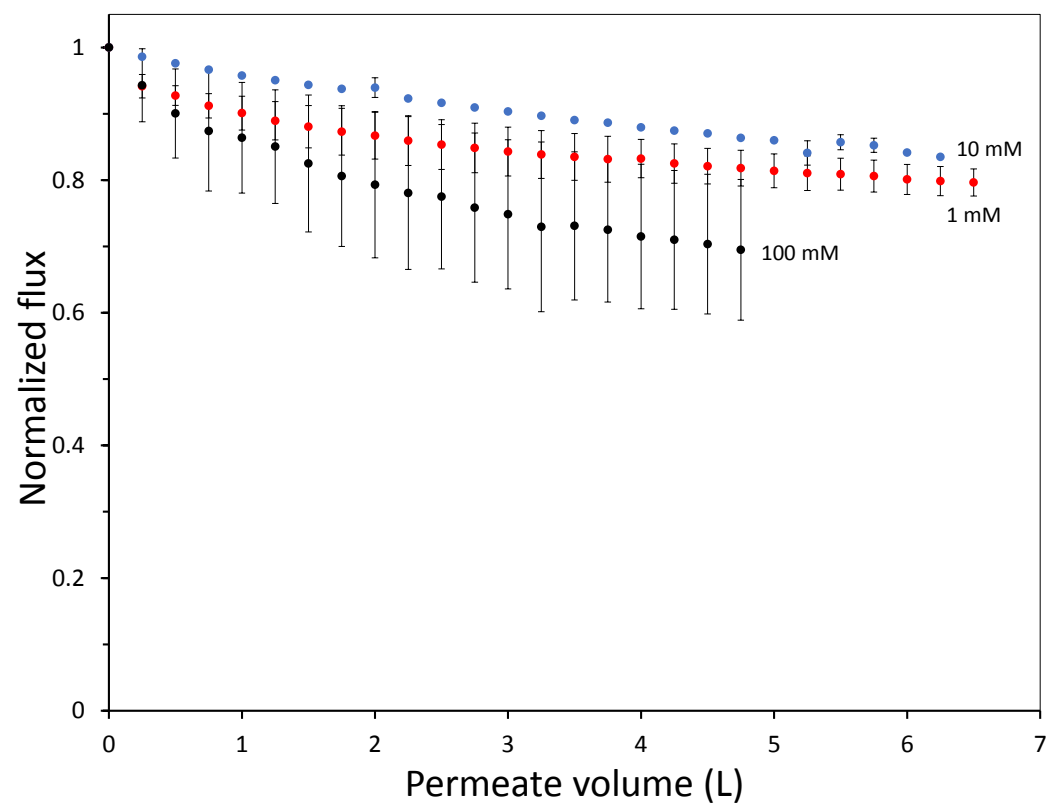

Figure 5.4: Flux decline of CTAB stabilized emulsions at a crossflow velocity of 0.2 $\mathrm{m} / \mathrm{s}$ and a transmembrane pressure of 1 bar. Error bars represent standard deviation after duplicates.

SDS-stabilized emulsions. The flux decline is much lower for CTAB-stabilized emulsions, reaching a value of $80 \pm 2 \%$ for $1 \mathrm{mM} \mathrm{NaCl}, 84 \pm 1 \%$ for $10 \mathrm{mM}$ $\mathrm{NaCl}$ and $70 \pm 10 \%$ for $100 \mathrm{mM} \mathrm{NaCl}$ after three hours of filtration. The flux decline is gradual for all three ionic strengths and seems to approach a steady value at the end of the filtration experiment.

The flux recovery of CTAB shows no clear trend with increasing ionic strength (Table 5.2). The values measured for the different experiments vary quite strong even after repetitions, suggesting that removal of this cake layer is sensitive to slight variations in the experiments. We do see however, that at $100 \mathrm{mM} \mathrm{NaCl}$, the flux recovery is high in all measurements. We also see, that for this ionic strength the oil retention is very low as almost all oil passes through the membrane. This means that there is simply not a lot of oil left on the feed side to form a cake layer, possibly also allowing easier cleaning. When we calculate the theoretical critical pressure required to push these CTAB-stabilized oil droplets through the membrane, it is clear that only at $1 \mathrm{mM} \mathrm{NaCl}$ we are above the critical pressure. At 10 and $100 \mathrm{mM} \mathrm{NaCl}$, oil would be expected to permeate through the membrane. While this is clearly the case for $100 \mathrm{mM} \mathrm{NaCl}$, the oil 


\begin{tabular}{|l|l|l|l|}
\hline Salt concentration & Flux recovery & Oil retention & Critical pressure (bar) \\
\hline $1 \mathrm{mM}$ & $90 \pm 9 \%$ & $95 \%$ & 1.1 \\
\hline $10 \mathrm{mM}$ & $82 \pm 10 \%$ & $89 \%$ & 0.2 \\
\hline $100 \mathrm{mM}$ & $91 \pm 2 \%$ & $3 \%$ & 0.2 \\
\hline
\end{tabular}

Table 5.2: Flux recovery, oil retention and critical pressure at $48 \mathrm{~kg} / \mathrm{h}$ and $1 \mathrm{bar}$ TMP for CTAB stabilized emulsions.

retention at $10 \mathrm{mM}$ however is still $89 \%$, despite being filtered above the critical pressure. It seems that with the theoretical critical pressure, as calculated with equation 5.6, we can explain the observed trends. At the same time, it cannot perfectly predict at which ionic strength oil will permeate.

\subsubsection{TX stabilized emulsions}

The flux decline of emulsions stabilized with the nonionic surfactant TX at three different salt concentrations is plotted in Figure 5.5. As expected, the increase in ionic strength has little influence of the flux decline. After three hours of filtration, the flux has decreased until $23 \pm 1 \%$ for $1 \mathrm{mM} \mathrm{NaCl}, 30 \pm 4 \%$ for $10 \mathrm{mM} \mathrm{NaCl}$ and $26 \pm 12 \%$ for $10 \mathrm{mM} \mathrm{NaCl}$. The nonionic head groups on the droplet surface do not give a surface charge, so there is no electrostatic repulsion between the droplets. This leads to a dense cake layer and therefore more resistance.

The flush recovery for the membrane after filtering TX-stabilized emulsion is in all cases around $80 \%$ (Table 5.3). This indicates that there is a substantial amount of irreversible fouling. This can be due to a cake layer that is hard to remove, or the fouling takes place in the pores of the membrane in addition to the formation of a cake layer on the surface. The oil retention for TX-stabilized emulsion is below $80 \%$ for all ionic strengths (Table 5.3). The calculated critical pressure is however higher than the applied pressure, suggesting that oil passes through the pores by another mechanism. At sufficient high shear forces, droplets can break up and pass through the membrane [27] Since oil can pass through the membrane and the flux recovery after forward and back washing is relatively low, the irreversible fouling of the membrane might take place primarily inside of the pores.

\subsubsection{DDAPS stabilized emulsions}

Finally, we studied the flux decline upon filtration of an emulsion stabilized by the zwitterionic DDAPS. Surprisingly, this surfactant has not been studied as much as the other three surfactants, while the anti-fouling properties attributed to 


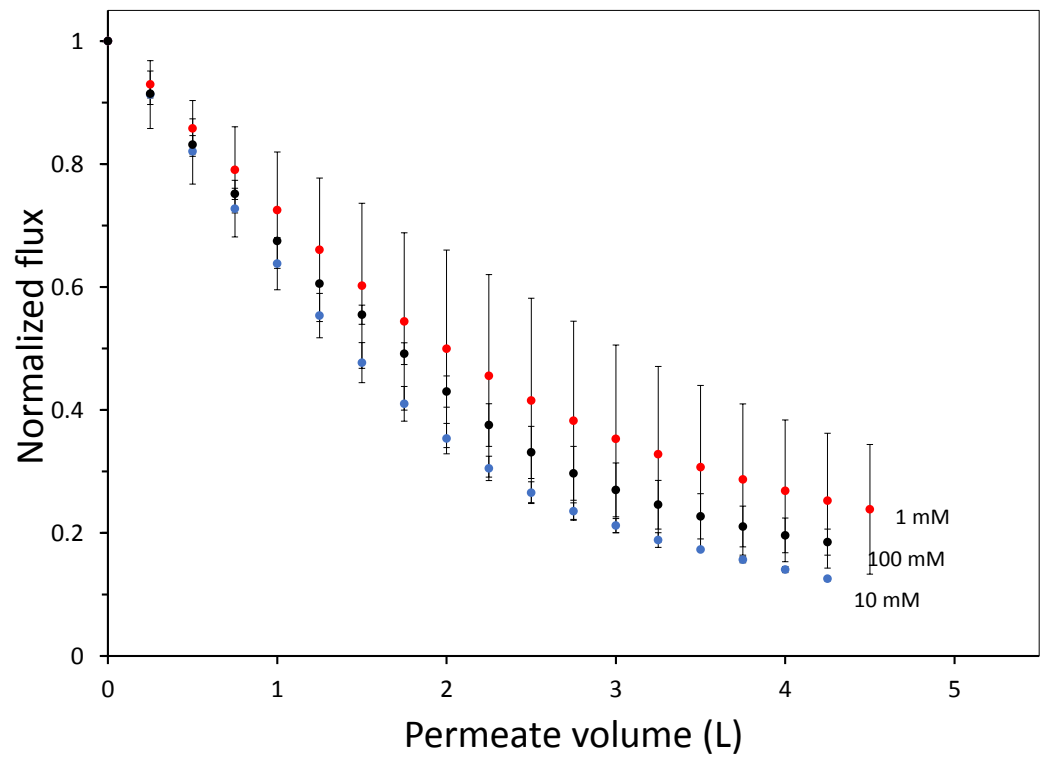

Figure 5.5: Flux decline of TX stabilized emulsions at a crossflow velocity of $0.2 \mathrm{~m} / \mathrm{s}$ and a transmembrane pressure of 1 bar. Error bars represent standard deviation after duplicates.

\begin{tabular}{|l|l|l|l|}
\hline Salt concentration & Flux recovery & Oil retention & Critical pressure (bar) \\
\hline $1 \mathrm{mM}$ & $78 \pm 11 \%$ & $77 \pm 1 \%$ & 3.8 \\
\hline $10 \mathrm{mM}$ & $80 \pm 1 \%$ & $69 \pm 4 \%$ & 4.6 \\
\hline $100 \mathrm{mM}$ & $79 \pm 11 \%$ & $74 \pm 12 \%$ & 4.5 \\
\hline
\end{tabular}

Table 5.3: Flux recovery, oil retention and critical pressure at $48 \mathrm{~kg} / \mathrm{h}$ and $1 \mathrm{bar}$ TMP for TX stabilized emulsions. 


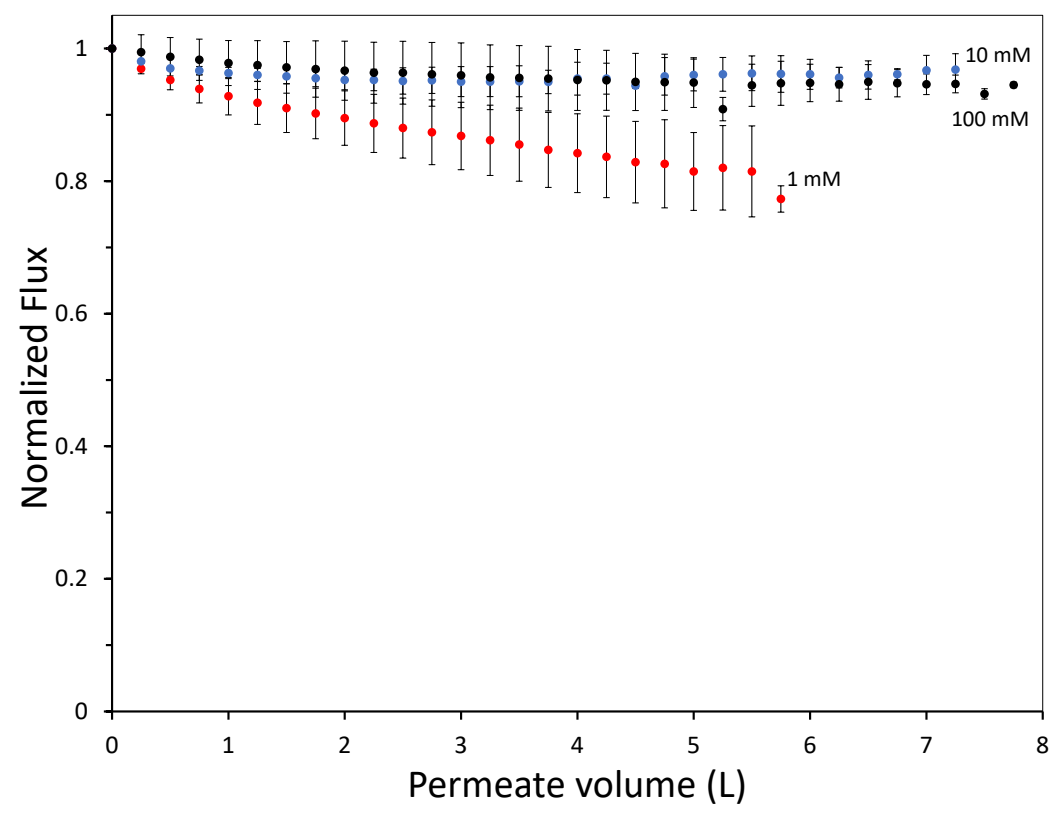

Figure 5.6: Flux decline of DDAPS stabilized emulsions at a crossflow velocity of 0.2 $\mathrm{m} / \mathrm{s}$ and a transmembrane pressure of 1 bar. Error bars represent standard deviation after duplicates.

zwitterionic species might make it very relevant for this challenging application. The head group of a zwitterionic surfactant has no net charge, but a positively and a negatively charged moiety. Because of this, it is capable of forming a hydrated layer around the head group. Therefore, we expect it to have excellent antifouling properties, because hydrophobic interactions will be hindered [28]. The flux decline of the membrane filtration experiment at three different salt concentrations is given in Figure 5.6. The flux decline after 3 hours of filtration is $81 \pm 7 \%$ for $1 \mathrm{mM} \mathrm{NaCl}, 97 \pm 2 \%$ for $10 \mathrm{mM} \mathrm{NaCl}$ and $95 \pm 1 \%$ for $100 \mathrm{mM}$ $\mathrm{NaCl}$. Especially for the higher ionic strengths, the flux decline is so low that either no cake layer forms on the surface, or the cake layer is extremely open. We also noted that the flux decline decreased at increasing ionic strength. This is is line with expectations, as we expect that the stabilizing effect of DDAPS increases with increasing ionic strength[25].

The flux recovery after forward flushing and backwashing is given in Table 5.4. For all ionic strengths the flux recovery is above $96 \%$, which indicates excellent cleaning properties. Since there was virtually no flux decline, there is probably not a lot of fouling to remove. The oil retention for DDAPS stabilized emul- 


\begin{tabular}{|l|l|l|l|}
\hline Salt concentration & Flux recovery & Oil retention & Critical pressure (bar) \\
\hline $1 \mathrm{mM}$ & $98 \pm 2 \%$ & $78 \pm 6 \%$ & 1.4 \\
\hline $10 \mathrm{mM}$ & $96 \pm 1 \%$ & $70 \pm 20 \%$ & 1.4 \\
\hline $100 \mathrm{mM}$ & $98 \pm 2 \%$ & $44 \pm 6 \%$ & 1.4 \\
\hline
\end{tabular}

Table 5.4: Flux recovery, oil retention and critical pressure at $48 \mathrm{~kg} / \mathrm{h}$ and 1 bar TMP for DDAPS stabilized emulsions.

sions is also given in Table 5.4. The oil retention decreases with increasing ionic strength, but it is not completely clear why. There is no evidence from the interfacial tension data that the oil droplets become more deformable at higher ionic strength, neither does the predicted critical pressure change.

\subsection{Discussion}

In the previous section, we showed results of the membrane filtration of emulsions stabilized with four different surfactants and at 3 different ionic strengths. In our theory section 5.1.1, we stated that according to the DLVO theory and the Kozeny-Carman term, we expect that charged surfactants show a change in flux decline with increased ionic strength due to a changing porosity of the cake layer. A higher ionic strength is expected to lead to a lower porosity of the cake layer and thus a higher flux decline. For SDS, an anionic surfactant, this effect was very pronounced, as at higher ionic strength the flux decline was much more severe. For CTAB however, a cationic surfactant, the effect was less pronounced. At higher ionic strength, the oil permeation increased substantially, especially at $100 \mathrm{mM}$ (only $3 \%$ oil retention). With more oil permeating, less oil will remain as a fouling layer. The oil permeating, especially at high ionic strength, is in line with the very low interfacial tension (and thus low critical pressure) of CTAB stabilized oil droplets. For surfactants without a head group charge, we expected no or little effect of changing the ionic strength on membrane fouling and flux decline. Indeed for the non-ionic surfactant TX and the zwitterionic surfactant DDAPS, the observations in membrane filtration were different from those observed for CTAB and SDS. Changing the ionic strength did not have a large effect on the flux decline for both TX and DDAPS, although for DDAPS the flux decline was lower at the higher ionic strengths. The extent of flux decline, however, was very different for these surfactants. Whereas TX stabilized emulsions showed a very strong flux decline, DDAPS stabilized emulsions showed almost none. We propose that this has to do with the different stabilizing mechanisms of the head groups. TX stabilizes by steric hindrance by a long non-ionic head group. As this is a short range interaction (compared to ionic interactions) 
this leads to a cake layer with a rather low porosity and thus a high flux decline. DDAPS however is a zwitterionic surfactant. The positive and negative moieties on the head group are capable of forming a hydration layer around the oil droplets, providing a very strong inter droplet repulsion. With very low flux declines, especially at higher ionic strengths, it seems that the high repulsion is even able to prevent a cake layer from forming. Such behaviour is in line with the excellent anti-fouling properties normally attributed to zwitterionic headgroups and zwitterionic polymers, especially at increasing ionic strength [24, 28].

As our results show, the type of surfactant can have a large influence on the fouling potential of otherwise identical oil-in-water emulsions. Moreover, the effects of ionic strength are different, depending on the exact type and especially charge of the surfactant. Where charged surfactants stabilize emulsions well because of their electrostatic repulsion, factors such as interfacial tension or interactions with the membrane surface definitely play an important role too in determining its appropriateness for membrane filtration and should be considered in the choice of surfactant. Especially at high salt concentrations, often found in produced waters, the use of charged surfactants can either lead to more fouling or to the passing of oil through the membrane. Nonionic surfactants, which are far less influenced by a high salt concentration, did however also not show desirable behavior. Because of a lack of electrostatic repulsion and their short range steric interactions the cake layer becomes far too dense, leading to a high flux decline. The zwitterionic surfactant DDAPS showed good performance due to its hydration layer, with almost no flux decline at higher ionic strengths, but unfortunately also a quite low oil retention. We propose that a zwitterionic surfactant with a slightly shorter carbon tail, and therefore a higher interfacial tension, would be especially suitable for successful treatment of oily waste waters at high salinity, provided the zwitterionic surfactant can replace the surfactants used now for the oil recovery [29]. It would retain the headgroup chemistry that allows for such low fouling, while a higher surface tension would increase oil retention. Alternatively, smaller membrane pore sizes could be used.

\subsection{Conclusion}

In this work we studied membrane fouling by artificial oily waste water, for four different surfactant types, all at varying ionic strength. In this way we demonstrate clearly that the effects of ionic strength on performance parameters such as flux decline, oil rejection and flux recovery after cleaning, are strongly linked to the type of surfactant used. For the anionic SDS, oil is retained well, but the flux decline is much stronger at higher ionic strength. Prolonged filtration leads to the formation of a cake layer at the membrane surface. At low ionic 
strength, strong electrostatic repulsion between SDS stabilized oil droplets leads to the formation of an open cake layer and a relatively low flux decline. But at higher ionic strength the electrostatic repulsion is reduced, leading to denser cake layers and higher flux declines. For the cationic surfactant CTAB, much lower flux reductions are observed including a less pronounced effect of the ionic strength compared to SDS. For CTAB the oil-water interfacial tension at high salt is so low, that the oil droplets can be pushed through the membrane. While at $1 \mathrm{mM}$ of $\mathrm{NaCl}, 95 \%$ of oil is retained, at $100 \mathrm{mM}$ of $\mathrm{NaCl}$, only $3 \%$ of oil is retained. For charged surfactants, increasing the ionic strength can thus lead to denser cake layers, but can also lead to a drop in oil retention. As expected, the effect of ionic strength for the non-ionic surfactant TX, and the zwitterionic DDAPS, are small compared to the effects observed for CTAB and SDS. Still the extend of fouling differs greatly. For TX the flux decline is large (around $80 \%$ for all ionic strengths), while for DDAPS the flux decline is negligible, especially at higher ionic strengths $(>10 \mathrm{mM})$. The highly hydrated nature of the zwitterionic headgroup makes this surfactant type especially promising for successful oily waste water filtration. Still, a zwitterionic surfactant with a higher interfacial tension (shorter carbon tail) would be preferred to increase the now relatively low $(70 \%$ at $10 \mathrm{mM} \mathrm{NaCl})$ oil retention. 



\section{Bibliography}

[1] G. Daufin, J.-P. Escudier, H. Carrère, S. Bérot, L. Fillaudeau, and M. Decloux, Recent and Emerging Applications of Membrane Processes in the Food and Dairy Industry, Food and Bioproducts Processing 79, 89 (2001). p.108.

[2] B. Van Der Bruggen, C. Vandecasteele, T. Van Gestel, W. Doyen, and R. Leysen, A review of pressure-driven membrane processes in wastewater treatment and drinking water production, Environmental Progress 22, 46 (2003). - p.108.

[3] W.-J. Lau and A. Ismail, Polymeric nanofiltration membranes for textile dye wastewater treatment: Preparation, performance evaluation, transport modelling, and fouling control a review, Desalination 245, 321 (2009). p.108.

[4] Y. Zhu, D. Wang, L. Jiang, and J. Jin, Recent progress in developing advanced membranes for emulsified oil/water separation, NPG Asia Materials 6, 1 (2014). - p.108.

[5] S. O. Ganiyu, E. D. van Hullebusch, M. Cretin, G. Esposito, and M. A. Oturan, Coupling of membrane filtration and advanced oxidation processes for removal of pharmaceutical residues: A critical review, Separation and Purification Technology 156, 891 (2015). — p.108.

[6] J. Dickhout, J. Moreno, P. Biesheuvel, L. Boels, R. Lammertink, and W. de Vos, Produced water treatment by membranes: A review from a colloidal perspective, Journal of Colloid and Interface Science (2016). — p.108.

[7] N. S. A. Mutamim, Z. Z. Noor, M. A. A. Hassan, and G. Olsson, Application of membrane bioreactor technology in treating high strength industrial wastewater: a performance review, Desalination 305, 1 (2012). - p.108.

[8] A. Ambrosi, N. S. M. Cardozo, and I. C. Tessaro, Membrane Separation Processes for the Beer Industry: a Review and State of the Art, Food and Bioprocess Technology 7, 921 (2014). — p.108.

[9] T. Mohammadi and A. Esmaeelifar, Wastewater treatment of a vegetable oil factory by a hybrid ultrafiltration-activated carbon process, Journal of Membrane Science 254, 129 (2005). — p.108.

[10] A. Cassano, R. Molinari, M. Romano, and E. Drioli, Treatment of aqueous effluents of the leather industry by membrane processes: A review, Journal of Membrane Science 181, 111 (2001). — p.108. 
[11] K. W. Trzaskus, W. M. de Vos, A. Kemperman, and K. Nijmeijer, Towards controlled fouling and rejection in dead-end microfiltration of nanoparticles Role of electrostatic interactions, Journal of Membrane Science 496, 174 (2015). - p.108.

[12] S. Alzahrani and A. W. Mohammad, Challenges and trends in membrane technology implementation for produced water treatment: A review, Journal of Water Process Engineering 4, 107 (2014). — p.108.

[13] A. Fakhru'l-Razi, A. Pendashteh, L. C. Abdullah, D. R. A. Biak, S. S. Madaeni, and Z. Z. Abidin, Review of technologies for oil and gas produced water treatment., Journal of hazardous materials 170, 530 (2009). — p.108.

[14] B. Chakrabarty, A. Ghoshal, and M. Purkait, Cross-flow ultrafiltration of stable oil-in-water emulsion using polysulfone membranes, Chemical Engineering Journal 165, 447 (2010). - p.108.

[15] H.-J. Li, Y.-M. Cao, J.-J. Qin, X.-M. Jie, T.-H. Wang, J.-H. Liu, and Q. Yuan, Development and characterization of anti-fouling cellulose hollow fiber UF membranes for oilwater separation, Journal of Membrane Science 279, 328 (2006). - p.109.

[16] P. Lipp, C. Lee, A. Fane, and C. Fell, A fundamental study of the ultrafiltration of oil-water emulsions, Journal of Membrane Science 36, 161 (1988).

- p.109.

[17] D. Lu, T. Zhang, and J. Ma, Ceramic Membrane Fouling during Ultrafiltration of Oil/Water Emulsions: Roles Played by Stabilization Surfactants of Oil Droplets, Environmental Science \& Technology 49, 4235 (2015). p.109.

[18] G. Singh and L. Song, Quantifying the effect of ionic strength on colloidal fouling potential in membrane filtration, Journal of Colloid and Interface Science 284, 630 (2005). - p.109.

[19] L. Song, Flux decline in crossflow microfiltration and ultrafiltration: mechanisms and modeling of membrane fouling, Journal of Membrane Science 139, 183 (1998). - p.110.

[20] F. Wang and V. V. Tarabara, Pore blocking mechanisms during early stages of membrane fouling by colloids, Journal of Colloid and Interface Science 328, 464 (2008). - p.110.

[21] J. D. Seader, E. J. Henley, and J. Wiley, Separation process principles, 2 ed. (John Wiley \& Sons, 2006). - p.110.

[22] P. Ghosh and M. Banik, Effects of Salts Containing Mono-, Di-, and Trivalent Ions on Electrical and Rheological Properties of Oil-Water Interface in Presence of Cationic Surfactant: Importance in the Stability of Oil-in-Water Emulsions, Journal of Dispersion Science and Technology 35, 471 (2014). p.112.

[23] C.-M. Chen, C.-H. Lu, C.-H. Chang, Y.-M. Yang, and J.-R. Maa, Influence of $p H$ on the stability of oil-in-water emulsions stabilized by a splittable sur- 
factant, Colloids and Surfaces A: Physicochemical and Engineering Aspects 170, 173 (2000). - p.112.

[24] J. B. Schlenoff, Zwitteration: coating surfaces with zwitterionic functionality to reduce nonspecific adsorption., Langmuir : the ACS journal of surfaces and colloids 30, 9625 (2014). — p.112, 126.

[25] D. Schulz, D. Peiffer, P. Agarwal, J. Larabee, J. Kaladas, L. Soni, B. Handwerker, and R. Garner, Phase behaviour and solution properties of sulphobetaine polymers, Polymer 27, 1734 (1986). — p.112, 116, 124.

[26] J. Altmann and S. Ripperger, Particle deposition and layer formation at the crossflow microfiltration, Journal of Membrane Science 124, 119 (1997). - p.120.

[27] T. Darvishzadeh and N. V. Priezjev, Effects of crossflow velocity and transmembrane pressure on microfiltration of oil-in-water emulsions, Journal of Membrane Science 423-424, 468 (2012). - p.122.

[28] J. de Grooth, M. Dong, W. M. de Vos, and K. Nijmeijer, Building Polyzwitterion-Based Multilayers for Responsive Membranes, Langmuir 30, 5152 (2014). - p.124, 126.

[29] H. Yarveicy and A. Javaheri, Application of Lauryl Betaine in enhanced oil recovery: A comparative study in micromodel, Petroleum (2017). — p.126. 



\section{CHAPTER 6}

\section{Summary and outlook}

\subsection{Summary}

The aim of this thesis is to create increased understanding regarding membrane fouling by oil-in-water emulsions, and more specifically regarding membrane fouling by produced water (PW). Produced water is the largest waste stream from the petrochemical industry (about 3 barrels of PW per barrel of oil). It contains dispersed and dissolved hydrocarbons, surface-active compounds, solid particles and usually has a high salinity. This complex mixture has to be treated before the water can be disposed or re-used, and membrane treatment is a viable method to achieve this. Membranes, however, suffer from fouling, but the extent to which this results from the many different components in PW and/or from interactions between these many components is poorly understood. This is worrying, as understanding of the causes and mechanisms of membrane fouling, is essential to develop the membrane materials and membrane processes that would allow successful PW treatment.

To identify the most important factors for the fouling potential of PW, we perform a literature review (Chapter 2). In this review, we study the composition and properties of oil-in-water emulsions, and determine which factors are important to include in our study on PW. We discuss multiple components that can influence emulsion stability. Our conclusion is that the type of surfactant (head group charge) and the ionic strength, and especially the interactions between these components, play a critical role. In addition, we present multiple studies on membrane filtration of oil-in-water emulsion, both in the lab and on pilot scale. It becomes clear that oil-in-water emulsions from various sources can be separated successfully by membrane filtration, but that $\mathrm{PW}$ is a more challenging feed. We believe that the complex composition, and especially the high salinity and the presence of surfactants (both added and naturally occurring) are major factors in this observation. Besides, we see that there is a knowledge gap in membrane treatment of produced water. Much research is focused on developing new membranes and processes to reduce the fouling, but far less research is performed into the more fundamental background of membrane fouling by PW. From this literature review, we concluded that with our own research we want to focus on 
the interaction between surfactants en ionic strength, and what the influence of those factors is on interactions between oil droplets and the membrane surface. To be able to study the interaction between oil droplets and a surface, we developed a novel flow cell technique, which allows facile visual inspection of droplets on surfaces under an applied shear force. By combining this flow cell with a surface that can easily be chemically modified and a model emulsion containing oil, surfactant (anionic sodium dodecyl sulphate, SDS) and salt we study the adhesion of oil droplets to the surface (Chapter 3). We modify the surface to be either hydrophilic or hydrophobic and change the surfactant concentration, ionic strength en the surfactant species to study the influence of those specific components. By increasing the shear force on the oil droplets that are attached to the model surface, and optically observing at which shear force the droplets detach from the surface, we measure the adhesion force. In addition, we perform supporting measurements to explain our observations, such as surfactant adsorption, contact angle and interfacial tension. We conclude that there is an optimum in the cleanability of the surface as a function of surfactant concentration. At increasing ionic strength more droplets adhere to the surface. Due to the adsorption of surfactant to the hydrophobic surface, the hydrophobic surface repels droplets slightly better than the hydrophilic surface. Finally, we vary the properties of the surfactant by repeating the experiment with cationic hexadecyltrimethylammonium bromide (CTAB) and nonionic Triton X-100 (TX). We conclude that charged surfactants prevent the adsorption of oil droplets the strongest.

The flow cell technique from Chapter 3 is used to study droplet adhesion of a SDS-stabilized emulsion as a function of ionic strength. Cellulose is spincoated on the glass surface of the flow cell to create a chemically identical surface to that of a cellulose membrane.The results are compared with membrane filtration of a identical emulsion on a regenerated cellulose ultrafiltration membrane (Chapter 4). The emulsion contains oil, anionic SDS and sodium chloride at three different ionic strengths. From the flow cell we deduce that the adhesion force between the surface and the droplets does not increase, but that the number of droplets that adheres to the surface does increase. We attribute this to reduced electrostatic repulsion between the droplets and the slightly negatively charged cellulose surface. From membrane filtration, we observe an increasing flux decline at increasing ionic strength. This suggests a denser cake layer forming on the surface, due to reduced electrostastic repulsion. We observe, however, that at 10 $\mathrm{mM} \mathrm{NaCl}$ the initial flux decline is far stronger than the initial flux decline at 1 and $100 \mathrm{mM} \mathrm{NaCl}$. We suspect this is caused by pore blocking instead of cake layer formation in the first few minutes of the filtation. Why we only observe this at $10 \mathrm{mM}$ however is not completely clear and requires more research. We conclude that our observations from the flow cell can give useful insights into membrane fouling, but that the flow cell can not explain all of our observations 
from the membrane filtration experiments. This is expected, as the flow cell lacks permeation flux and cake layer formation.

Finally, we study the influence of ionic strength on membrane filtration of oilin-water emulsions stabilized by four different surfactants (Chapter 5): anionic SDS, cationic CTAB, nonionic TX and zwitterionic N-dodecyl-N,N-dimethyl-3ammonio-1-propanesulfonate (DDAPS). The ionic strength is varied at 1, 10 and $100 \mathrm{mM}$ for each of those surfactants. We measure flux decline, oil retention and flux recovery of a cellulose membrane, as well as contact angle and interfacial tension for all surfactants and salt concentrations. For charged surfactants, we expect the strongest influence of ionic strength, which is confirmed by our measurements; the flux decline for SDS with increasing ionic strength also increases. For CTAB this effect is less strong but also present. We do observe however that at increasing ionic strength in CTAB-stabilized emulsions the oil retention goes down, at $100 \mathrm{mM} \mathrm{NaCl}$ only $3 \%$ of the oil was retained. We attribute this to a low interfacial tension, which also lowers the critical pressure required to push an oil droplet through a pore. For the nonionic TX and zwitterionic DDAPS surfactant, we expect a far weaker effect of the ionic strength. Our experiments confirm this. For TX the flux decline is very high for all ionic strengths, whereas for DDAPS there is almost no flux decline. We do see, however, that for DDAPS the flux decline even decreases at increasing ionic strength. The headgroup of the zwitterionic surfactant is more hydrated at high ionic strength. At higher ionic strength we also observe a lower oil retention. Zwitterionic surfactants are required with a higher interfacial tension, as that would allow a higher oil retention, while retaining the low fouling properties. We conclude that zwitterionic surfactants are promising in the field of PW treatment.

To conclude, we gained valuable insights into the interaction between oil droplets in an emulsion and surfaces, as a function of surfactant properties and ionic strength. Understanding this interaction is key to work towards new and improved membrane applications in challenging feed streams, such as PW. The knowledge presented in this thesis is a good starting point for further research into PW treatment with membranes, both on a fundamental and at an applied level, but could also already point to new directions for more successful treatment in the field.

\subsection{Outlook}

As illustrated by this thesis, oil-in-water separation by membranes is a complex and sensitive process. Changes in virtually all process parameters and emulsion constituents reflect directly on membrane performance and permeate quality. In this thesis, we used a model emulsion with well-defined composition, but we are well aware that real produced water is much more complex than that. With 
this work, we made a start to understand the complex interaction between ionic strength and surfactant in membrane filtration, but the topic is far from concluded. In this section, we will discuss how we believe this research should be continued in the lab, but also what the field can already learn from the obtained results.

\subsubsection{Towards further understanding}

To better understand the interaction between an emulsion with a complex composition, such as PW, we need to continue our efforts in the lab. There is room for improvement and expansion on various facets of this subject, such as observation of the cake layer instead of single droplets, more study on membrane cleaning, the chemistry of the membrane surface and a more detailed investigation into the effects of other components found in PW.

\section{Direct observation of the cake layer}

In this thesis, we developed a rather simple flow cell method to study droplet adhesion to the surface. Although we gained quite some valuable insights with this setup, it has its limitations. As shown in Chapter 3, the flow cell allows the study of separate oil droplets on a surface as seen from above. This only allows us to study the first layer of oil droplets, and not the layers attaching to these droplets. Therefore, we only study droplet-surface interactions, and not the droplet-droplet interactions which we believe are key to the cake layer formation. Furthermore, our flow cell does not allow for transmembrane flow and pressure. Therefore, it might be valuable to either study the cake layer from the side in a modified flow cell design which would allow us to insert a real membrane, or to use a different technique, such as optical coherence tomography [1], confocal microscopy [2] or fluorescence microscopy [3]. This way, we can directly study the influence of pressure, shear, membrane permeation, surfactant properties and salt concentration on the cake layer formation and structure. If this system allows us to study the cake layer in real-time, we can also study the removal of the cake layer. This way, we might be able to confirm some of the proposed mechanisms from this thesis, such as the presence of more surfactant in the cake layer upon flushing with water at high ionic strengths (Chapter 3). This could also show that for successful backflushing, it is important to use a surfactant solution, to stabilize the emulsion during cleaning. In addition, modelling of droplet adhesion and subsequent cake formation can identify the processes and interactions that take place [4].

Apart from cake layer formation, it is also important to further study cake layer removal [5]. An option to remove the cake layer is adding air bubbles to the flushing medium [6]. Air bubbles create instabilities in the flow over the membrane, 

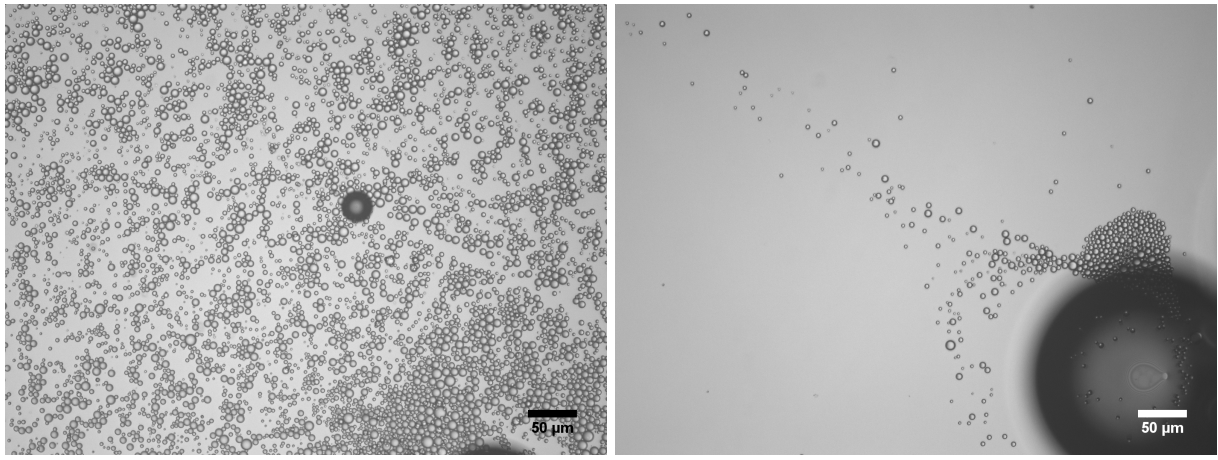

Figure 6.1: Air bubbles in the flow cell while flushing with a solution containing 463 $\mathrm{mg} / \mathrm{L}$ SDS and $1 \mathrm{mM} \mathrm{NaCl}$. Small air droplets trigger the release of oil droplets from the surface (left) whereas larger droplets that stick on the surface can collect oil droplets (right)

preventing concentration polarization and removing the cake layer from the membrane surface. Air bubbles are however not suitable for removing foulants from the pores of the membrane. In the flow cell, we observed that small air bubbles trigger the release of oil droplets from the surface when they pass by (Figure 6.1 , left). We also saw however, that larger droplets can become points where oil droplets collect (Figure 6.1, right). In this thesis, experiments that showed air bubbles were discarded, but they could provide insight into improved approaches to cleaning.

\section{Zwitterionic surfactants}

Low fouling and high flux recovery are very important factors in any membrane filtration processes. As shown in Chapter 5 of this thesis, zwitterionic surfactants show excellent performance when it comes to the prevention of membrane fouling, which leads to less flux decline. Therefore, continuing research into the potential of zwitterionic surfactants is necessary. Zwitterionic surfactants stabilize emulsions through hydration of the head group, and this effect even increases with ionic strength, in contrast to charged surfactants, which suffer from electrostatic screening at higher ionic strengths. In this work, we only went up to salt concentrations of $100 \mathrm{mM} \mathrm{NaCl}$, but the salt concentrations in real PW are usually even higher. Zwitterionic surfactants could be the key to successful filtration at high ionic strengths.

Combining zwitterionic surfactants with charged surfactants can give synergistic effects, such as increasing stability of mixed micelles, especially with increasing ionic strength [7], changing rheological properties due to screening and hydropho- 
bic interactions between the surfactant molecules [8] and changing shape of the micelles $[9,10]$. Molecular simulations also indicate that the electrostatic attraction between the charged and zwitterionic headgroups changes the properties of the mixed surfactants with respect to pure surfactants [11]. The effectiveness of those mixtures as stabilizers in oil-in-water emulsions has not been studied extensively, but we do believe this is an interesting direction. By mixing surfactants, the properties of the mixture can be tailored to the specific need of the process it is involved in, such as food, medicine, or oil recovery.

As good as the surfactant might be, the membrane has to be compatible with the properties of the feed stream. As shown in Chapters 3 and 4, the hydrophilicity and surface chemistry can influence the adhesion force of oil droplets to the surface. It also influences the behavior of oil droplets on the surface. We also observed, that the surfactant used has an influence on the interactions with the membrane surface and the formation of a cake layer (Chapter 5). Therefore, tailoring the membrane surface properties to the process it is intended for is very important. In recent years, antifouling membranes have been made using sacrificial layers, where the top layer can be removed together with the fouling layer [12]. Just as zwitterionic surfactants show potential, zwitterionic membrane surfaces also show antifouling properties. Zwitterionic membranes can be made by layer-by-layer deposition of polymers on the membrane surface [13] or by modifying the surface of the membrane itself [14]. In the case of PW, it is important to note that most polymeric membranes suffer from swelling because of the dissolved hydrocarbons present. Therefore, the chemistry of the membrane as a whole should also be resistant to this swelling, as well as resistant towards any cleaning procedure applied.

\section{Other components in produced water}

In this thesis, we used a highly simplified model emulsion of hexadecane, various surfactants and salt. As explained in Chapter 2, however, PW is far more complex, and we chose those components, because we identified the combined effects of surfactant and ionic strength as a key factor. Other components and properties of the emulsion, however, can also influence emulsion stability and therefore the adhesion and cake layer formation in membrane filtration.

Whereas in this thesis we used the monovalent $\mathrm{NaCl}$ in relatively low concentrations, seawater and formation water often also contain di- and trivalent ions and high salt concentrations. At higher ionic strengths, coalescence in the emulsion increases and the shear viscosity of the emulsion decreases. The mechanism of electrostatic screening by higher valency ions is stronger than for monovalent ions [9], meaning that less salt is needed for instability due to the presence of higher valency ions. Especially for charged and zwitterionic surfactants, this can have a pronounced influence, which requires more study. 
Solid particles from the oil reservoir are also present in PW. As explained in Chapter 2, these particles can stabilize the emulsion by surface wetting on the interface, forming a so-called Pickering emulsion. Pickering emulsions can show increased thermal stability, which is of particular interest in studying PW, as its temperature is often elevated [15]. Another interesting feature of Pickering emulsions containing surfactants is that they can be switched between stable and unstable states reversibly. The trigger for this mechanism can be for instance adding a surfactant [16], or, in case a zwitterionic surfactant is already present, changing the $\mathrm{pH}$ [17]. This illustrates that interactions between solid particles and surfactant in oil-in-water emulsions can play an important role in membrane filtration and droplet adhesion.

Finally, it would be interesting to look into the physical properties of our model emulsion and filtration, such as temperature, droplet size distribution and applied pressures and crossflow. These parameters can influence for instance fouling and oil permeation, as droplets can also break into smaller droplets under high shear forces [18]. Modelling could further explain some of our results as found in Chapter 5.

\subsubsection{Application in the field}

In the petrochemical industry, surfactants are often used as corrosion inhibitors or to enhance the recovery of oil from the reservoir. The surfactants or surfactant mixtures used for these purposes are mainly chosen to perform good on the desired task at an as low as possible cost. We propose, however, that the used surfactant should also be chosen with the membrane process at the end of the process in mind. As we have shown in Chapter 5, the properties of the surfactant can greatly influence the applicability of membranes for oil removal from water. The focus cannot just be on improving membrane materials to achieve lower fouling, the chemistry of the PW must always be taken into account. As every oil reservoir and every oil recovery operation is different, there is no single applicable technique or recipe for all reservoirs, but it is a highly tailored process. In regard to the new insights presented in this thesis however, we would like to present some suggestions as to where the future could develop.

\section{Low salinity flooding}

In multiple recent articles, the benefits of low salinity flooding (LSF) of a reservoir are reported [19-21]. The exact mechanism by which this works is not clear yet, but proposed mechanisms are multi-ion exchange, a local increase of $\mathrm{pH}$ or double layer expansion [22]. The true underlying mechanism is however poorly understood and depends on the mineral composition of the bedrock and the nature of the injected fluid [19]. Divalent ions present in the reservoir have 
been shown to play a large role in the wettability of substrates by oil-watersubstrate systems. For a simple model system of oil, stabilized by stearic acid, and a muscovite surface, Haagh et al. showed that reducing the concentration of the divalent ions while keeping the ionic strength of the injected fluid the same, changes the wettability significantly for muscovite sustrates, but not for silica substrates [23]. Changing the ionic strength of the injection fluid while keeping the concentration of divalent the same however did not show this effect. Simply diluting seawater accomplishes exactly this, which opens possibilities for field application. This effect was also observed at elevated temperatures [24]. Since many of the surface-active components in PW are charged (added chemicals and naturally present acids for instance), a low salinity will improve membrane filtration in presence of those components (Chapter 5). In addition, low salinity injection water implies less or no corrosion inhibitors, and thus less surfactants, will have to be added. This might give a less stable emulsion, where more oil might be removed using conventional techniques.

\section{Zwitterionic surfactants for enhanced oil recovery}

If the addition of surfactants to the injected stream is neccessary, zwitterionic surfactants are a possibility. Whereas nowadays the injected surfactants are often ionic in nature, a shift to zwitterionic might be possible in the future. Indeed, in literature we can find promising examples of successful enhanced oil recovery (EOR) with zwitterionic surfactants. Especially in situations with high salinity, zwitterionic surfactants show excellent oil recovery in the laboratory, whilst also increasing the breakthrough time of the reservoir (the amount of recovered oil in a model at the moment the first drop of injected fluid comes out) [25]. It has also been reported that by using zwitterionic surfactants, less surfactant is lost in the reservoir by adsorption to the sandstone because they carry no charge [26]. Using zwitterionic surfactants in EOR, would subsequently allow much more successful PW treatment, due to the low fouling propensity of zwitterionic surfactant stabilized emulsions.

\subsection{General conclusion}

As we discussed in Chapter 1 of this thesis, oil recovery is the reality of modern society, and will most likely be for many years to come. The way in which oil recovery is performed however, and especially how we deal with the waste it produces, is a field in motion. As discussed, incorporation of Best Available Techniques (BAT) and Best Environmental Practice (BEP) in the North Sea region pushes the field forward to develop new techniques and methods of dealing with 
PW. In some regions, treated PW is also used for beneficial purposes, catering to the reality of water shortage. Therefore, it is of paramount importance to not just look at how to treat PW, but to include the complete process of oil recovery into future considerations.

In this chapter, we presented multiple suggestions to further improve our knowledge on membrane filtration of surfactant-stabilized oil-in-water emulsions. From a fundamental point of view, the complex effect of the interaction between the surfactant and the ionic strength on the cake layer could be studied even further. By using different optical techniques, the structure and removal of the cake layer can be further studied in detail. In addition, focusing more on zwitterionic surfactants and their role in complex emulsions can elucidate whether these surfactants are applicable in for instance EOR. Therefore, it is also important to include the rest of the components present in produced water.

In our opinion, developments in the field application of membrane treatment for PW should focus not just on removing the foulants in the end product, but a more general approach should be taken. By including the complete process of oil recovery, and by carefully selecting the chemicals pumped down into the reservoir, the treatment of PW with membranes can possibly be improved.

With increasing volumes of oil, increasing volumes of PW, and an increasing pressure on fresh water supplies it is clear that PW is not just a waste product, but might also become a valuable resource. Whether used for re-injection, irrigation or even drinking water, the quality of the treated water is very important. Membrane filtration is an excellent method, not just for PW, but also for many other wastewaters. Therefore, it will be an important technology in the future to ensure water quality for an a growing world population. 



\section{Bibliography}

[1] T. A. Trinh, W. Li, Q. Han, X. Liu, A. G. Fane, and J. W. Chew, Analyzing external and internal membrane fouling by oil emulsions via $3 D$ optical coherence tomography, Journal of Membrane Science 548, 632 (2018). p.136.

[2] H. Di, G. J. Martin, Q. Sun, D. Xie, and D. E. Dunstan, Detailed, real-time characterization of particle deposition during crossflow filtration as influenced by solution properties, Journal of Membrane Science 555, 115 (2018). - p.136.

[3] E. Yachnin and G. Z. Ramon, Separation Science and Technology Direct observation of macromolecular deposition on a nanofiltration membrane D $i$ rect observation of macromolecular deposition on a nanofiltration membrane, Separation Science and Technology 52, 258 (2017). — p.136.

[4] J. Lohaus, Y. Perez, and M. Wessling, What are the microscopic events of colloidal membrane fouling?, Journal of Membrane Science 553, 90 (2018). - p.136.

[5] S. Z. Abdullah, H. E. Wray, P. R. Bérubé, and R. C. Andrews, Distribution of surface shear stress for a densely packed submerged hollow fiber membrane system, Desalination 357, 117 (2015). — p.136.

[6] Y. Wibisono, E. Cornelissen, A. Kemperman, W. van der Meer, and K. Nijmeijer, Two-phase flow in membrane processes: A technology with a future, Journal of Membrane Science 453, 566 (2014). — p.136.

[7] A. Pan, S. Rakshit, S. Sahu, S. C. Bhattacharya, and S. P. Moulik, Synergism between anionic double tail and zwitterionic single tail surfactants in the formation of mixed micelles and vesicles, and use of the micelle templates for the synthesis of nano-structured gold particles, Colloids and Surfaces A: Physicochemical and Engineering Aspects 481, 644 (2015). — p.137.

[8] Y. Fan, H. Tang, and Y. Wang, Synergistic Behavior and Microstructure Transition in Mixture of Zwitterionic Surfactant, Anionic Surfactant, and Salts in Sorbitol/H2O Solvent: 1. Effect of Surfactant Compositions, Journal of Surfactants and Detergents 20, 435 (2017). — p.138.

[9] S. Ghosh, D. Khatua, and J. Dey, Interaction Between Zwitterionic and Anionic Surfactants: Spontaneous Formation of Zwitanionic Vesicles, Langmuir 27, 5184 (2011). - p.138.

[10] N. Christov, N. Denkov, P. Kralchevsky, K. Ananthapadmanabhan, and 
A. Lips, Synergistic Sphere-to-Rod Micelle Transition in Mixed Solutions of Sodium Dodecyl Sulfate and Cocoamidopropyl Betaine, Langmuir 20, 565 (2004). - p.138.

[11] B. Kanoje, S. Padshala, J. Parikh, S. K. Sahoo, K. Kuperkar, and P. Bahadur, Synergism and aggregation behaviour in an aqueous binary mixture of cationiczwitterionic surfactants: physico-chemical characterization with molecular simulation approach, Physical Chemistry Chemical Physics 20, 670 (2018). - p.138.

[12] W. M. de Vos, A. de Keizer, M. A. Cohen Stuart, and J. M. Kleijn, Thin polymer films as sacrificial layers for easier cleaning, Colloids and Surfaces A: Physicochemical and Engineering Aspects 358, 6 (2010). — p.138.

[13] J. de Grooth, M. Dong, W. M. de Vos, and K. Nijmeijer, Building Polyzwitterion-Based Multilayers for Responsive Membranes, Langmuir 30, 5152 (2014). - p.138.

[14] M. Hadidi and A. L. Zydney, Fouling behavior of zwitterionic membranes: Impact of electrostatic and hydrophobic interactions, Journal of Membrane Science 452, 97 (2014). - p.138.

[15] T. Sharma, G. S. Kumar, B. H. Chon, and J. S. Sangwai, Thermal stability of oil-in-water Pickering emulsion in the presence of nanoparticle, surfactant, and polymer, Journal of Industrial and Engineering Chemistry 22, 324 (2015). - p.139.

[16] Y. Zhu, J. Jiang, K. Liu, Z. Cui, and B. P. Binks, Switchable Pickering Emulsions Stabilized by Silica Nanoparticles Hydrophobized $<i>$ in Situ $</ i>$ with a Conventional Cationic Surfactant, Langmuir 31, 3301 (2015). p.139.

[17] K. Liu, J. Jiang, Z. Cui, and B. P. Binks, pH-Responsive Pickering Emulsions Stabilized by Silica Nanoparticles in Combination with a Conventional Zwitterionic Surfactant, Langmuir 33, 2296 (2017). - p.139.

[18] T. Darvishzadeh and N. V. Priezjev, Effects of crossflow velocity and transmembrane pressure on microfiltration of oil-in-water emulsions, Journal of Membrane Science 423-424, 468 (2012). - p.139.

[19] H. Mahani, A. L. Keya, S. Berg, W.-B. Bartels, R. Nasralla, and W. R. Rossen, Insights into the Mechanism of Wettability Alteration by LowSalinity Flooding (LSF) in Carbonates, Energy \& Fuels 29, 1352 (2015). - p.139.

[20] P. McGuire, J. Chatham, F. Paskvan, D. Sommer, and F. Carini, in Spe western regional meeting (Society of Petroleum Engineers, 2005). - p.139.

[21] T. Austad, A. Rezaeidoust, and T. Puntervold, in Spe improved oil recovery symposium (Society of Petroleum Engineers, 2010). - p.139.

[22] M. Jackson, J. Vinogradov, G. Hamon, and M. Chamerois, Evidence, mechanisms and improved understanding of controlled salinity waterflooding part 1: Sandstones, Fuel 185, 772 (2016). — p.139. 
[23] M. E. J. Haagh, I. Siretanu, M. H. G. Duits, and F. Mugele, SalinityDependent Contact Angle Alteration in Oil/Brine/Silicate Systems: the Critical Role of Divalent Cations, Langmuir 33, 3349 (2017). — p.140.

[24] M. E. Haagh, N. Schilderink, M. H. Duits, I. Siretanu, F. Mugele, and I. R. Collins, Salinity-dependent contact angle alteration in oil/brine/silicate systems: The effect of temperature, Journal of Petroleum Science and Engineering 165, 1040 (2018). - p.140.

[25] H. Yarveicy and A. Javaheri, Application of Lauryl Betaine in enhanced oil recovery: A comparative study in micromodel, Petroleum (2017). - p.140.

[26] B. Song, X. Hu, X. Shui, Z. Cui, and Z. Wang, A new type of renewable surfactants for enhanced oil recovery: Dialkylpolyoxyethylene ether methyl carboxyl betaines, Colloids and Surfaces A: Physicochemical and Engineering Aspects 489, 433 (2016). - p.140. 



\section{Algemene Nederlandse samenvatting}

Het doel van dit proefschrift is het creëren van meer kennis op het gebied van membraanvervuiling door olie-in-water emulsies, en meer specifiek membraanvervuiling door zogenaamd produced water (PW). Produced water is de grootste afvalstroom van de petrochemische industrie (gemiddeld maar liefst 3 vaten PW per vat olie). Het bevat opgeloste en gedispergeerde koolwaterstoffen, oppervlakte-actieve stoffen (surfactants), vaste deeltjes en bevat doorgaans ook veel zout. Dit complexe mengsel moet behandeld worden voordat het geloosd of hergebruikt kan worden, en behandeling met membranen is een van de mogelijkheden. Helaas hebben membranen last van vervuiling, maar welke rol de verschillende componenten in PW en/of de interacties tussen deze componenten spelen is nog niet goed onderzocht. Dit is zorgelijk, omdat het begrijpen van de oorzaken en mechanismen van membraanvervuiling essentieel is voor de ontwikkeling van membraanmaterialen en -processen voor de succesvolle behandeling van $\mathrm{PW}$.

Om de meest belangrijke factoren van de vervuilingspotentie van PW te identificeren, hebben we een literatuurstudie uitgevoerd (Hoofdstuk 2). In deze studie zetten we de samenstelling en eigenschappen van PW uiteen en bepalen welke factoren belangrijk zijn om in onze eigen studie op te nemen. We bespreken verscheidene componenten die invloed kunnen hebben op emulsiestabiliteit. Onze conclusie is dat het type surfactant (lading van de kopgroep) en de zoutconcentratie, en vooral het samenspel van deze twee componenten, een kritische rol spelen. Daarnaast presenteren we meerdere studies betreffende de membraanfiltratie van olie-in-wateremulsies, zowel op lab- als op pilotschaal. Het is duidelijk dat olie-in-wateremulsies van verschillende bronnen succesvol gescheiden kunnen worden met membranen, maar dat juist PW een lastig te behandelen stroom blijkt. Wij denken dat de complexe samenstelling, en dan met name de hoge zoutconcentratie en de aanwezigheid van surfactant (zowel toegevoegd als van nature aanwezig), een belangrijke oorzaak is van deze observatie. Daarnaast is er een gebrek aan kennis en begrip betreffende de behandeling van PW met membranen. Veel onderzoek focust op het ontwikkelen van nieuwe membranen en processen om vervuiling te verminderen, maar veel minder onderzoek is gericht geweest op de meer fundamentele achtergrond van membraanvervuiling door PW. Uit deze literatuurstudie concluderen we dat we in ons eigen onderzoek zullen focussen op het samenspel van surfactants en de zoutconcentratie, en wat de 
invloed van deze factoren is op de interactie tussen oliedruppels en het membraanoppervlak.

Om de interactie tussen oliedruppels en een oppervlak te kunnen bestuderen hebben we een nieuwe stroomcel-methode ontwikkeld, waarbij we de druppels op oppervlakken onder invloed van schuifkracht visueel waar kunnen nemen. Door deze stroomcel te combineren met een chemisch eenvoudig te manipuleren oppervlak en een modelemulsie die olie, surfactant (anionische natriumdodecylsulfaat, SDS) en zout bevat, bestuderen we de adhesie van oliedruppels aan het oppervlak (Hoofdstuk 3). We modificeren het modeloppervlak zodat het hydrofiel of hydrofoob is en variëren de surfactantconcentratie, zoutconcentratie en de soort surfactant om de invloed van deze specifieke componenten te bestuderen. Door de afschuifkracht op de oliedruppels die vast zitten aan het oppervlak te vergroten en te bepalen bij welke kracht de druppels loslaten, meten we de adhesiekracht. Daarnaast voeren we ondersteunende experimenten uit, zoals surfactantadsorptie, randhoek en oppervlaktespanning. We concluderen dat er een optimum is in hoe makkelijk het oppervlak schoon te maken is als een functie van surfactantconcentratie. Bij toenemende zoutconcentratie plakken er meer druppels aan het oppervlak. Door de adsorptie van surfactant aan het hydrofobe oppervlak, stoot dit oppervlak oliedruppels iets beter af dan het hydrofiele oppervlak. Tot slot variëren we de eigenschappen van de surfactant door het experiment te herhalen met cationische hexadecyltrimethylammoniumbromide (CTAB) en nonionische Triton X-100 (TX). We concluderen dat geladen surfactants de adhesie van oliedruppels het beste voorkomen. De stroomceltechniek van Hoofdstuk 3 wordt vervolgens gebruikt om de oliedruppeladhesie van een SDS-gestabiliseerde emulsie als functie van zoutconcentratie te bestuderen. We spincoaten op het glazen oppervlak voor de stroomcel cellulose om een oppervlak te creëren dat chemisch identiek is aan dat van een cellulose membraan. De resultaten worden vergeleken met data van een membraanfiltratie van een identieke emulsie op een geregenereerd cellulose membraan (Hoofdstuk 4). De emulsie bevat olie, anionisch SDS en natriumchloride in drie verschillende zoutconcentraties. Uit de data van de stroomcel trekken we de conclusie dat de adhesie tussen druppels en oppervlak niet toeneemt, maar dat het aantal druppels dat aan het oppervlak adsorbeert wel toeneemt. We schrijven dit toe aan een verminderde elektrostatische afstoting tussen de druppels en het licht negatief geladen celluloseoppervlak. In de membraanfiltratie zien we een toenemende fluxreductie bij hogere zoutconcentraties. Dit suggereert dat er een dichtere cakelaag op het oppervlak ontstaat door verminderde elektrostatische repulsie. We zien echter ook dat bij $10 \mathrm{mM}$ de initiële fluxafname veel sterker is dan bij 1 en $100 \mathrm{mM}$. We vermoeden dat dit komt doordat in de eerste minuten de blokkade van poriën overheerst in plaats van cakelaagformatie. Waarom we dit alleen bij $10 \mathrm{mM}$ zien is niet geheel duidelijk en moet verder onderzocht worden. We concluderen dat de observaties uit de stroomcel bruikbare inzichten kunnen geven in membraanvervuiling, maar dat 
we niet alle observaties uit de membraanfiltratie kunnen verklaren. Dit is naar verwachting, omdat in de stroomcel geen permeatie en cakelaagformatie plaatsvindt.

Tot slot bestuderen we de invloed van de zoutconcentratie op membraanfiltratie van olie-in-wateremulsies gestabiliseerd door vier verschillende surfactants (Hoofdstuk 5): anionische SDS, kationische CTAB, nonionische TX en zwitterionische N-dodecyl-N,N-dimethyl-3-ammonio-1-propanesulfonaat (DDAPS). De zoutconcentratie wordt voor iedere surfactant gevarieerd tussen 1, 10 en $100 \mathrm{mM}$. We meten de fluxafname, olieretentie en het fluxherstel van een cellulosemembraan, en daarnaast de randhoek en oppervlaktespanning van alle surfactants en zoutconcentraties. We verwachten de sterkste invloed van zoutconcentratie bij de geladen surfactants, wat bevestigd wordt in onze metingen: de fluxafname voor SDS is sterker bij hogere zoutconcentraties. Dit effect is minder sterk voor CTAB, maar wel aanwezig. We zien wel dat bij hogere zoutconcentraties de olieretentie van CTAB-gestabiliseerde emulsies omlaag gaat, bij $100 \mathrm{mM} \mathrm{NaCl}$ wordt slechts $3 \%$ van de olie tegengehouden. We schrijven dit toe aan de lage oppervlaktespanning, waardoor de kritische druk die nodig is om een oliedruppel door het membraan te duwen ook verlaagt. Voor de nonionische surfactants TX en DDAPS verwachten we een zwakker effect van de zoutconcentratie. Onze experimenten bevestigen dit. De fluxafname is zeer hoog voor alle zoutconcentraties bij TX, terwijl voor DDAPS de fluxafname zelfs kleiner wordt. De kopgroep van de zwitterionische surfactant raakt meer gehydrateerd bij hogere zoutconcentraties. Bij hogere zoutconcentraties zien we ook een lagere olieretentie. Een zwitterionische surfactant met een hogere oppervlaktespanning zou kunnen zorgen voor een hogere olieretentie, terwijl de lage vervuiling gehandhaafd blijft. We concluderen dat zwitterionische surfactants veelbelovend zijn voor gebruik in PW behandeling.

We concluderen dat we waardevolle inzichten hebben verkregen in de interactie tussen oliedruppels in een emulsie en oppervlakten als een functie van surfactant eigenschappen en ionische sterkte. Het begrijpen van deze interacties is essentieel om tot nieuwe en verbeterde membraantoepassingen te komen voor lastige afval stromen zoals PW. De kennis uit dit proefschrift is een goed startpunt voor verder onderzoek in PW-behandeling met membranen, zowel op een fundamenteel als een toegepast niveau. 



\section{Acknowledgements}

Finishing a thesis is no small feat, and also not something you do all by yourself. Therefore, I would like to thank everybody that in one way or another contributed to this booklet, but even more to making this time a good one.

To the members of my committee, thank you very much for reading my thesis and allowing me to defend it. Prof. Dr. Ir. Patrice Bacchin, thank you for travelling to the Netherlands to be here at my defense. Prof. Dr. Ir. Frieder Mugele, Prof. Dr. Ir. Arian Nijmeijer and Prof. Dr. Ir. Karin Schroen, thank you for coming here today at this special day. Dr. Ir. Mieke Kleijn, thank you very much for all the help on our article, both on the scientific aspect and the writing.

Rob Lammertink, thank you for being my promotor and for joining this project halfway. Despite the fact that you already had so many PhD students, you still found time to take on one extra. Your knowledge on colloids is phenomenal, and I am very grateful for your input, help and the times you asked me to calculate something.

Wiebe de Vos, I want to thank you for the opportunity to do my $\mathrm{PhD}$ under your supervision. Your knowledge, enthusiasm and positivity have been very important to this project we started more than four years ago. Despite the distance between Wetsus and the UT you kept close check on the project with our weekly phone calls. Your feedback, comments and criticism helped me to grow both as a scientist and as a person. You never gave up in moments I definitely wanted to, and reminded me that in the end it all would all work out. And it did!

Arie, thank you for helping me start this project in my first year at Wetsus, and making me feel welcome. Although you are no longer here, your name lives on in the very laboratory where I performed a great part of my experiments. Maarten, thank you for the valuable feedback and the nice talks we had.

Kitty, thank you for being my promotor for the first two years, and listening to my questions and doubts, both personal and scientific.

Johannes and Cees, with Wetsus you have created a unique platform where science and industry meets. Thank you for providing us as PhD's with this inspiring working environment. I would also like to thank the members of the Concentrates theme for the discussions, feedback and cooperation in the past four years. Your constructive criticism helped placing my work in a broader perspective.

For all of the practical work in this thesis, I would like to thank the excellent 
support of the Wetsus technical team: Wim, Harm, JJ, Ernst, Piet, Janneke T, Mieke, Ton, Jan Willem, John, Marianne, Lisette, Erwin, Gerrit and Jelmer, for solving small and larger problems and helping out whenever needed. Rienk, thank you for helping out with everything computer-related. You can't do science on an empty stomach, so Riet, Gerben en Katharina, thank you so much for the soup, milk, tea, 'stiekeme frietjes' and all the nice conversations in the morning over a cup of tea. You make Wetsus a welcoming place to everyone! To the administrative, HR and secretarial staff, thank you all for taking care of the paperwork and contracts.

Although the majority of my work took place at Wetsus, I also belonged to the MST group in Twente. Greet and Audrey, thank you for helping me with all the paperwork, plane tickets and taking care of the things that were not possible to do from Leeuwarden. Antoine, thank you for your help and words of encouragement, I made it to a Dr.! Bob, apart from your help in the lab I also want to thank you for all the fun and good laughs. Herman, Harmen, Erik R, and Iske, thank you for the help with finding my way around the lab in Twente. Esra, it was a nice surprise to meet you again in this group! Ozlem, Wouter, Dennis (thanks for the help with the adsorption experiments), Timon ('Murica!), Shazia, Sinem, Joris and everybody else: thank you for welcoming the "Wetsus people" so many times.

I would also like to thank my students Olivia (one question), Maxime (no probs) and Zanina (so exciting!) for their hard work. It was a pleasure and honor to work with each and every one of you, to teach you and above all, to learn from you. I wish all of you the best for the rest of your lives and carreers!

Ettore, thank you so much for continuing this path of research. I have taught you everything I know on the subject, and I am very curious to see where you are going to take it. Completing the last filtration experiments with you was a nice way for me to end my time in the lab, and I think it was a good way for you to start. Most importantly, I want to thank you for your enthusiasm and friendship (and arancina). Good luck!

I want to thank my running friends at Wetsus for keeping me sane for the past four years. Sanne, Jouke, Jorrit, I hope I still meet you in the Wetsus building every now and then. Bianca, thank you for joining me on that last run before my contract ended, you are a good listener and I hope to run together in the future again!

To my office mates of Hw1.03, this is where it all started. Charu (I loved your wedding!), Jan Willem (hello, is it me you're looking for), Victor (my paranymph), Bob L. (alweer collega's!) and Dries (schilderen), thank you for making me feel welcome at the 'old' Wetsus. To my office mates from the new office 1.18E Pawel (silent force), Mark (goeiemorgen!), Mithun, Kanwal, Gaofeng (can I tell you a secret?), Tim, Veerle, Sebastian (kicking under the table), Hanieh (we miss you!), Sofia and Deepika (gulab jamun), thanks for the office dinners, laughs and 
our shared frustration over the office doors. Rik, Jorrit and Natasha, we made up the silent office upstairs for a bit. Thanks to you for sharing this last bit of time and hard work. Anna Joeri, Olivier and Adam, thank you for your help in paranymphing Tericas defense while writing a thesis, you definitively saved the day.

To the laser lab crew, thank you for all the help and the fun! Adam, thanks for the help with building a microscope, but also for the fun times. Gerwin, I am very grateful to have you as a friend in my life, let's do some more LARP soon. Sandra, the other lady in the laser lab! Joeri, thank you so much for your wise words, hugs and laughs.

To my wonderful paranymph and friend Terica, I am so happy you stand by me today. Your endless words of motivation, humor and compassion have saved me from giving up more often than I can count these years, and you have my highest gratitude for that. More than that, you are a wonderful and fun person, and travelling to wherever we had (or wanted) to go was always a pleasure. Thank you for being you, never change!

Victor, after sharing and office with you for the full 4 years, I am very grateful you can be here with me as my paranymph. More importantly, you are a great friend, and I want to thank you for all the nice talks, Tonys Chocolonely and support over the years. I am so happy we are colleagues again and I can keep learning from you, and you will also get there in the end!

Apart from people that took the scientific journey with me, there is also the people outside of the scientific world, that maybe didn't understood what exactly I was doing, but where always there nonetheless.

Als eerste mijn lieve familie. Pap en mam, bedankt voor alles. Het was best even schakelen van Nijmegen naar het noorden, maar jullie voortdurende steun, liefde en aanmoediging zijn heel belangrijk geweest in het voltooien van deze onderneming. Renske en Margo, jullie herinneren me er keer op keer aan dat er nog een hele wereld buiten de wetenschap ligt waarvan je niet moet vergeten te genieten, bedankt daarvoor. Bart en Kaj, bedankt voor het compleet maken van de Zaagmachine. Letty, bedankt voor je luisterende oor, je bent een leuke tante maar bovenal een hele fijne vriendin.

Frank (grote broer) en Joyce, jullie zijn als familie voor me. Bedankt voor de mooie en gezellige gedeelde momenten, en de steun als het even lastig was. Niet alleen nu, maar vooral ook in de tijd daarvoor (Martijn en Wendy, ook jullie bedankt).

Dan mijn tweede familie in het noorden: Cees, Nicky, Lon, Cas, Martin, Aimee en meneer Jansen, jullie maken het noorden een thuis. Jullie voortdurende steun, liefde maar vooral ook gekheid en gezelligheid maken dat ik me hier volledig thuis voel.

Emmie, dankjewel voor alle goede zorgen en hulp. Reynold en Willy, voor de 
talloze goede gesprekken, etentjes en spontane bezoekjes. Tita, bedankt voor je wijsheden: 't komt zo 't komt. Ik zal het niet vergeten!

Alle mensen bij Elbaria, Einheri, Fase 3, Ravenskeep, Drachenfest, Mythodea, mijn DnD-groepjes en Compagnie te voet, bedankt voor de uitstapjes naar andere werelden en/of tijden. Renee, Marcel, Elise, voor het elkaar af en toe toch zien en het dan weer oppakken alsof er geen tijd is verstreken. Al mijn vrienden, maar in het bijzonder Emily, Warmold, Charley, Johan, Hannes, Kiaya, Anja, Menerik, Arie. Bedankt voor de steun, lieve woorden, bordjes eten, een brommer, domme verkleedfeestjes en het talloze keren overhalen om me toch even los te maken van het werk wat moest gebeuren. Ik kan me niet meer wensen in vrienden.

Last but not least: Wijbe. Mijn beste vriend en maatje, bedankt dat je er voor me bent, in wat voor een situatie dan ook. Op naar het volgende avontuur, ik hou van je! 

